\title{
Food and Agriculture
Organization of the
United Nations
}

\section{The State of Agricultural Commodity Markets}

Trade and food security: achieving a better balance between national priorities and the collective good

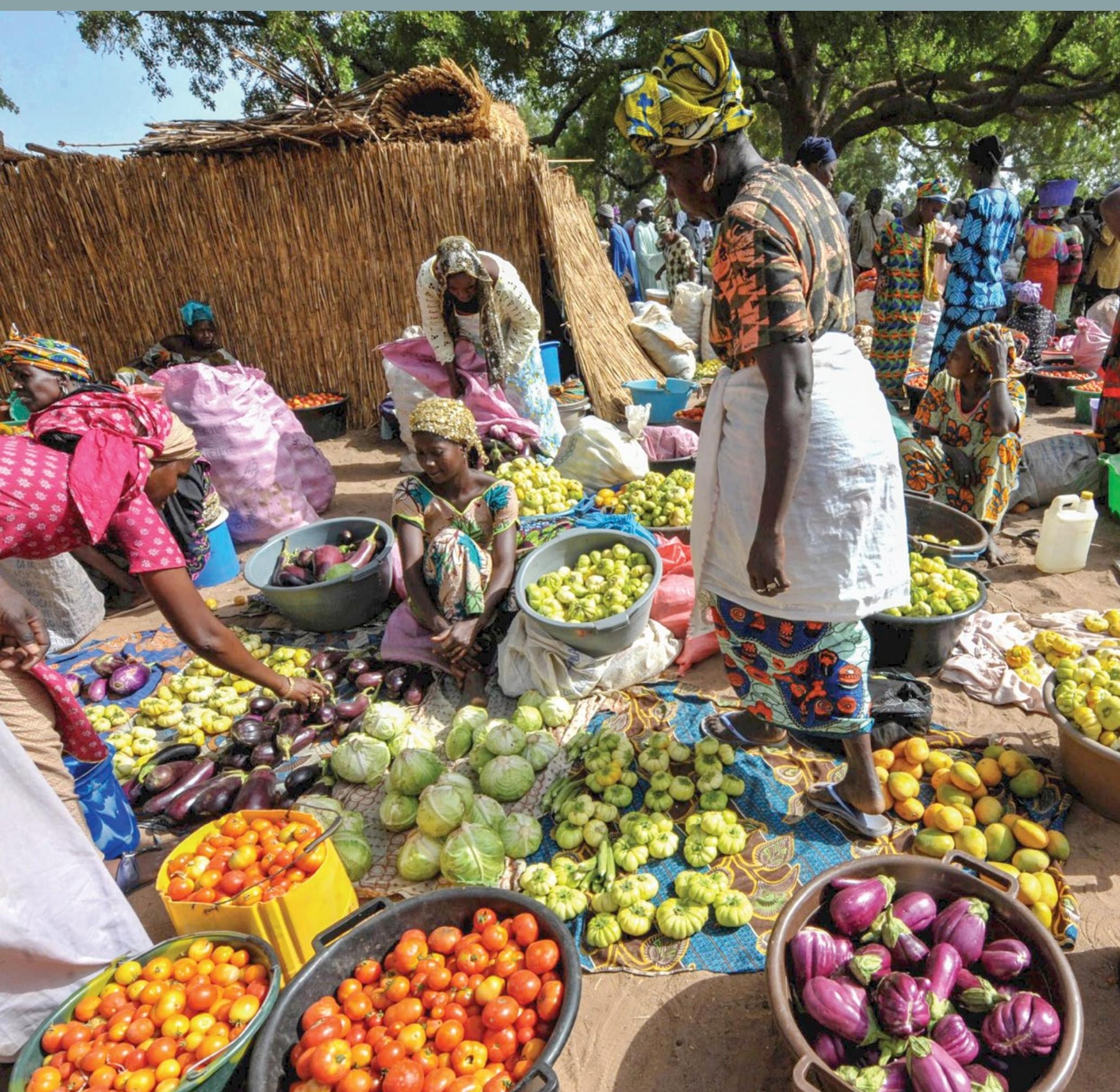




\section{Key messages}

1 Global trade in food products continues to expand rapidly, but the structure and pattern of trade differs significantly by commodity and by region. Key drivers of production and demand, including trade and related policies, shape these patterns in different ways, with potentially important implications for food security. ${ }^{1}$

Greater participation in global trade is an inevitable part of most countries' national trade - strategies. However, the process of opening to trade, and its consequences, will need to be appropriately managed if trade is to work in favour of improved food security outcomes.

Trade affects each of the four dimensions of food security: food availability, access, utilization and stability. The interaction of trade with these dimensions is complex and depends on a variety of underlying factors, producing great differences in country experiences and making it difficult to ascertain a generalizable relationship.

The relationship between the level of engagement in trade and food security is influenced by the - way food markets work, by the ability and willingness of producers to respond to the changing incentives that trade can bring, and by the geography of food insecurity, each of which needs to be accounted for in the formulation of trade policy interventions.

5 . Trade and related policy objectives address different dimensions of food security, will differ across countries, and will change over time. The appropriateness of alternative trade policy options is largely determined by longer-term processes of economic transformation and the role of the agriculture sector within these.

6.

Episodes of food price spikes are important for their potential negative impacts on food security. Geopolitical and weather uncertainties, as well as government responses, are likely to exacerbate these episodes in the future, with increasing potential for disruptions to trade flows. The likelihood of price spikes, even if episodic, needs to be factored into longer-term decisions related to the management of trade in food and agricultural products.

7 Trade and food security concerns can be better articulated in the multilateral trading system through improvements to the World Trade Organization's Agreement on Agriculture. However, the right balance needs to be struck between the benefits of collective action brought through disciplines on the use of trade policy, and the policy space required by developing countries, the identification of which needs to be informed by specific country-level needs.

Shifting attention from the pros and cons of specific policies towards addressing weaknesses in the governance processes of agriculture and trade policy-making will improve identification of required policy space and its appropriate use. Strengthening these processes requires building synergies to increase policy coherence for food security, to enable governments to balance priorities in the design of trade policies, and to improve their compliance with regional and global trade frameworks. 


\section{The State of Agricultural Commodity Markets}

Trade and food security: achieving a better balance between national priorities and the collective good 
The designations employed and the presentation of material in this information product do not imply the expression of any opinion whatsoever on the part of the Food and Agriculture Organization of the United Nations (FAO) concerning the legal or development status of any country, territory, city or area or of its authorities, or concerning the delimitation of its frontiers or boundaries. The mention of specific companies or products of manufacturers, whether or not these have been patented, does not imply that these have been endorsed or recommended by FAO in preference to others of a similar nature that are not mentioned.

The designations employed and the presentation of material in the map(s) do not imply the expression of any opinion whatsoever on the part of FAO concerning the legal or constitutional status of any country, territory or sea area, or concerning the delimitation of frontiers.

ISBN 978-92-5-108931-6

(c) FAO, 2015

FAO encourages the use, reproduction and dissemination of material in this information product. Except where otherwise indicated, material may be copied, downloaded and printed for private study, research and teaching purposes, or for use in non-commercial products or services, provided that appropriate acknowledgement of FAO as the source and copyright holder is given and that FAO's endorsement of users' views, products or services is not implied in any way.

All requests for translation and adaptation rights, and for resale and other commercial use rights should be made via www.fao.org/contact-us/licence-request or addressed to copyright@fao.org.

FAO information products are available on the FAO website (www.fao.org/publications) and can be purchased through publications-sales@fao.org. 


\section{Contents}

Foreword

Acknowledgements vii

Acronyms xiii

Executive summary ix

Part I - The changing nature of agricultural trade $\quad 1$

1. Agricultural trade in a changing global landscape: context, trends and prospects 2

2. Evolving market structures 8

3. Potential issues related to food imports 11

Part II - Trade and food security: conceptual linkages 17

1. Measuring trade and food security:

definitions, indicators and approaches $\quad 18$

2. Analysing the linkages: a conceptual framework 23

3. Trade expansion and the four dimensions of food security 27

4. Determinants of the strength of linkages: markets in the trade and food security nexus 32

Part III - Trade and related policy supportive of food security $\quad 35$

1. Policies and policy objectives 36

2. Determining the impact of short-term trade policy interventions on food security 38

3. Longer-term structural transformation and defining policy interventions

4. Changing patterns of support to agriculture: lessons for the future $\quad 46$

5. Determinants of national trade strategies 49 
Part IV - Towards improved governance for trade and food security

1. Food security in the multilateral trading system 54

2. The policy space available to developing countries 56

3. From policies to processes for improving coherence and policy space

4. Linking trade and food security in the post-2015 development framework 


\section{Foreword}

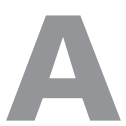

chieving the eradication of global hunger by 2030 is a key objective of the United

Nations system as reflected in the new post-2015 sustainable development agenda.

As patterns of consumption and production continue to evolve, trade in agricultural and food products will play an increasingly important role in ensuring that growing demands from food-deficit countries can be satisfied.

Global trade in agricultural and food products has grown rapidly in recent decades, with countries becoming more engaged in this trade, whether as exporters or importers. However, the manner in which countries should increase their engagement in trade is subject to significant debate.

Making trade work for, and not against, improved food security and nutrition is a key challenge for policy-makers. While opening to trade can increase the availability of food in importing countries and put downward pressure on consumer prices, it also brings potential risks with it. A greater reliance on international markets can leave countries vulnerable to short-term market shocks, both those resulting in tighter supplies and increased consumer prices, as well as those resulting from surges in imports and consequent depressions in producer prices.

Opening to trade too quickly can undermine domestic production in import-competing sectors - a particular issue during earlier stages of agricultural transformation when the agriculture sector still has a key role to play in driving wider economic growth and as a source of employment for the majority of the rural poor.

Although countries with the ability to increase exports are expected to benefit from increasing trade opportunities, trade expansion is not without its risks for these countries either. Increased levels of exports can put upward pressure on domestic consumer prices, which is a particular concern during periods of below average production. Conversely, rapid falls in commodity prices, such as those observed in the dairy sector during 2015, can create significant difficulties in countries pursuing an agricultural export-led strategy.

The existence of such risks lies behind most countries' propensity to manage trade in agricultural and food products. Food security and nutrition objectives, particularly in lowand middle-income countries, often provide a key and legitimate rationale for intervention through trade and related policy. Such policies may be targeted at improvements in one or more of the four dimensions of food security and nutrition: availability, access, utilization and stability.

However, the design of appropriate policy interventions in the management of trade has proved to be very challenging. Policy-makers need to balance the concerns of different national constituencies, which will be differentially affected by greater openness to trade. They also need to balance the achievement of national food security and nutrition objectives with their obligations under trade agreements to minimize any potentially negative effects of their actions on their trading partners.

Complicating matters further is that the appropriateness of alternative trade and related policy interventions will differ across countries, depending on their level of agriculture sector development and the potential role of these sectors in contributing to improved food security and nutrition, and will change over time as these sectors develop. Such challenges 
have contributed to intense debates as to whether, and how, countries should manage trade in agricultural and food products.

This edition of The State of Agricultural Commodity Markets attempts to clarify the role of trade in contributing to improved food security and nutrition and to contribute to the debate on the rationale for, and approaches to, managing trade in agricultural and food products. It cautions against attempting to identify the "best" set of policy instruments for managing trade, recognizing that this will be highly context-specific.

Rather, the publication encourages practitioners to place more emphasis on strengthening the policy processes that guide the design and implementation of trade and related policy. Such processes, whether at the level of the post-2015 sustainable development agenda, multilateral or regional trade negotiations, or national development strategies, all suffer from weaknesses in coordination that reduce their effectiveness. Strengthening these processes, particularly the levels of coordination among organizations responsible for trade, agriculture and food security strategies, will be imperative if trade in agricultural and food products is to realize its essential contribution to the elimination of hunger.

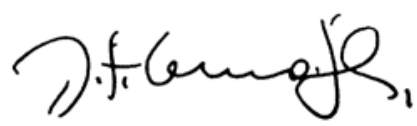

José Graziano da Silva

FAO Director-General 


\section{Acknowledgements}

T

he State of Agricultural Commodity Markets 2015-16 has been prepared by the Trade and Markets Division (EST) of the Economic and Social Development Department (ESD). Under the overall guidance of Jomo Kwame Sundaram, Assistant Director-General, ESD, and Boubaker Ben-Belhassen, Director, EST, the technical work was led by Jamie Morrison with the support of Eleonora Canigiani and Ekaterina Krivonos. Pedro Arias and Yasmine Iqbal provided inputs on the market trends and projections in Part I, together with Filippo Gheri. Valuable comments and suggestions were provided by other FAO departments and regional offices including the Agriculture and Consumer Protection Department, the Fisheries and Aquaculture Department, the Forestry Department, and the Regional Offices for Europe and Central Asia, and for Asia and the Pacific.

The report was informed by a series of four informal consultations, which served to review existing evidence, debate potentially contentious issues, determine the structure of the report and provide a peer review of the messages to be included. The consultations involved many experts from academic institutions, international non-governmental organizations and intergovernmental organizations: Ammad Bahalim, Jean Balié, Eduardo Bianchi, Clemens Boonekamp, Susan Bragdon, Lars Brink, Patterson Brown, Antony Chapoto, David Cheong, Ephraim Chirwa, Jennifer Clapp, Eugenio Díaz-Bonilla, Diwakar Dixit, Charlotte Dufour, Cheng Fang, William Foster, Thierry Giordano, Jared Greenville, David Hallam, Corinna Hawkes, Jonathan Hepburn, Simon Hess, Adrian Hewitt, Nicolas Imboden, Marie-Agnes Jouanjean, Ulla Kask, Rashid Kaukab, Suffyan Koroma, David Luke, Will Martin, Alan Matthews, Emiliano Magrini, Steve McCorriston, Nalishebo Meebelo, Georgios Mermigkas, Pierluigi Montalbano, Cristian Morales, Silvia Nenci, Signe Nelgen, Ralf Peters, Francesco Rampa, Mohan Rao, Sherman Robinson, Luca Salvatici, Kostas Stamoulis, Jo Swinnen, Daria Taglioni, Zoltan Tiba, and Sean Woolfrey.

In support of the consultations, background papers were prepared by: Jennifer Clapp, Eugenio Díaz-Bonilla, Alan Matthews, Pierluigi Montalbano, Silvia Nenci and Luca Salvatici.

Further inputs and peer review were provided during the FAO Symposium on Trade and Food Security, hosted by the World Trade Organization in Geneva on 5 June 2015, at which the main messages were tested. 


\section{Acronyms}

AfT Aid for Trade

AMS aggregate measurement of support

AoA Agreement on Agriculture

CAADP Comprehensive Africa Agriculture Development Programme

DTIS diagnostic trade integration study

EIF Enhanced Integrated Framework for Trade-related Technical Assistance

EU European Union

FDI foreign direct investment

FfD financing for development

GATT General Agreement on Tariffs and Trade

GCC Arab Gulf Cooperation Council

GDP gross domestic product

GVC global value chain

IFPR I International Food Policy Research Institute

LDC least-developed country

LIFDC low-income food-deficit country

MDG Millennium Development Goal

Mol means of implementation

NFIDC net food-importing developing country

NGO non-governmental organization

NRA nominal rate of assistance

ODA overseas development assistance

OECD Organisation for Economic Co-operation and Development

RTA regional trade agreement

SDG Sustainable Development Goal

SPS

sanitary and phytosanitary measures

SSM special safeguard mechanism

WTO World Trade Organization 


\section{Executive summary}

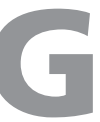

lobal trade in agricultural products is expected to continue to increase

significantly over the coming decades. As a consequence, trade will play an

increasingly important role in influencing the extent and nature of food security

across all regions of the globe. The challenge has therefore become one of ensuring that the

expansion of agricultural trade works for, and not against, the elimination of hunger, food insecurity and malnutrition.

The objectives of this edition of The State of Agricultural Commodity Markets are to reduce the current polarization of views on the impacts of agricultural trade on food security and on the manner in which agricultural trade should be governed to ensure that increased trade openness is beneficial to all countries. By providing evidence and clarity on a range of topics, the report seeks to contribute to a more informed debate on policy choices and to identify required improvements in the policy processes within which these choices are made.

Part I explores the rapidly changing global market context with a view to identifying how developments in the production of, and demand for, food are likely to play out. These changes will have implications for the future reliability of international markets as a source of accessible food, not only in terms of its timely availability, but also in terms of the volatility of these markets and its wider implications for food security and nutrition.

Evidence on the impacts of trade on food security is limited and, where it does exist, suggests that the impacts are mixed. A recent systematic review of the impacts of trade reforms on food security reveals that of the 34 studies analysed in detail, 13 reported improvements in the utilized food security indicators, 10 showed a deterioration, and the other 11 had mixed results, "with food security metrics varying across segments of the population, regions and time or with alternative food security metrics indicating different outcomes for specific countries" (see Box 6 in Part II).

Given the difficulty of generalizing a relationship between greater openness to trade and the implications for food security, Part II introduces a conceptual framework for better understanding this relationship and attempts to explain the mixed results in terms of the key economic and social variables affected by trade and the factors that modify their impacts on the different dimensions of food security. It also recognizes that the relationship between trade and food security goes beyond economic considerations to include political, social and ecological dimensions that require a multidisciplinary analytical approach.

Appropriate use of trade and related policy in support of individual countries' food security objectives is considered in Part III. Often, debates related to trade and food security focus on the short-term impacts of market shocks, and the resulting changes in trade flows and prices that consumers and producers face. In this report, positioning the debate in the perspective of longer-term structural transformation in growing economies has significant implications for the development and use of trade policies compatible with improved food security.

In doing so, the report calls for a shift in emphasis from the analysis of short-term policy reactions to shocks to longer-term policy approaches focused on taking advantage of the opportunities and reducing the risks associated with greater openness to regional and global agricultural markets. In this perspective, understanding the specific country context is 
fundamental in defining how agricultural trade can be supportive of food security, but it can also complicate the identification of appropriate trade and related policies.

This edition of The State of Agricultural Commodity Markets aims to demonstrate that a more pragmatic approach focused on context specificity will help ensure that trade policies are better tailored to the specific agriculture and food security conditions and strategies of different countries. It will also help to overcome the polarized ideological positions as to whether trade, or analogously, different trade and related policies, are good or bad for food security. Part IV therefore considers the challenges and opportunities for improving coherence in the governance of trade and food security to ensure that the associated policy-making processes and frameworks result in trade and related policies being better crafted in support of national objectives, while remaining cognizant of their potential implications for the food security status of trading partners. It also describes how such improvements in coherence depend on broader reform of global governance and of the institutional and financial architecture that supports it. This will require strengthening the synergies among sectoral processes at all levels and improving capacity to identify and agree on common and shared goals across sectors.

Policy-making processes refer to the interactions and competing forces that shape policy decisions. "Processes" guide policy discussion and decision-making by setting the overarching sectoral objectives and priorities. "Policies" are the instruments for achieving such objectives and priorities. Processes have a political connotation; policies a more technical one. Shifting attention towards trade- and agriculture-related processes, rather than focusing exclusively on the pros and cons of different policies, will help reconcile multiple views, objectives and tradeoffs. It will assist in reaching agreement on common and shared priorities across sectors, in identifying the mix of policies most appropriate for achieving them, and in optimizing the availability, and ensuring the appropriate use, of policy space in trade agreements. Further, it will contribute to increased coherence and predictability of national policies while respecting the choice of national governments on how to balance different priorities in the context of agreed global frameworks.

The messages emerging from this report resonate well with the ongoing dialogue on the post-2015 development agenda. In particular, they reflect the discussions on "universality and differentiation", which recognise that the achievement of common goals is subject to consideration of the varying capacities, realities and development progress of countries. The messages also tie in with emerging views on the evolution of development cooperation and on the growing importance of domestic resource mobilization.

The expansion of global agricultural trade is inevitable and will play a role, whether proactively supported or not, in defining future food security and nutrition prospects. Trade and related policy must be formulated as part of a broader package of policies, and must prioritize long-term structural transformation objectives over short-term political or commercial interests. 


\section{Part I}

\section{The changing nature of agricultural trade}

$\mathrm{T}$ his first part of The State of Agricultural Commodity Markets 2015-16 introduces the global market context for the analysis of linkages between trade and food security presented in the report. Drawing on analyses of short-term market developments, medium-term projections and longer-term scenarios, Part I illustrates the key dynamics, trends and prospects that influence the patterns and composition of agricultural trade.

Likely evolutions in the structure and patterns of trade among geographical regions are first considered on the basis of the determinants of changes in demands for food and the way in which trade is conducted, noting in particular the diversity of market structures across commodities.

Understanding the dynamics of agricultural trade is key to understanding the potential implications for food security, for example in terms of price levels and volatility and of the implied projections of food import bills for net foodimporting developing countries (NFIDCs). It is also critical in determining the extent to which the factors driving these dynamics need to be managed at the national, regional and global levels, particularly given growing concerns about the reliability of global markets as a source of food.

\section{Main messages}

- Global trade in food has grown almost threefold in value terms over the past decade, and rates of growth are projected to continue to rise, with some regions becoming increasing net exporters and others increasing net importers.

- The structure of trade differs significantly by commodity and by region and will continue to evolve, affected by developments in global value chains, intrafirm trade, and bilateral and regional trade relations.

- The recent increase in global food prices, with spikes in 2007-08 and 2011, needs to be considered against the longer-term trend of falling real prices. Food price spikes are important for their potential negative impacts on food security and nutrition and, even if episodic, need to be factored into longer-term decisions on the management of trade in food and agricultural products.

- Geopolitical and weather uncertainties are likely to exacerbate these episodes of food price spikes in the future, with an increasing number of potential disruptions to trade flows expected. 


\section{Agricultural trade in a changing global landscape: context, trends and prospects}

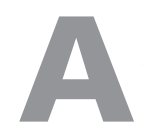
s food prices rose sharply between 2006 and 2011, the issue of feeding the world came to the forefront of both the development agenda and, because of the increasing role that trade will need to play, the international trade agenda. ${ }^{3}$

By 2050 the world's population will reach 9.1 billion, 34 percent higher than today. Nearly all of this population increase will occur in developing countries. Urbanization will accelerate, with about 70 percent of the world's population expected to be urban, compared with 49 percent today. To feed this larger, more urban and potentially richer population, food production will need to increase by 60 percent from the $2005-07$ baseline to $2050 .{ }^{4} \mathrm{An}$ estimated annual average of US\$83 billion of net investment in developing country agriculture will be required to deliver this production increase. ${ }^{5}$

Meanwhile, the geography of poverty is changing. Incomes in developing countries have been converging with those in rich countries since the 1990s, as growth has accelerated in developing economies while slowing in developed ones. These development patterns have been transforming the world's income distribution. ${ }^{6}$ Poor people used to live in poor countries, but today there are 1 billion extremely poor people living in middle-income countries such as India and Nigeria. ${ }^{7}$ Economic growth is continuing to narrow the gap in wealth and economic power between developed and developing countries. Geopolitical power is shifting towards a growing, heterogeneous group of middle-income countries. International trade has played a major role in this redistribution of resources and power. Evolving patterns of agricultural trade reflect the changed geopolitical dynamics, as does the development of global value chains.

This evolving global landscape has repercussions for the patterns, composition and governance of agricultural trade. An improved understanding of the drivers and implications of these evolutions is critical in providing the context in which discussion of the relationship between trade and food security should be set. Data and analysis on current market drivers are key, but understanding of how markets are evolving and their future prospects is also important in identifying the most relevant issues for discussion.

\section{Evolving composition and patterns of trade}

Trade of agricultural products has continued to expand, driven by high demand, particularly in emerging economies. The value of global agricultural exports nearly tripled between 2000 and 2012, while agricultural exports increased by about 60 percent in volume terms over the same period. ${ }^{8}$ With global demand for agricultural products expected to remain firm in future decades, this evolution is expected to continue. The OECD-FAO Agricultural Outlook ${ }^{9}$ examines the consequences of the interplay of supply and demand factors to project the likely evolution of production, consumption and, as a result, net trade. It projects that the increasing divergence in trends in net trade in agricultural products by region since 2000 will widen further in the period to 2024 (Figure 1).

Many regions are expected to increase their reliance on trade, either as net exporters or net importers. Asia has been the fastest growing net importer, with a sharp increase after 2007, driven especially by China's evolution to net-importing status for many agricultural commodities. Latin America has become the largest net exporter of food, with significant production growth outstripping sustained consumption growth. North America follows as the second largest net exporter, but more as a result of stagnant consumption in the region than of production growth. Eastern Europe and Central Asia is shifting from being a net importer to becoming a net exporter. By contrast, sub-Saharan Africa's net imports have been growing, primarily because of population growth, while the Near East and North Africa is rapidly becoming a net importing region as food production is unable to keep pace with growing demand.

Changing consumption patterns are a major driver of this evolution. Per capita consumption of animal protein in developed countries appears to have reached a plateau, as has per capita consumption of staples in developing countries in aggregate, although in many countries there remains an excess demand for staples among the poor. In developing countries, increases in incomes, population and urbanization - albeit occurring at different rates - are contributing to changes in lifestyle habits and dietary structure. Typically, the shift from a traditional cereal-based 
FIGURE 1

\section{Billion US\$}

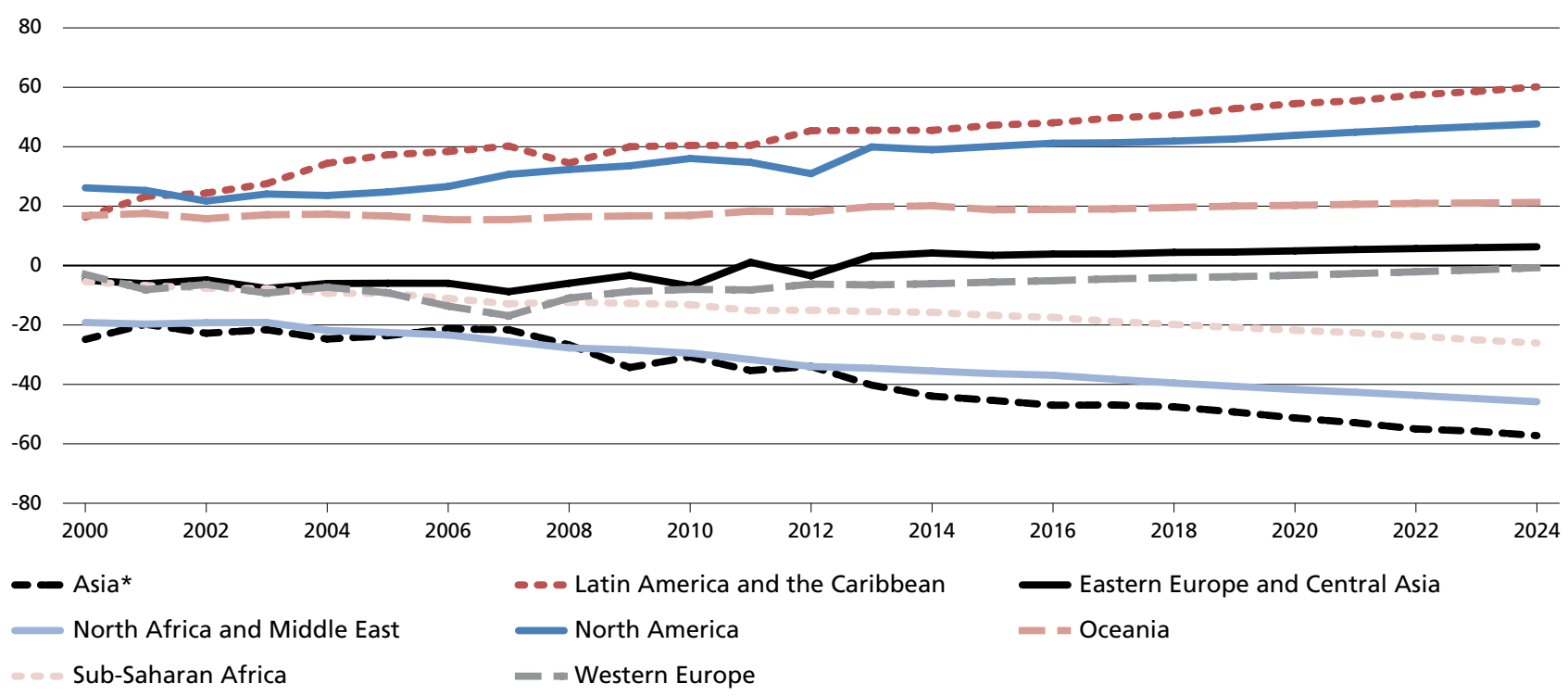

Notes: Net exports of cereals, oilseeds, sugar crops, meats, fish and dairy products evaluated at 2004-06 constant international reference prices. Data from 2014 onward are projections.

* "Asia" covers all Asia except for Central Asia and includes Southeast Asia, South Asia, and East Asia (including China).

Source: FAO and OECD. 2015. OECD-FAO Agricultural Outlook 2015-2024. Paris, OECD Publishing.

diet to a more protein-rich and diversified diet results in changes in the composition of trade, as global consumption tends towards value-added products, including processed and prepared foods, and developing countries account for a growing share of global consumption. More than 95 percent of consumption growth between now and 2024 will be in the developing world. ${ }^{10}$

At the global level, the share of processed products in agricultural exports remained constant between 2001-04 and 2009-12, at approximately 41 percent, while it shrank in least-developed countries (LDCs), from 31 to 26 percent. Over the same period, the share of raw commodities in the total value of agricultural exports increased substantially in LDCs, from 37.8 to 48.5 percent, and in landlocked developing countries, from 33.5 to 46.7 percent. By contrast, in small island developing states, the proportion of unprocessed exports declined from 52.9 to 38.3 percent, while the share of processed products increased from 37.8 to 48.3 percent. Total agricultural exports increased substantially for all product categories and country groupings (Figure 2).

Food use is also changing. While cereals remain the core of human nutrition, their contribution to industrial uses has been increasing and will continue to do so in the coming decades. At the global level, food remains the most important use of cereals, but the demand for animal feed is the fastest growing in the cereal sector, in line with shifting dietary preferences. After rapid expansion over the past decade, ethanol use currently accounts for 12 percent of global coarse grain consumption. ${ }^{11}$ Although the expansion of maize-based ethanol is expected to slow down significantly in the coming years, projections suggest that this use of coarse grains will remain significant in the developed country aggregate and may also emerge in the developing country aggregate (Figure 3).

Regarding market dynamics for specific crops, oilseeds are expected to gain in importance, supported by a strong demand for vegetable oils and protein meals. Sugar consumption will also grow rapidly, notably in the developing countries, while it will show little or no growth in many developed countries because of saturated consumption levels and competition from other sweeteners. Growing incomes, urbanization and the globalization of eating habits all contribute to more food being consumed ready-made, increasing the consumption of meats, vegetable oils and sugar. These three categories now account for 35 percent of the caloric intake per capita in developing countries, increasing from 30.1 percent in 2002-04 (Figure 4). They are important components in human diets and constitute a crucial source of energy, especially in many 
FIGURE 2

Value of agricultural exports by stage of processing, 2001-04 and 2009-12

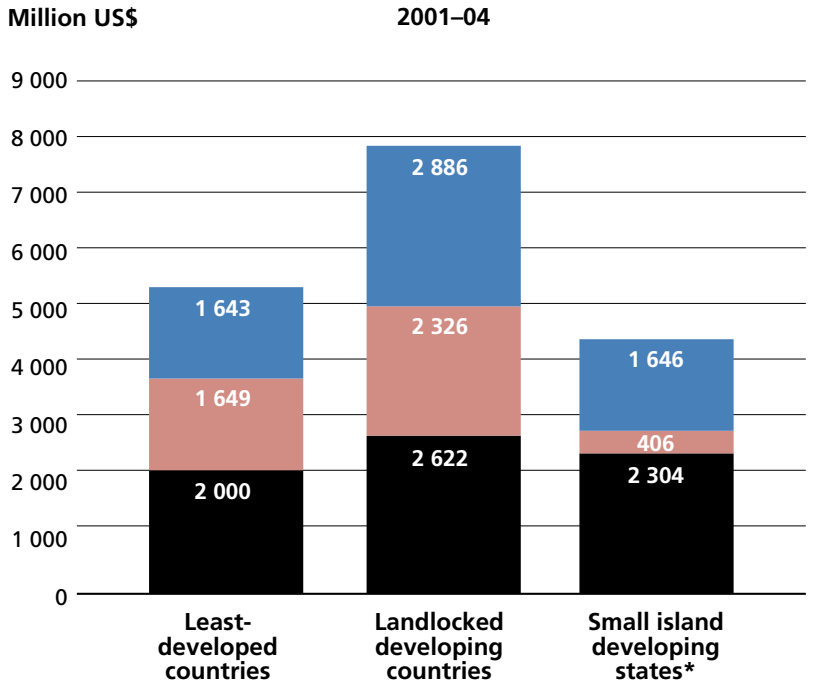

countries developing states*

Raw Semi-processed

Million US\$

2009-12

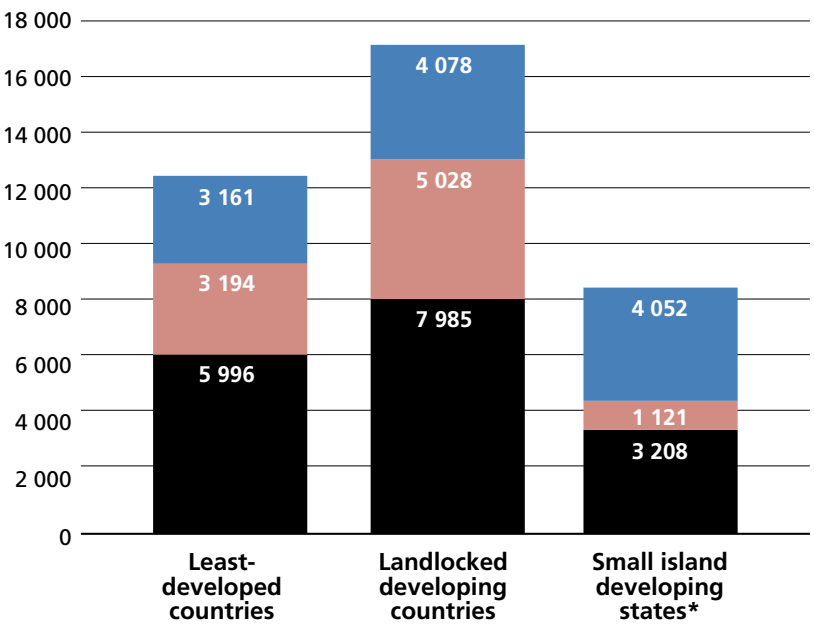

*Excluding Singapore.

Source: FAO. 2014. Agriculture and Food Security Statistics of the Least Developed Countries, Landlocked Developing Countries and Small Island Developing States 2014. Special issue. Rome.

FIGURE 3

Coarse grain utilization in developed and developing countries

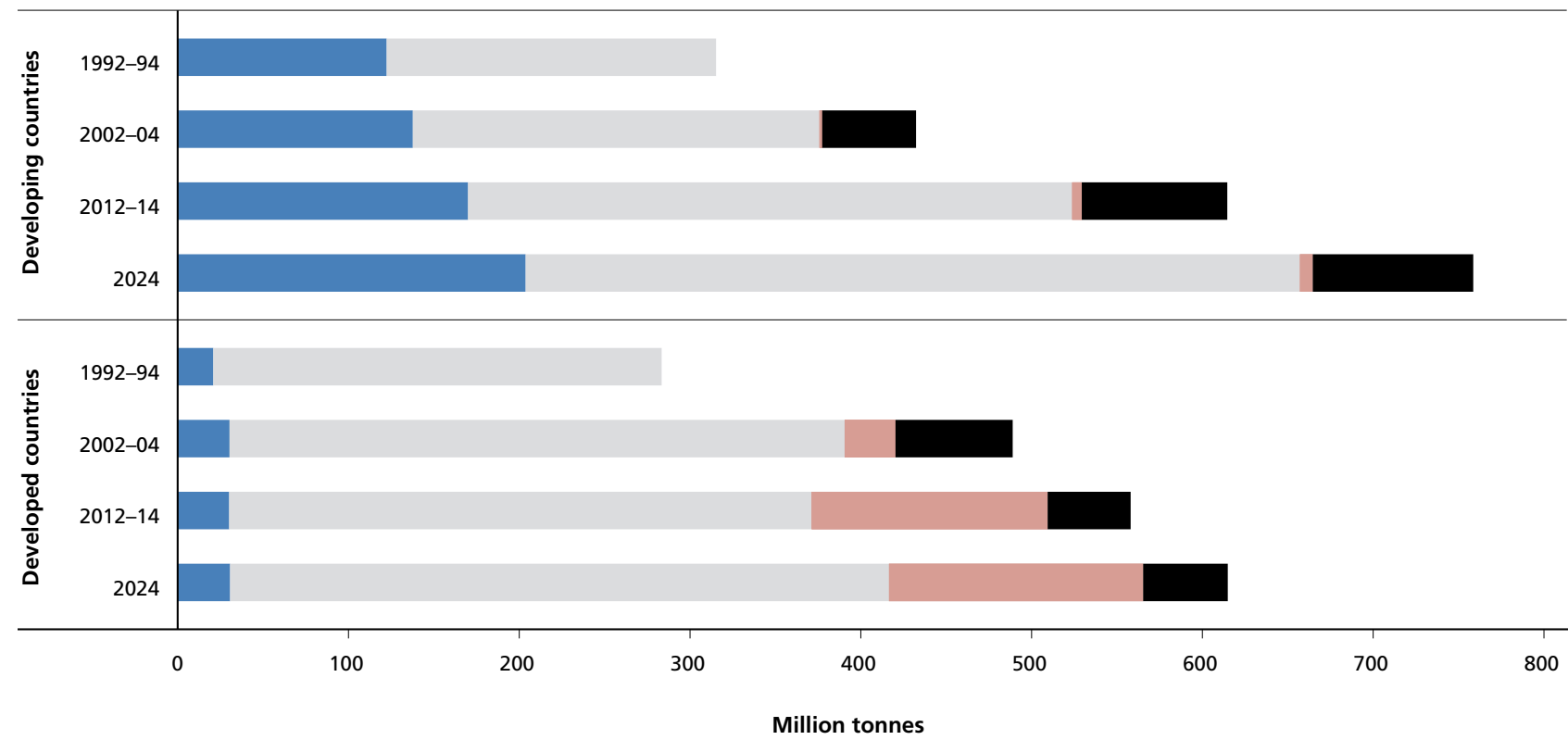

Food use Feed use Biofuel use $\quad \square$ Other use

Source: FAO and OECD. 2015. OECD-FAO Agricultural Outlook 2015-2024. Paris, OECD Publishing 


\section{$\mathrm{kcal} / \mathrm{day} /$ person}

3000

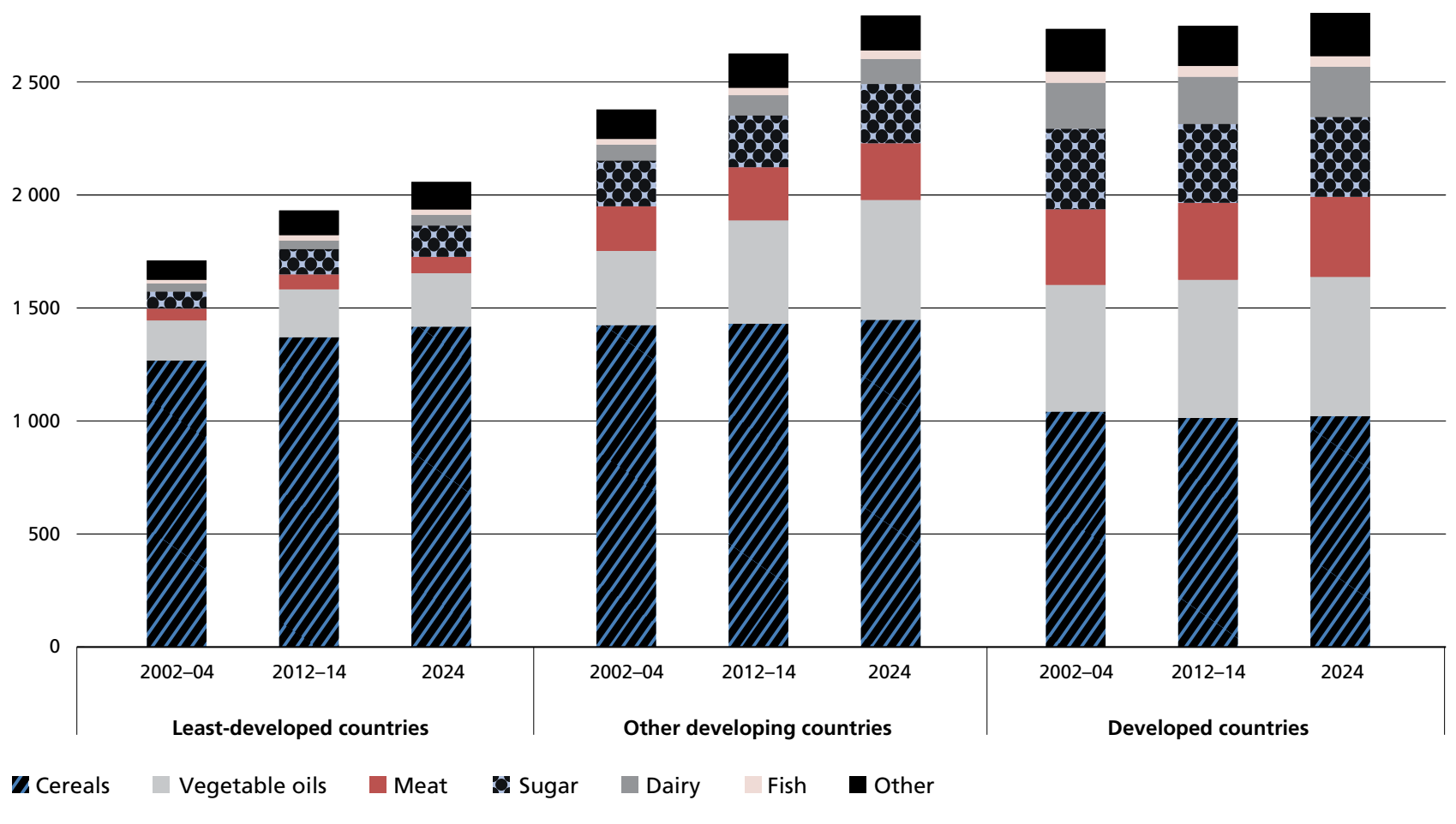

Source: Adapted from FAO and OECD. 2015. OECD-FAO Agricultural Outlook 2015-2024. Paris, OECD Publishing.

developing economies. At the same time, increasing consumption of vegetable oils and sugar in processed and packaged food is raising nutrition concerns.

Changes in the importance of certain crops are reflected to some extent in changes in the composition of exports, with increased exports of high-value commodities, such as meat, ethanol, sugar, oilseeds and cotton, from the Americas (Table 1)

Counterposing production and consumption trends provides an indication of likely trends in the net trade position of different commodities by region. Figure 5 shows the evolution of trade in major products in the main developing country regions. Points above the 45-degree line denote net export status and those below net import status. For each of the main crops and products, the production/consumption position in 2012-14 and the projected position in 2024 are plotted. The direction of change in net trade status is indicated by the arrows connecting these positions.

The contrasts among regions are significant. In Africa, all major commodities are in net import status, and this situation is expected to intensify over the next decade, particularly for higher-value products. By contrast, in Latin America, most major commodities are in net export status, especially coarse grains and sugar. Asia - by far the largest consuming and producing region for all commodities except beef - displays a more balanced trade trajectory, with most commodities remaining net imports, but with rice and vegetable oils in slight surplus.

Rapidly growing Asian economies are expected to continue to account for the greatest share of the increase in global food consumption. In Africa, population growth will drive significant increases in total consumption, despite per capita consumption in the region being much lower than in the rest of the world. By supplying these two regions, a number of Latin American countries are positioning themselves as major global suppliers.

Exports of agricultural commodities tend to be concentrated in a few countries and regions, while imports are dispersed over a larger number. The United States of America, the European Union (EU) and Brazil are expected to remain among the top exporters, with some exports highly concentrated in one country, such as sugar from Brazil, which accounts for more than half of global sugar exports, 
FIGURE 5

Production and consumption trends from 2012/14 to 2024, by developing country region

CEREALS

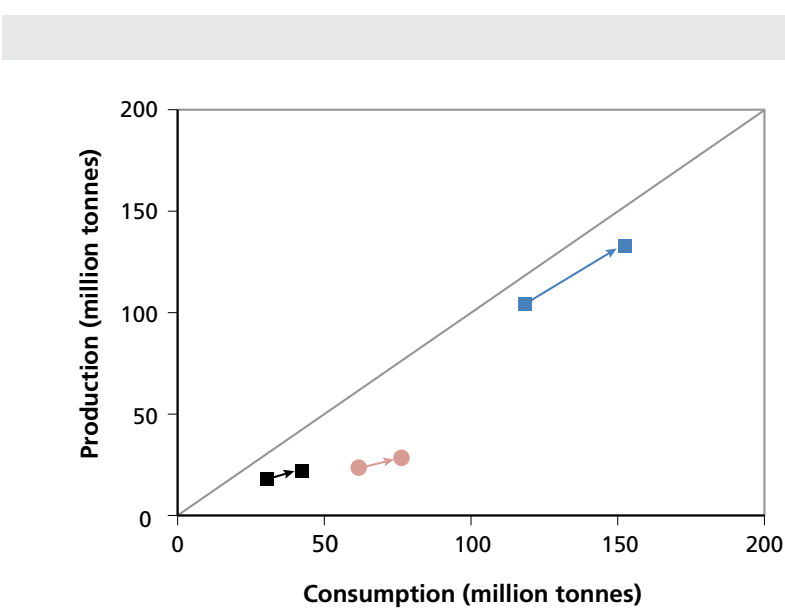

Africa

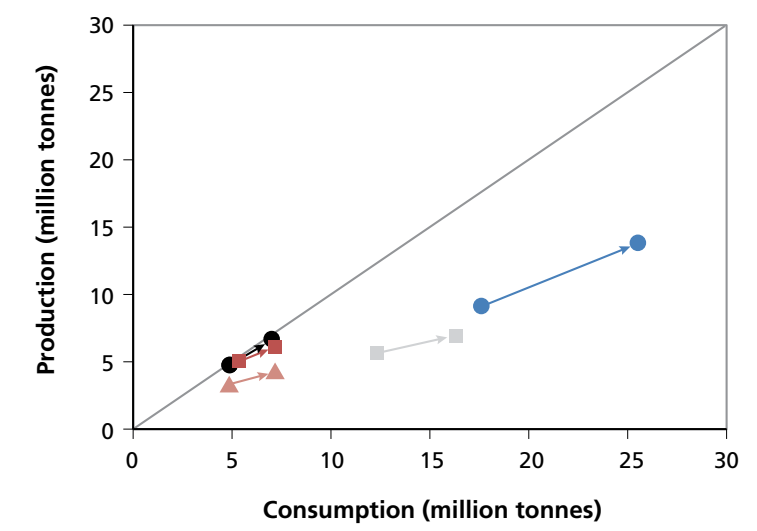

Asia
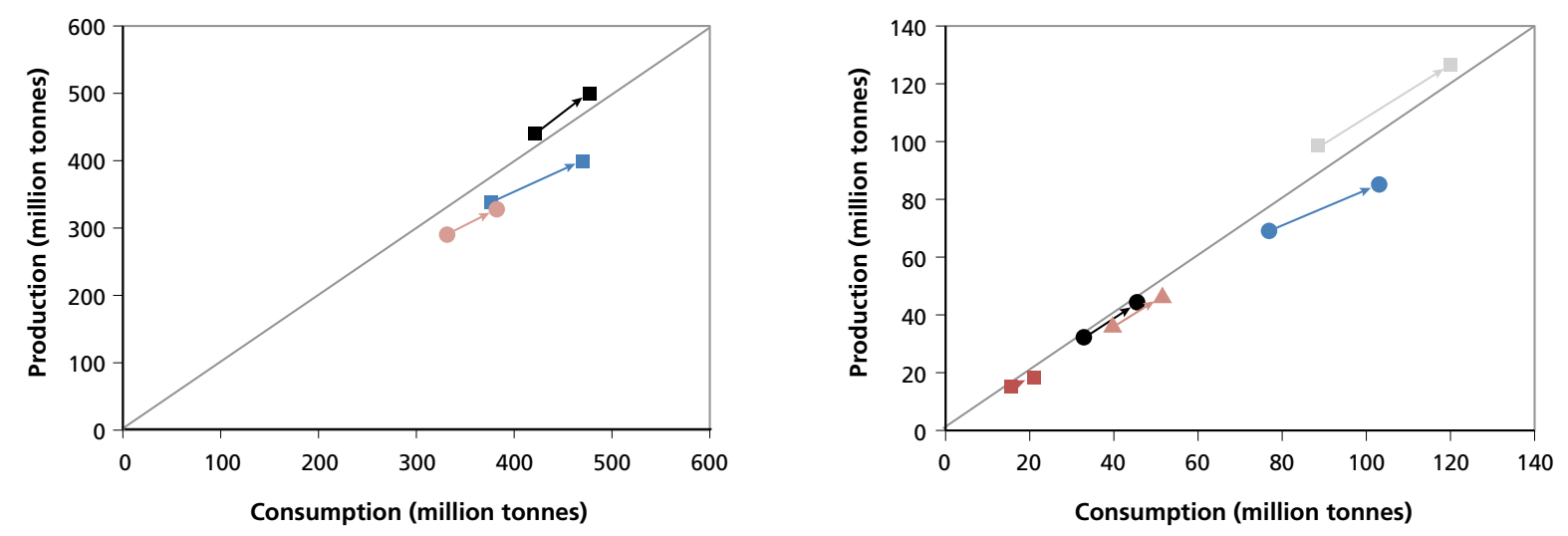

Latin America
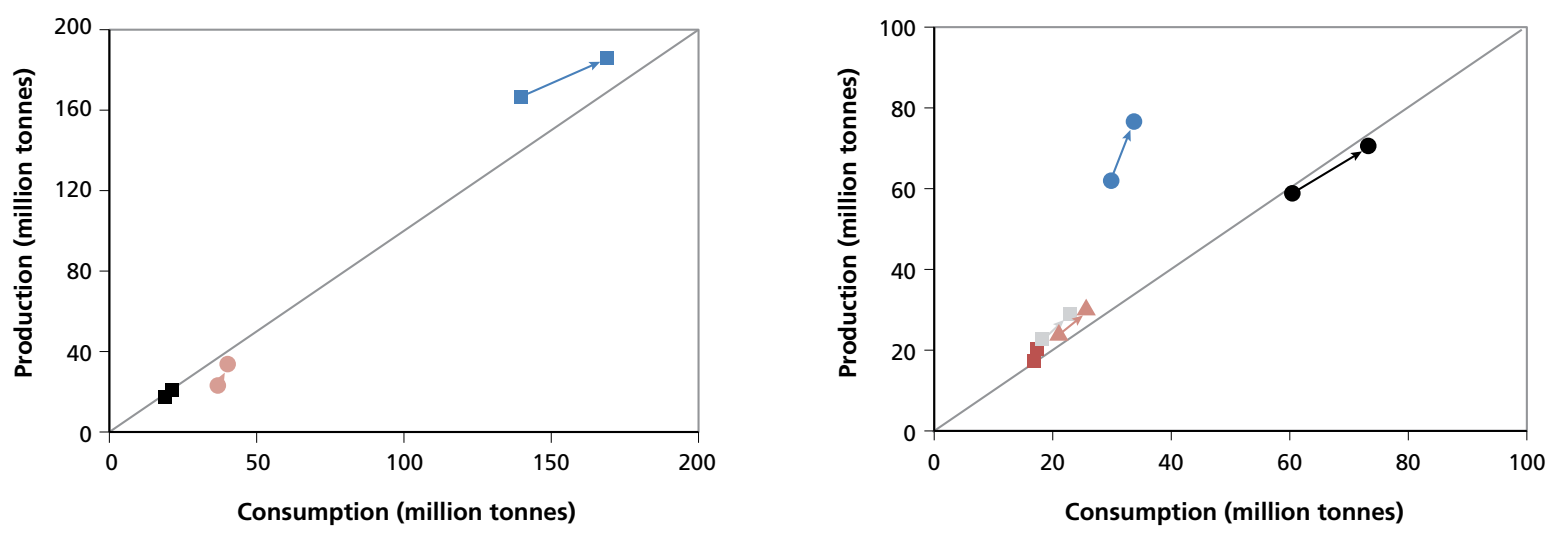

- Rice Wheat Coarse grains

- Dairy $\quad$ Beef $\Delta$ Poultry $\quad$ Vegetable oil $\quad$ Sugar 
Trade balance in volume terms in 2023

\begin{tabular}{|c|c|c|c|c|c|c|c|}
\hline & Africa & $\begin{array}{l}\text { Asia and the } \\
\text { Pacific }\end{array}$ & Europe & $\begin{array}{l}\text { Latin America } \\
\text { and the } \\
\text { Caribbean }\end{array}$ & North America & $\begin{array}{c}\text { Oceania } \\
\text { developed } \\
\text { countries }\end{array}$ & $\begin{array}{l}\text { Other developed } \\
\text { countries }\end{array}$ \\
\hline & \multicolumn{7}{|c|}{ Volume of net exports, thousand tonnes } \\
\hline Wheat & -44987 & -49963 & 45788 & -7074 & 46206 & 18329 & -8299 \\
\hline Rice & -18052 & 21083 & -1368 & -1192 & 2419 & 299 & -2637 \\
\hline Coarse grains & -22851 & -63999 & 30402 & 21795 & 53574 & 4154 & -19595 \\
\hline Oilseeds & -3494 & -98449 & -11469 & 57748 & 58323 & 2921 & -5185 \\
\hline Protein meals & -4461 & -27206 & -19586 & 49715 & 8963 & -2669 & -4912 \\
\hline Beef & -877 & -2105 & -1110 & 3341 & 42 & 2224 & -1147 \\
\hline Pork & -714 & -2625 & 1715 & -376 & 3621 & -362 & -1280 \\
\hline Sheep & 53 & -790 & -140 & 9 & -71 & 1032 & -40 \\
\hline Poultry & -2192 & -5234 & 877 & 3677 & 4710 & 57 & -1729 \\
\hline Fish & -3323 & 9625 & -1822 & 2015 & -3406 & -220 & -2769 \\
\hline Fish meal & 43 & -1418 & -7 & 1398 & 125 & -28 & -112 \\
\hline Fish oil & 56 & -124 & -189 & 296 & 4 & -12 & -30 \\
\hline Butter & -161 & -413 & 80 & -22 & 98 & 476 & -39 \\
\hline Cheese & -219 & -633 & 879 & -284 & 318 & 518 & -365 \\
\hline Skim milk powder & -387 & -1241 & 640 & -367 & 826 & 642 & -95 \\
\hline Whole milk powder & -618 & -1372 & 379 & -46 & 4 & 1656 & -21 \\
\hline Vegetable oils & -8775 & 5447 & -2366 & 8362 & 235 & -386 & -2279 \\
\hline Sugar & -11684 & -17342 & -591 & 38337 & -4511 & 3636 & -4475 \\
\hline Cotton & 1620 & -7164 & 48 & 927 & 2562 & 1035 & 741 \\
\hline
\end{tabular}

Source: Adapted from FAO and OECD. 2015. OECD-FAO Agricultural Outlook 2014-2023, Table 1.1. Paris, OECD Publishing.

or coarse grains and pork from the United States of America, each accounting for one third of its global export market. Kazakhstan, the Russian Federation and Ukraine are becoming prominent cereal exporters, particularly of wheat, with the share of the three countries expected to reach 22 percent of the world's total wheat exports in $2024 .^{12}$
While international trade is of vital importance in smoothing the risks associated with disruptions to supplies that would result from reliance on domestic production alone, heavier concentration on few suppliers could introduce other types of risks, such as those driven by the sudden and unexpected adoption of trade measures. 


\section{2.}

\section{Evolving market structures}

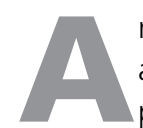
nother characteristic of global markets is that they are often segmented, with implications for the potential destinations of traded commodities. Figures 6 and 7 illustrate this point. The rice market is segmented along regional lines, with the bulk of trade occurring in the region of origin. By contrast, the soybean market is dominated by exports from three American countries to China and a small number of importing developed and middle-income countries. The soybean market and the more complex cattle markets are notable for the absence of low-income countries, reflecting these countries limited engagement in trade of such higher-value products.

\section{The changing architecture of international trade}

The patterns of global trade are not only determined by market fundamentals and international trade rules, but - to a growing extent - they are also influenced by other, subtler dynamics.

An increasing share of global trade is taking place through bilateral and regional agreements. The number of regional trade agreements (RTAs) has expanded from fewer than 20 in 1990 to the 262 currently in force. Concluding the so-called "mega-regionals" will raise this share further. Together, the Transatlantic Trade and Investment Partnership (TTIP) between the EU and the United States of America, the Trans-Pacific Partnership (TPP), and the Regional Comprehensive Economic Partnership - which joins the Association of Southeast Asian Nations with other regional partners - would represent more than three-quarters of global gross domestic product (GDP) and two-thirds of world trade. ${ }^{13}$ By limiting the number of parties involved and focusing on the parties' strategic areas of interest, RTAs tend to establish deeper trade and economic integration provisions than other agreements, deriving significant benefits from removing non-tariff barriers, harmonizing standards and facilitating trade, rather than reducing tariffs and other formal barriers to market access. For example, more than half of the RTAs contain deeper commitments on sanitary and phytosanitary measures (SPS) than those currently covered by the relevant World Trade Organization (WTO) agreements. As SPS and technical barriers to trade play a major role in determining de facto market access for goods, harmonizing and streamlining these measures within trading blocs has potential for boosting intraregional trade substantially.

A second factor in changing the patterns of global trade is that intrafirm trade is gaining ground with the emergence of global value chains and vertical integration. In the United States of America, for example, intrafirm trade flows accounted for 48 percent of goods imports and 29 percent of goods exports in 2010. In multinational companies, internal procedures and standards may play a far greater role in determining volumes and conditions of trade transactions than government trade policy does. Another important issue in the context of intrafirm trade is transfer pricing, which refers to the pricing of goods, services or other assets exchanged among affiliated companies. These prices are used for internal accounting of the companies, and although they are different from market prices, they could affect the general level of domestic prices and trade patterns, through their effects on supply and demand. The extent to which existing trade rules are equipped to deal with the new competition issues arising in this vertical relationship is yet to be seen. ${ }^{14}$

The implication of these developments is that the multilateral system is becoming less important as a driver of trade expansion, although the WTO still provides the most comprehensive and readily available mechanisms for discussing the application of trade rules and settling disputes among countries. Coupled with the concentration in few countries of both imports and, particularly, exports of agricultural commodities, the evolution in the architecture of global agricultural trade means that actions of one country or a group of countries could have significant spillover effects on the rest of the world. Production variability, turbulence in domestic markets and policy changes in one major importer or exporter could therefore have implications for world markets, affecting global supplies and prices, with potentially significant impacts on food security.

The changing context of agricultural trade is further complicated by the increasing fragmentation of global production and by its reorganization into complex global value chains (GVCs). Recent literature describes the competitiveness of a country and/or its industries by looking 
FIGURE 6

\section{Rice export flows}

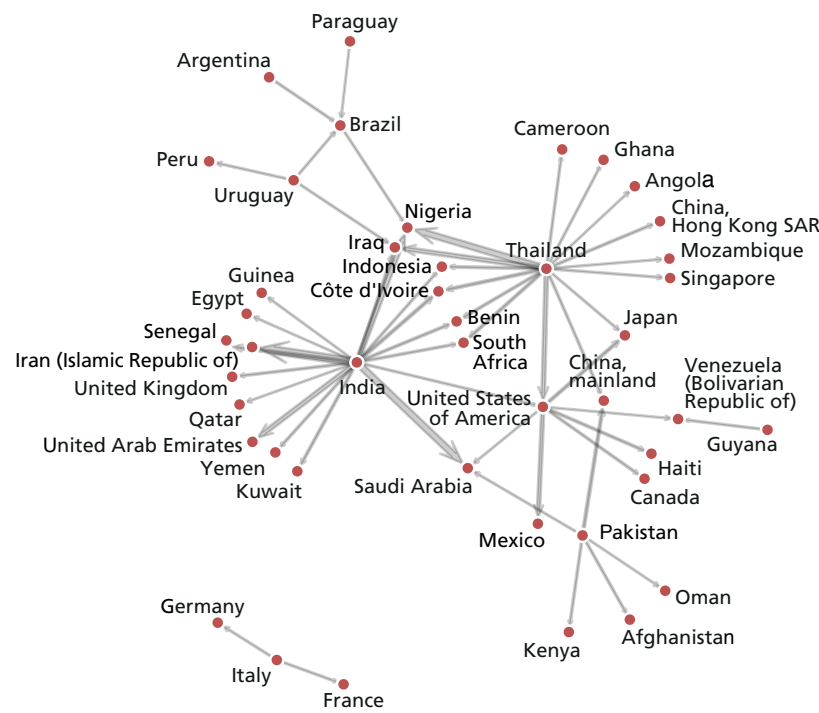

Note: The relative thickness of the arrows refer to the value (in US\$) of the exports of rice (milled equivalent), covering 60 percent of international rice exports in 2012.

Source: FAO.

specifically at the country's production of value-added products and its level of integration into GVCs. ${ }^{15}$

GVCs have become important links in the relationships among competitiveness, trade, growth and development. Some observers argue that participation in GVCs allows greater competitiveness, better inclusion in trade and investment flows, access to new types of production technology, upgrading towards higher value-added activities, and socio-economic upgrading through potentially more and better remunerated jobs, more sustainable use of resources, and better governance and political stability. Countries that participate in GVCs do not need to develop vertically integrated industries to participate in global trade. They can develop capacities in specific segments of the chain (production, tasks or business functions) and, consequently, even small countries with limited capacities along a value chain have the chance to export goods or services. ${ }^{16}$

However, the organization of the modern food system into complex GVCs also raises questions about the assumption of competitive markets. In the agriculture sector, there is a high degree of concentration among firms both within countries and internationally, pointing to a lack of competition. Transnational agribusiness companies that dominate GVCs in the food sector are highly mobile and able to invest in developing countries to capitalize on the absolute advantage that may exist in these locations, and this may undermine the comparative advantages of other countries.
FIGURE 7

Soybean export flows

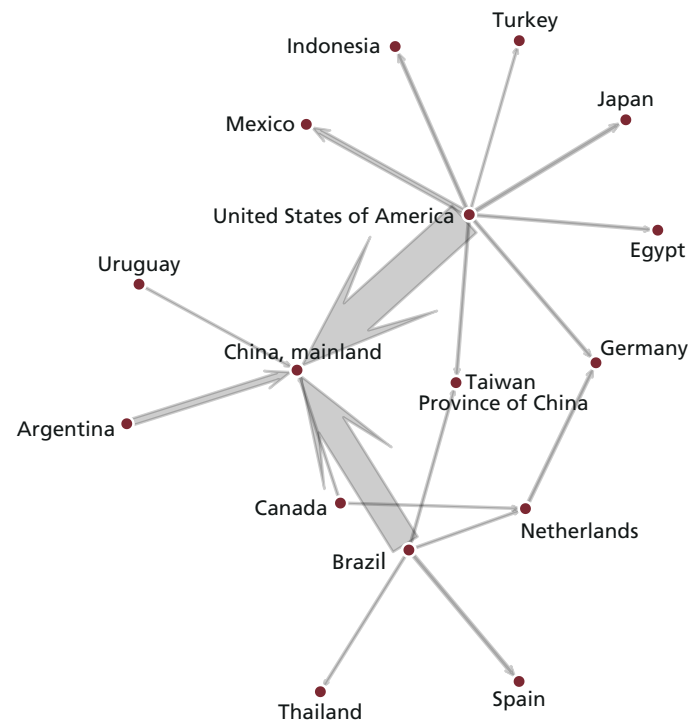

Note: The relative thickness of the arrows refer to the value (in US\$) of the exports of soybeans, covering 80 percent of international soybean exports in 2012

Source: FAO.

Foreign direct investment (FDI) in agriculture, processing and retail operations has increased the global integration of agrifood markets. Players in these segments include state trading enterprises and large private firms, which operate, both domestically and internationally, under market structures with different degrees of competition.

A traditional preoccupation has been the role of large multinational corporations in the global markets of primary products. Some studies ${ }^{17}$ have pointed to the dominant presence of the four major commodity traders, Archer Daniels Midland (ADM), Bunge, Cargill and Louis Dreyfus. At the same time, these multinational companies are facing increasing competition from a number of new trading companies. The banana market, for example, has been transformed from being dominated by a handful of multinationals controlling production, distribution and trade to become a market with a multitude of operators in both importing and exporting countries, characterized by varied and complex interactions among different segments (Box 1).

If integration is achieved, countries' increased exposure to trade and foreign investment can result in development benefits through knowledge and technology spillovers and can trigger favourable structural transformations by relocating labour from agriculture to higher-productivity and higher-paying jobs in manufacturing or services. ${ }^{18}$ However, not all countries will achieve integration immediately. Only those that are sufficiently close to producing in line with 
BOX 1

Shift in market power in the banana market

Multinational trading companies, particularly the three largest banana traders (Chiquita, Dole and del Monte), have historically played a major role in the international banana trade, exerting substantial market power, particularly on the purchasing side. These vertically integrated multinational firms engage in production, purchase, transport and marketing of bananas. They own fleet and ripening facilities and have their own distribution networks in the importing countries, creating significant economies of scale. However, the scope of their operations and their influence over the banana trade have changed over time. The combined market share of the top three companies was at its highest in the 1980s, when they controlled almost two-thirds (65.3 percent) of global banana exports, and has gradually declined since. In 2013, the market share of these companies was slightly over one-third (36.6 percent), while the share of the top five companies was 44.4 percent, down from 70 percent in 2002. As a consequence, other companies now account for more than half of all exports.

This shift of market power away from the major banana trading brands towards other market players, including supermarkets that have started sourcing directly from producers, was largely driven by the EU's dismantling of its highly regulated banana import regime and was facilitated by the establishment of direct container liner services from South America to Europe and the Russian Federation. There is also a notable trend towards less concentration among the exporting firms in major banana-producing countries.

Source: FAO. 2014. The changing role of multinational companies in the global banana trade. Rome

global quality standards and efficiency levels will be able to participate. Moreover, involvement and participation in GVCs is not easy, especially for small rural producers, who often have limited access to the knowledge, capital and technology for upgrading their production.

In emerging and developing countries, strong economic growth and rising income levels, combined with growing urbanization, have changed dietary habits and triggered increases in demand for higher-quality products, and for retail and processed products in urban areas. Increased trade in fresh food products such as fruits, vegetables, meat and dairy products - which are either prone to food safety risks or subject to specific quality demands from consumers - has also increased the need to regulate trade through standards. The increased role of large multinational food and retail companies that emphasize freshness, product quality and food safety has increased the importance of private standards as a way of preventing potential reputational damage and loss in market share from selling unsafe food.

It is interesting to note that despite these more stringent and widespread standards, not only has global agricultural trade increased sharply over the past three decades, but growth has been strongest where standards are most important, i.e. in higher-value products such as fruits, vegetables, fish and fishery products, meat and dairy products. Moreover, the shift towards high-value exports has been most dramatic in developing country regions. ${ }^{19}$ The need for final consumer products to meet such standards has led to an increased emphasis on quality control within agricultural value chains, and this in turn has affected the way in which global agricultural value chains are organized, with increasing levels of vertical coordination, upgrading of the supply base, and increased dominance by large multinational food companies. 


\section{Potential issues related to food imports}

\section{Prices as indicators of change}

Agricultural markets change over time, sometimes cyclically and sometimes permanently. They are subject to an annual seasonality that is peculiar to agricultural production, but they also show periods of relative calm or instability that can last for several years.

The period from 1999 to 2006, which was one of historically low prices, was followed by an extended period of high and volatile prices from 2007 to 2013. In 2014, markets began to stabilize once again, and medium-term projections point to a return to lower prices (Figure 8). In real terms, prices for all agricultural products are expected to decrease over the next ten years, as productivity growth - helped by lower input prices - outpaces slowing demand increases. ${ }^{20}$

Falling real agricultural commodity prices are consistent with the expected tendency for long-term decline that is

\section{FIGURE 8}

Food price index in nominal and real terms, 1990-2015

\section{Index $(2002-04=100)$}
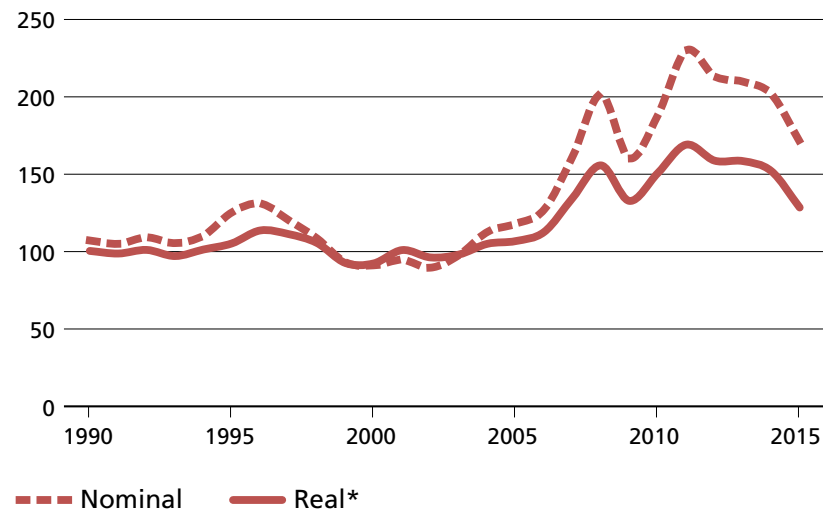

* The real price index is the nominal price index deflated by the World Bank Manufactures Unit Value index (MUV).

Source: FAO characteristic of world agricultural markets. Low commodity prices, particularly those observed in the 1980s and 1990s, have been cited as an impediment to development in agriculture-based economies, reducing the incentives for investment in production-enhancing technologies, with negative impacts on food security.

However, experience shows that such declining trends are interrupted by periods of high and volatile prices. These unexpected price spikes can also be a major threat to food security. Recently, the policy debate around agricultural trade has focused on high price levels and short-term policy interventions for reducing domestic price pressures. However, a short-term horizon is not always compatible with implementing policy that is supportive of longer-term structural transformation, as explained in Part III.

\section{Increasing costs of food imports}

Combined with higher food prices, the trends in trade described in the previous section have had significant impacts on food import bills in low-income and food-deficit developing countries. The trends in cereal import bills, which increased in both LDCs and NFIDCs, are emblematic (Figure 9). ${ }^{21}$

The increase in food import bills - combined with the increasing degree to which, in aggregate, developing countries and specific categories such as LDCs, NFIDCs and low-income food-deficit countries (LIFDCs) ${ }^{22}$ became net food importers in the 1980s and 1990s - has raised growing concerns. FAO data show that food imports to LDCs between 1992 and 2011 increased about fivefold, although a reduction is expected in 2015/16 as food prices continue to fall.

However, net food import status may not be a good indicator of food insecurity. A better indicator may be the size of the nominal food import bill compared with total merchandise export revenues, overall income or GDP, or other metrics of affordability or economic potential to pay for increased food imports. For example, while the food import bill has increased in LDCs, the increase in total exports from these countries has been much sharper (Figure 10). This implies that LDCs' ability to pay for food imports has increased in aggregate as a result of the overall expansion of trade. The same can be shown of NFIDCs and LIFDCs. 
FIGURE 9

Cereal imports of least-developed countries and net food-importing developing countries, $1993 / 94$ to $2015 / 16$

\section{Million US\$}

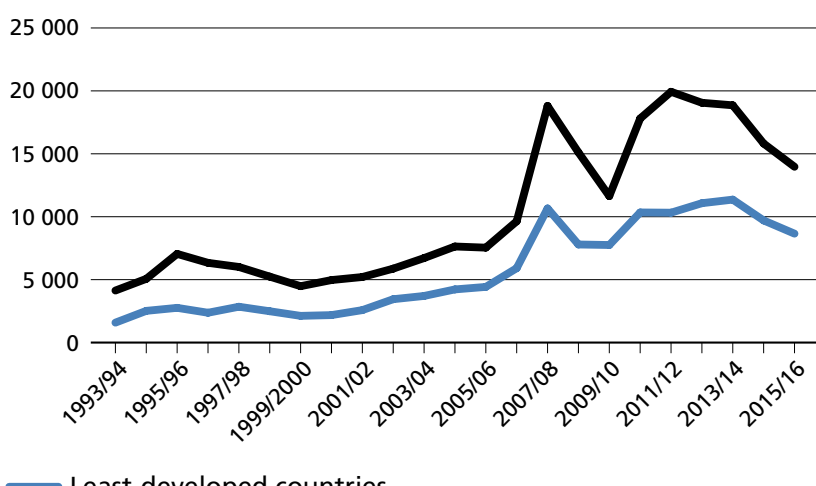

Least-developed countries

Net food-importing developing countries

Note: Data for 2014/15 are estimates (as of September 2015) and for 2015/16 are forecasts.

Source: FAO.
FIGURE 10

Food imports and total exports for least-developed countries, 1961-2012

\section{Billion US\$}

250

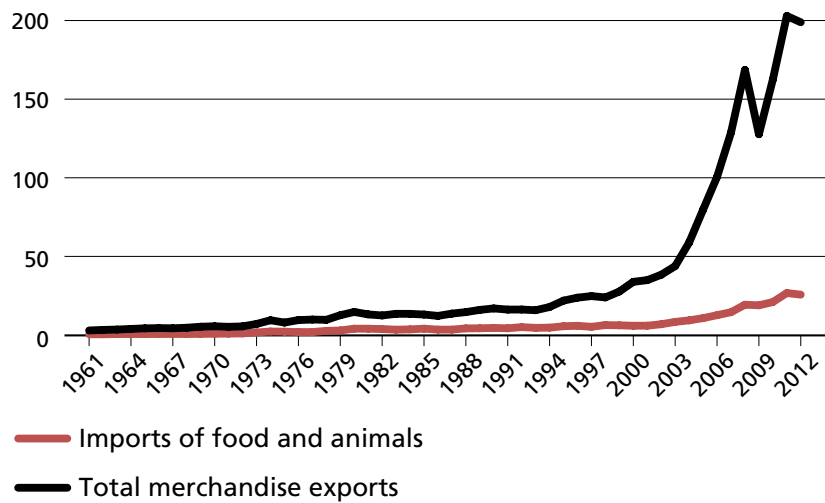

Source: E. Díaz-Bonilla. 2015. Lost in translation: the fractured conversation about trade and food security. Background paper prepared for The State of Agricultural Commodity Markets 2015-16. Rome, FAO.

TABLE 2

Ratio of value of total merchandise exports to food imports

\begin{tabular}{|c|c|c|c|}
\hline Region & 1990s & 2000-2007 & 2008-10 \\
\hline WORLD & 6.2 & 5.0 & 5.0 \\
\hline Developing regions & 6.9 & 4.7 & 5.0 \\
\hline Africa & 14.1 & 10.4 & 10.0 \\
\hline North Africa & 21.2 & 12.3 & 13.0 \\
\hline Sub-Saharan Africa & 10.9 & 9.5 & 9.0 \\
\hline Asia & 5.2 & 3.7 & 4.0 \\
\hline Caucasus and Central Asia & 19.4 & 6.7 & 7.0 \\
\hline East Asia & 3.7 & 2.6 & 3.0 \\
\hline East Asia (excluding China) & 4.3 & 3.1 & 3.0 \\
\hline South Asia & 11.1 & 7.6 & 7.0 \\
\hline South Asia (excluding India) & 15.8 & 10.5 & 11.0 \\
\hline Southeast Asia & 4.4 & 4.1 & 5.0 \\
\hline West Asia & 9.2 & 5.5 & 6.0 \\
\hline Latin America and the Caribbean & 9.8 & 6.9 & 6.0 \\
\hline Caribbean & 23.6 & 22.1 & 21.0 \\
\hline Latin America & 8.8 & 6.6 & 6.0 \\
\hline Oceania & 17.1 & 17.8 & 19.0 \\
\hline
\end{tabular}

Source: E. Díaz-Bonilla. 2015. Lost in translation: the fractured conversation about trade and food security. Background paper prepared for The State of Agricultural Commodity Markets 2015-16. Rome, FAO. 
A declining trend can be observed in the ratio of total merchandise exports to food imports in most developing country regions apart from Southeast Asia and Oceania (Table 2). It can also be observed that the food import bill as a percentage of GDP has remained quite stable in LDCs and LIFDCs, despite some oscillations (Figure 11).

However, while the aggregate data for many developing country regions and categories show declines in the burden of the food import bill relative to merchandise trade revenues, in some countries food imports bill are very high. Moreover, the heterogeneity of countries requires more in-depth analysis of specific country situations, as greater revenues from merchandise exports may not be used to offset growing food imports, and the distribution of these revenues may not increase the access to food of the individuals and/or groups that are more vulnerable to food insecurity.

\section{Longer-term concerns about international food markets}

In light of increased prices, and despite increases in the volumes of trade, many countries are concerned about the reliability of global markets as a source of affordable food, given the markets' susceptibility to shocks and to the actions of trading partners. However, in addition to price increases, other economic, environmental and social factors can also affect trade flows and, therefore, the reliability of markets as a source of affordable food.

Based on research by Chatham House and using the Black Sea and Gulf regions as an example, Box 2 demonstrates
FIGURE 11

Food imports as a share of GDP in low-income food-deficit countries and least-developed countries

\section{Percentage}

4.5

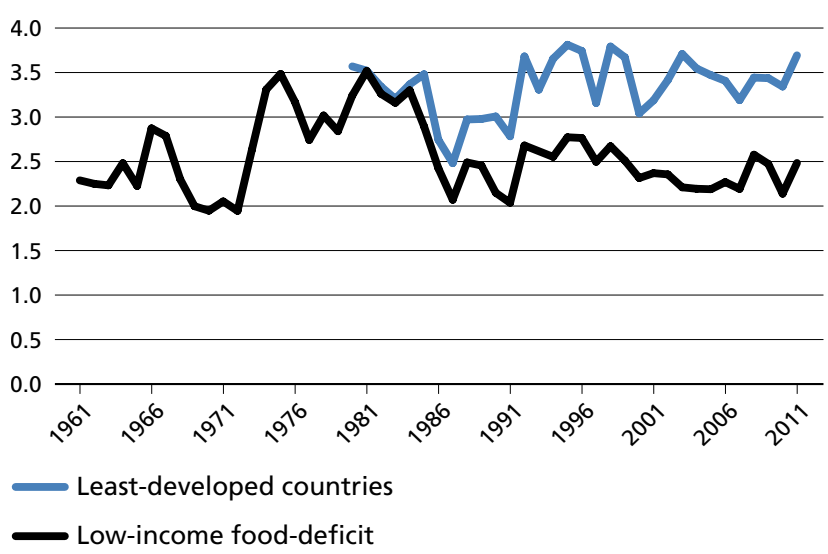

Source: E. Díaz-Bonilla. 2015. Lost in translation: the fractured conversation about trade and food security. Background paper prepared for The State of Agricultural Commodity Markets 2015-16. Rome, FAO.

how climatic shocks, conflict and congested infrastructure can constrain the potential growth of trade and increase its susceptibility to shocks.

Part II considers the current and potential future contexts of the relationship between trade and food security. 
BOX 2

\section{Pinch points in global food trade}

The global trade in food is exposed to multiple and varied disruptive risks. Resource constraints and climate change are not only threatening production in the world's breadbasket regions, but are causing many countries around the world to become increasingly dependent on imports of staple commodities such as wheat, coarse grains and rice. This growing dependence on international markets brings additional and unconventional risks to food security and supply, often far removed from the consumer.

Those countries for which pursuit of self-sufficiency is either highly risky or impossible depend on the unimpeded flow of these commodities through a number of major pinchpoints, from the point of production through inland and maritime transit corridors to the point of import. These pinchpoints are subject to a range of chronic and acute threats, including aging infrastructure, congestion, rising sea levels and storm surges, risk of physical and cyber attacks, and interruption resulting from regional unrest and piracy.

By way of example, take the countries of the Gulf Cooperation Council (GCC), who are at a comparative disadvantage in agricultural production: natural reserves of water and arable land in the region are among the lowest in the world. As the prospects for domestic production become ever slimmer with climate change and a rapidly growing population, the GCC is increasingly dependent on imports. Between 80 and 90 percent of the region's total food supply is imported, and each year around 6 billion tonnes of barley and 4.5 billion tonnes of wheat are unloaded in the six states.

A fifth of these shipments originate in the Black Sea region ${ }^{1}$ (see map), where productivity is relatively low and is expected to worsen with rising temperatures and increased variability in rainfall patterns. ${ }^{2}$ Harvest shocks not only threaten the availability of grain for export, but also risk triggering protectionist trade measures, as have been imposed by governments in the region in recent years. ${ }^{3}$

From the Black Sea, grain shipments must pass through four key maritime chokepoints - the Turkish Straits, the Suez Canal and the Straits of Bab el-Mandeb, all of which are vulnerable to temporary closure owing to high sea levels and storm surges. Ongoing conflicts in the Black Sea and Near East regions, together with the pervasive threat of piracy, also pose a threat to the security of cargo and crews.

Critical infrastructure may itself become a pinchpoint for trade between the Black Sea and the GCC: roads and railways in the Russian Federation and Ukraine, essential to the transit of grains from farm to port, suffer from a lack of investment and are increasingly vulnerable to weather-related damage, while port facilities are in need of modernization and adaptation measures to mitigate the impact of rising sea levels and storm surges. After reaching the GCC, grain shipments must be stored in silos at low temperatures, requiring considerable energy input. Without sufficient investment, the wastage of grain in silos poses a further infrastructural risk to essential food reserves.

Disruption to one or several of these pinchpoints - in the case of coordinated terrorist attacks on ships in the Straits of Hormuz and Bab-el-Mandeb, for example, or a period of unusually severe storm activity in the eastern Mediterranean Sea closing the Bosphorus Strait or Suez Canal - could render the countries of the GCC at risk not only of food price spikes, but of severe and sustained disruption to critical food supplies. As their import dependence rises, and climate change exerts increasing pressure on already tight food supply, the GCC states will need to look beyond local and regional vulnerabilities and consider the disruptive risk posed by pinchpoints the length of the food supply chain.

1 Estimated trade volumes based on preliminary findings from forthcoming Chatham House publication (2016) on critical pinchpoints in global food trade.

2 N. Dronin and A. Kirilenko. 2011. Climate change, food stress, and security in Russia. Regional Environmental Change, 11(Suppl. 1): S167-S178.

3 T. T. Glauben, M. Belyaeva, I. Bobojonov, I. Djuric, L. Götz, H. Hockmann, D. Müller, O. Perekhozhuk, M. Petrick, S. Prehn, A. Prishchepov, S. Renner and F. Schierhorn. 2014. Eastern breadbasket obstructs its market and growth opportunities. IAMO Policy Brief No. 16 (available at http://www.econstor.eu/bitstream/10419/97275/1/78606630X.pdf).

Source: Chatham House. 2015 (forthcoming). Vulnerabilities and pinchpoints in global food trade. London. 


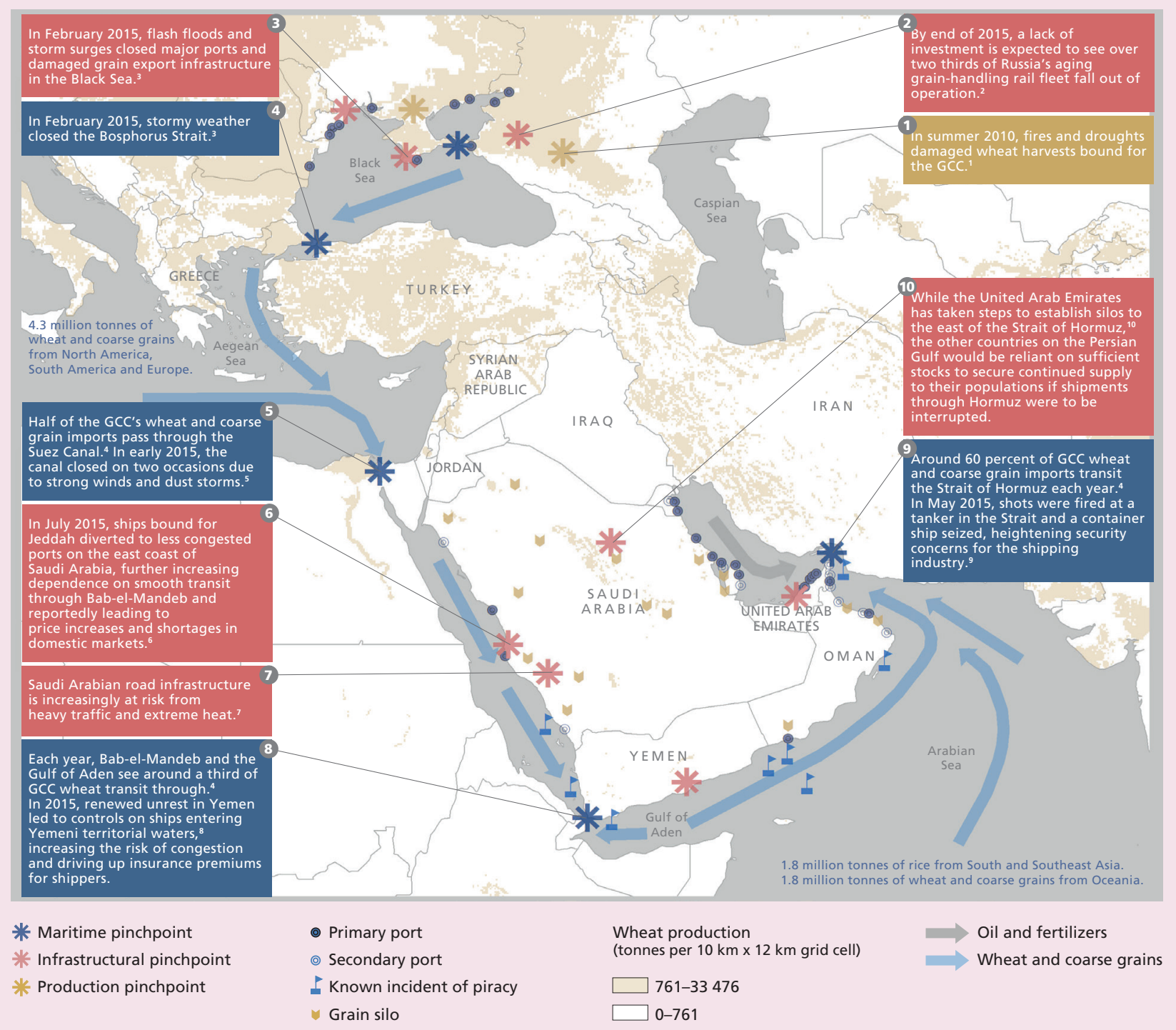

Note: Unit for wheat production $=$ tonnes per $10 \mathrm{~km}$ by $12 \mathrm{~km}$ gridcell.

Sources:

${ }^{1}$ World Bank and FAO. 2012. The grain chain: food security and managing wheat imports in Arab countries. Washington, DC, The World Bank.

${ }^{2}$ S. Burkitbayeva and W.A. Kerr. 2013. The accession of Kazakhstan Russia and Ukraine to the WTO: what will it mean for the world trade in wheat? CATPRN Commissioned Paper 2013-06 (available at http://www.uoguelph. ca/catprn/PDF-CP/CP-2013-06-burkitbayeva-kerr.pdf).

${ }^{3}$ Platts McGraw Hill Financial. 2015. Bosporus Strait, port of Novorossiisk shut due to bad weather: shipping sources (available at http://www.platts. com/latest-news/shipping/london/bosporus-strait-port-of-novorossiisk-shutdue-26014981).

${ }^{4}$ Chatham House Resource Trade Database (2015) - data for 2012 excluding intra-EU trade.

${ }^{5}$ Al Arabiya News. Storm Yohan lashes Mideast, shuts Suez Canal. 2015 (available at http://english.alarabiya.net/en/News/middle-east/2015/02/12/ Storm-Yohan-lashes-Mideast-shuts-Suez-Canal-html).

${ }^{6} \mathrm{~J}$. Avancena. 2015. Ports still choked causing market scarcity. Saudi Gazette. July 6 (available at http://www.saudigazette.com.sa/index. cfm?method=home.PrintContent\&action=Print\&content ID $=0000000019751$ ).

${ }^{7}$ C. Gerbich. 2015. Saudi Arabia needs major road surface rethink. Construction Week Online. February 10 (available at http://www. constructionweekonline. com/article-32530-saudi-arabia-needs-major-road-surface-rethink/).
8 J. Saul. 2015. Yemen struggles to import food as coalition navies hold up more ships. Reuters. 27 April (available at http://www.reuters.com/ article/2015/04/28/us-yemen-ships-food-idUSKBNONI19220150428).

${ }^{9}$ P. Hafezi. 2015. Iran uses maritime confrontations to project power in Gulf. Reuters. 17 May (available at http://www.reuters.com/ article/2015/05/18/us-iran-saudi-gulf-idUSKBN0O31JQ20150518).

${ }^{10}$ D. McKee. 2011. Strategic grain reserves. World-Grain.com. 24 May (available at http://www.world-grain.com/News/News\%20Home/ Features $/ 2011 / 5 /$ Strategic\%20grain $\% 20$ reserves.aspx?cck=\&cck=1).

\section{Data sources:}

Trade flows - Chatham House Resource Trade Database (2015), data for 2012, excluding intra-EU trade.

Light grey canvas basemap - Esri GIS OpenStreetMap contributers, and the GIS user community.

Wheat production GIS shapefile - C. Monfreda, N. Ramankutty, and J.A. Foley. 2008. Farming the planet. Part 2: Geographic distribution of crop areas, yields, physiological types, and net primary production in the year 2000. Global Biogeochemical Cycles, 22, GB1022

doi:10.1029/2007GB002947.

Port and silo locations - R. Bailey and R. Willoughby. 2013. Edible oil: food security in the Gulf. London, Chatham House.

Known piracy incidents - ICC Commercial Crime Services. 2014. IMB Piracy \& Armed Robbery Map 2014 (available at https://icc-ccs.org/piracyreporting-centre/live-piracy-map/piracy-map-2014). 



\section{Part II}

\section{Trade and food security: conceptual linkages}

$\mathrm{T}$ his second part of the report examines the links between trade and the four dimensions of food security - availability, access, utilization and stability focusing on the channels through which changes in trade can affect food security, and the underlying factors that determine the strength and outcomes of this relationship. Trade has direct implications for food security because in most countries imports constitute an important part of total food supplies. While competition with imports can have disruptive effects on local producers, it can also stimulate productivity-enhancing changes and innovations in domestic production and associated supply chains. Exports can contribute to poverty reduction if export revenues improve the incomes of low-income populations.

Greater involvement in trade can have both positive and negative consequences for a country's food security. Domestic production and consumption and the prices at all stages of the value chain can be affected by changes in trading patterns. How trade affects food security is largely context-specific, as countries engage in trade under different circumstances and are at different levels of development. Outcomes will depend on the effects of trade on overall growth, employment, incomes, government revenues and other key variables determining the economic and social situation of a country.

These linkages and the associated transmission channels depend on a variety of underlying characteristics of a country's economy, including the level of economic and institutional development; the trade status, particularly whether the country is intrinsically a net food importer or exporter; the structure of domestic markets; and the characteristics of agricultural producers, differentiating especially between countries where smallholders account for the majority of agricultural output and those where production is driven primarily by large commercially oriented farms.

\section{Main messages}

- The level of trade affects many of the economic and social variables that ultimately determine the food security and nutrition status of populations, including growth, incomes, poverty levels, inequality, food prices and government budgets.

- Trade affects market structures, infrastructural development, the productivity and composition of agricultural output, the variety, quality and safety of food products, and the composition of diets. These factors affect food availability, access, utilization and stability to various degrees.

- Changes in trade interact with a country's initial situation, producing differences in country experiences that make it difficult to ascertain a general relationship.

- Trade itself is neither an inherent threat to nor a panacea for improved food security and nutrition, but it poses challenges and risks that need to be considered in policy decision-making. General and unqualified assertions about trade "hurting" or "helping" food security should be considered with caution, and the nature of the variables and links behind these assertions must be scrutinized carefully. 


\section{Measuring trade and food security: definitions, indicators and approaches}

$\mathrm{T}$ he linkages between trade and food security have been subject to intense debate at both the national and international levels and have become central to many trade-related discussions, including in the context of trade negotiations. At least part of the disagreement on the appropriate role of trade in meeting food security objectives is driven by different perceptions regarding exactly what the concepts "trade" and "food security" refer to. The lack of a clear understanding of how these concepts are measured adds to the difficulty of finding common ground.

In defining trade, it is useful to distinguish trade as the physical and economic exchange of goods and services, from trade policies as the interventions of governments in these economic and physical flows, including the policies governed by trade agreements. In a nutshell, trade is simply the connection between supply and demand through which the exchange of goods and services takes place. The notion of trade considers events that may occur through the forces of technology, demography and other factors, with or without the influence of government intervention.

Trade policies are the interventions that governments make to modify trade or that indirectly affect levels of trade. In economic terms, trade policies usually denote government measures applied when goods and services cross a country's frontier. They also include domestic support to agriculture, as any government policy that affects production is also likely to affect trade flows. This part focuses on trade, while trade policies are discussed in Part III, distinguishing between trade openness as a state and opening to trade as a policy change.

The concepts of trade utilized have to be quantified to enable analysis of the potential links to food security. For instance, controversies over the virtues or defects of protected versus liberal economies are complicated by the measurement of these concepts. "Protected" and "liberal" are usually not binary categories but refer to different levels of implementation. It is also important to distinguish indicators of outcomes, such as trade as a percentage of GDP, from indicators of policies, such as tariffs or tariff equivalents. ${ }^{23}$

"Food security" is a descriptive concept first articulated in the area of food policy in the mid-1970s. The concept has evolved and expanded from a focus on food supply at the national level. A widely used definition put forward by the World Summit on Food Security in 1996 states that "food security exists when all people, at all times, have physical and economic access to sufficient, safe and nutritious food that meets their dietary needs and food preferences for an active and healthy life", while the more explicit distinction from the World Summit on Food Security in 2009 states that the "four pillars of food security are availability, access, utilization, and stability". These four dimensions of food security are briefly explained in Box 3. To achieve food security, all four dimensions must be fulfilled simultaneously.

For much of the twentieth century, discussion of malnutrition focused on undernutrition, and specifically the lack of sufficient caloric intake. In recent decades, there has been growing attention to the "triple burden of malnutrition", which refers not only to chronic undernourishment, but also to micronutrient deficiencies "hidden hunger" - and to obesity and problems associated with being overweight. All three forms of malnutrition are important and can afflict societies simultaneously. Greater awareness of the complexity of malnutrition has informed conceptualizations of food security, which increasingly include over- and underconsumption of calories, and the public health implications of micronutrient deficiencies. ${ }^{24}$

As food security is a multidimensional concept, organizing and presenting the large array of potential indicators is challenging. FAO provides a set of indicators that aim to capture various aspects of food insecurity grouped according to whether they affect access, availability, utilization or stability (Table 3).

Other approaches present a classification that seeks to measure food security and nutrition in terms of status or outcomes; drivers, determinants and risks; and policy interventions and processes. ${ }^{25}$ Others have attempted to aggregate indicators into a single measure, such as the Global Hunger Index ${ }^{26}$ or the Global Food Security Index published by the Economist Intelligence Unit.

\section{Disputed narratives on trade and food security ${ }^{27}$}

The variety of definitions and potential indicators of both trade and food security reflects the difficulties in 
TABLE 3

\section{FAO food security indicators}

\begin{tabular}{|c|c|}
\hline Dimension & Indicator \\
\hline Availability & $\begin{array}{l}\text { - Average dietary energy supply adequacy } \\
\text { - Average value of food production } \\
\text { - Share of dietary energy supply derived from cereals, } \\
\text { roots and tubers } \\
\text { - Average protein supply } \\
\text { - Average supply of protein of animal origin }\end{array}$ \\
\hline Access & $\begin{array}{l}\text { - Percentage of paved roads over total roads } \\
\text { - Road density } \\
\text { - Rail lines density } \\
\text { - Gross domestic product per capita } \\
\text { - (in purchasing power equivalent) } \\
\text { - Pomestic food price index } \\
\text { - Prevalence of undernourishment } \\
\text { - Depth of the food deficit } \\
\text { - Prevalence of food inadequacy }\end{array}$ \\
\hline Utilization & $\begin{array}{l}\text { - Access to improved water sources } \\
\text { - Access to improved sanitation facilities } \\
\text { - Percentage of children under } 5 \text { years of age } \\
\text { affected by wasting } \\
\text { - Percentage of children under } 5 \text { years of age } \\
\text { who are stunted } \\
\text { - Percentage of children under } 5 \text { years of age } \\
\text { who are underweight } \\
\text { - Percentage of adults who are underweight } \\
\text { - Prevalence of anemia among pregnant women } \\
\text { - Prevalence of anemia among children under } \\
5 \text { years of age } \\
\text { - Prevalence of vitamin A deficiency in the population } \\
\text { - Prevalence of iodine deficiency }\end{array}$ \\
\hline Stability & $\begin{array}{l}\text { - Cereal import dependency ratio } \\
\text { - Percentage of arable land equipped for irrigation } \\
\text { - Value of food imports over total merchandise } \\
\text { exports } \\
\text { - Political stability and absence of violence/terrorism } \\
\text { - Domestic food price volatility } \\
\text { - Per capita food production variability } \\
\text { - Per capita food supply variability }\end{array}$ \\
\hline
\end{tabular}

Source: FAO

unequivocally linking the multidimensional concept of trade with the even more multidimensional notion of food security, which can be expanded into food security and nutrition, thus adding complexity. The different interpretations of concepts and approaches and methods of analysis have resulted in a number of disputed narratives, which contribute to a polarized policy debate. One of the most controversial disputes is on food security versus food sovereignty (Box 4).

In recent years, views regarding the strategy for achieving food security have become progressively polarized, with trade being perceived as a threat by some and an opportunity by others. The "trade as opportunity" narrative emerges largely from neoclassical economics and relies on the ideas of gains from trade predicted by trade theory, drawing on the concept of comparative advantage.
BOX 3

\section{The four dimensions of food security}

Availability: physical availability of food. Food availability addresses the supply side of food security and is determined by the levels of food production, stocks and net trade.

Access: economic and physical access to food. Economic access is determined by disposable income, food prices and the provision of and access to social support. Physical access is determined by the availability and quality of infrastructure and other installations that facilitate the functioning of markets. In many developing countries, incomes earned in agriculture, forests, fisheries and aquaculture play a primary role in determining food security outcomes.

Utilization: the way in which the body uses the various nutrients in food. Individuals achieve sufficient energy and nutrient intake through good care and feeding practices, food preparation, diet diversity and intrahousehold distribution of food. Combined with biological utilization of the food consumed, energy and nutrient intake determine the nutrition status of individuals.

Stability: the stability of the other three dimensions over time. Even if individuals' food intake is adequate today, they are still considered foodinsecure if periodically they have inadequate access to food, risking deterioration of their nutrition status. Adverse weather conditions, political instability or economic factors (unemployment, rising food prices) may have an impact on individuals' food security status.

Source: FAO and EU. 2008. An introduction to the basic concepts of food security. Rome, EC-FAO Food Security Programme (available at http://www.fao.org/docrep/013/ al936e/al936e00.pdf).

This narrative advocates for trade openness as a way of reducing distortions and enhancing efficiencies and stability in the sector, as opposed to the costs of trade protection. The supporters of this narrative promote the idea of selfreliance and regard the concept of food exceptionalism as being inefficient. In this narrative, food security is seen as relying on market forces to drive more efficient allocation of resources, and therefore to increase efficiency in food production, which in turn triggers economic growth, higher 


\section{BOX 4}

\section{Food security and food sovereignty}

The terms "food security" and "food sovereignty" originally emerged to describe different things. Food security referred to a condition regarding access to adequate food, while discussions of food sovereignty were more explicitly political in seeking to address inadequate access to food and land rights. Over time, the two concepts have increasingly been referred to as oppositional rather than relational to one another. This has resulted in an ideological debate that is in many ways more confusing than helpful to policy dialogue.

The concept of "food sovereignty" calls for the right of nations and people to determine the contours of their own food systems, including the form of market relations, ecological dimensions and cultural aspects. ${ }^{1}$ The term was coined in the 1990s by the smallholder organization La Via Campesina, which encourages political mobilization around agrarian and food rights through a highly prescriptive agenda based on seven principles ${ }^{2}$ and centred on reducing global food trade and reorienting food systems around local production grounded in agroecological principles.

The movement emerged mainly in response to the incorporation of agriculture into the international trade regime during the Uruguay Round of negotiations for the General Agreement on Tariffs and Trade (GATT), and one of its main objectives has been to "get agriculture out of the WTO". ${ }^{3}$ This social movement gained consensus among non-governmental organizations (NGOs) and academics seeking to relegitimize the norm of "food exceptionalism" at the state level - where the role of governments in making up for market failures by providing public goods was long recognized - and the community level. It is important to note that, along with social movements, different governments also continued to press for the exceptional treatment of food, arguing that it is a nation's sovereign right to pursue policies that ensure the food security of its population before subjecting its agriculture sector to trade.

The food sovereignty movement advocates for reducing reliance on imported food and strengthening domestic and local food systems. This approach implies that a substantial part of national consumption requirements is met through domestic food supplies rather than imports. However, producing enough food to meet national demand does not necessarily mean that all households in a country have equal access to the food that they require or that food supplies are more stable or more affordable compared with imports.

1 H. Wittman, A.A. Desmaris and N. Wiebe, eds. 2010. Food sovereignty: reconnecting food, nature and community. Halifax, Canada, Fernwood Publishing.

2 Via Campesina's Food Sovereignty Principles: 1. Food: A Basic Human Right; 2. Agrarian Reform; 3. Protecting Natural Resources; 4. Reorganizing Food Trade; 5. Ending the Globalization of Hunger; 6. Social Peace; 7. Democratic Control.

3 Via Campesina. 2003. Peoples' food sovereignty - WTO out of agriculture. Webpage. September 2 (available at http://viacampesina. org/en/index.php/main-issues-mainmenu-27/food-sovereignty-and-trade-mainmenu-38/396-peoples-food-sovereignty-wto-out-ofagriculture).

Source: J. Clapp. 2015. Food security and international trade: unpacking disputed narratives. Background paper prepared for The State of Agricultural Commodity Markets 2015-16. Rome, FAO.

incomes and greater employment, thus improving both availability of and access to food (Figure 12). Supporters of this narrative recognize that public interventions play an important role, but would confine these interventions to correcting market failures or modifying the resulting distribution of income, and advocate for targeted policies to achieve these objectives.

The "trade as threat" narrative emerges from a range of other social scientific disciplines and agroecological science. This narrative is based on the idea that agriculture is not only an economic sector, but also a provider of the public goods that markets alone will fail to provide, hence the "exceptionalism" of agriculture. This narrative results in an alternative vision for food security built on the multifunctional nature of agriculture in society and the multiple values attached to these diverse functions, leading to consideration of the costs of trade liberalization. The result is a strong focus on more "local" agriculture, smallholder farmers and biodiverse farming systems. The supporters of this narrative advocate for a radical reduction in the reliance on - but not the elimination of - international trade for meeting food security needs, and therefore for a stronger role of the state in establishing food policy at the national level, or for food sovereignty at the community level. Each of these approaches raises valid arguments, but also has weaknesses and inconsistencies (Table 4).

These two narratives emerge from different scholarly traditions grounded in their own notions of science. 
Open economy spurs competition and

specialization based on comparative advantage
Specialization leads to greater production efficiencies
Efficiency increases food production and enhances economic growth
Greater food supply, freely traded, results in lower prices and greater access to food
Economic growth raises incomes and further improves access to food

Source: J. Clapp. 2015. Food security and international trade: unpacking disputed narratives. Background paper prepared for The State of Agricultural Commodity Markets 2015-16. Rome, FAO.

TABLE 4

Main components and limitations of the trade narratives for food security

$\begin{array}{lll}\text { Narrative Main components Weaknesses } & \text { Weats }\end{array}$

Trade $\quad$ Reference to the classical trade theory of as opportunity comparative advantage which demonstrates that efficiency gains through more open trade increase food supplies both globally and nationally, resulting in more available and more affordable food.

- Reference to trade as a "transmission belt" that helps to smooth out food deficits and surpluses across countries.

- Reference to the ways in which trade restrictions negatively impact food security.
The theory of comparative advantage builds on assumptions that do not hold in today's global economy:

- Capital and labour is highly mobile between countries through global value chains, and transnational corporations are often characterized by a high degree of concentration.

- The agriculture sector is highly inflexible, and mobility of agricultural labour and capital is low.

- Externalities, including environmental impacts of specialized agriculture, are not captured in food prices.

- Competitive advantage prioritizes short-term conditions versus long-term structural transformation.

- Efficiency gains are prioritized over other social goals.

- Self-sufficiency is not feasible for all countries.

- Protection measures may have extraterritorial impacts that can harm food security of others.

- Farmers' right to choose also includes the option of producing/ exporting cash crops.

- Challenges ensuring that small-scale agriculture produces sufficient food for all in an increasingly urbanized world.

- Distributional and nutritional issues are not well addressed.

- In the absence of external competition food prices tend to be higher, disproportionally affecting the poor.

- Supplies may be more volatile as downfalls in domestic production are not compensated by external supplies.

Source: Adapted from J. Clapp. 2015. Food security and international trade: unpacking disputed narratives. Background paper prepared for The State of Agricultural Commodity Markets 2015-16. Rome, FAO.

Each of them has its own language and they both focus analysis on different themes and have different understandings of the kinds of methods, measures and indicators that provide scientific and legitimate evidence. The difficulty in finding a common point of analysis results in both sides tending to simplify each other's viewpoint and portray it in extreme forms. For example, those who see trade as an opportunity tend to portray the other perspective as based on a pure form of self-sufficiency. By contrast, those who see trade as a threat portray the other viewpoint as advocating for pure free trade. Both sides dismiss the opposite extreme as problematic for a variety of 
reasons, and use rhetorical strategies that often result in an either/or approach.

A closer look at the two narratives shows that there are some elements of common ground from which dialogue can be fostered. For example, both narratives stress the importance of self-reliance. The disagreement between the two regards the degree to which trade should be relied on and the extent to which the state's domestic food policies should, or should not, include measures that might restrict trade. It is therefore important to step back from the rhetoric in the debate and to weigh the costs and benefits of both sides. 


\section{Analysing the linkages: a conceptual framework}

onsidering the definitions of trade and food security presented in the previous section and the debates regarding the relationship between trade and food security, this section discusses the effects of trade in its primary sense - the exchange of goods and services - on the four dimensions of food security.

A stylized representation of the channels through which trade can affect food security indicators is depicted in
Figure 13, which considers interactions in the markets for goods, inputs and factors of production. This depiction extends the framework introduced by the International Food Policy Research Institute (IFPRI) ${ }^{29}$ by incorporating the explicit links among the different economic variables affected by trade, and the four pillars of food security. The following analysis considers the possible positive and negative effects of trade on the four dimensions of food

FIGURE 13

Trade and the four pillars of food security: channels of interaction

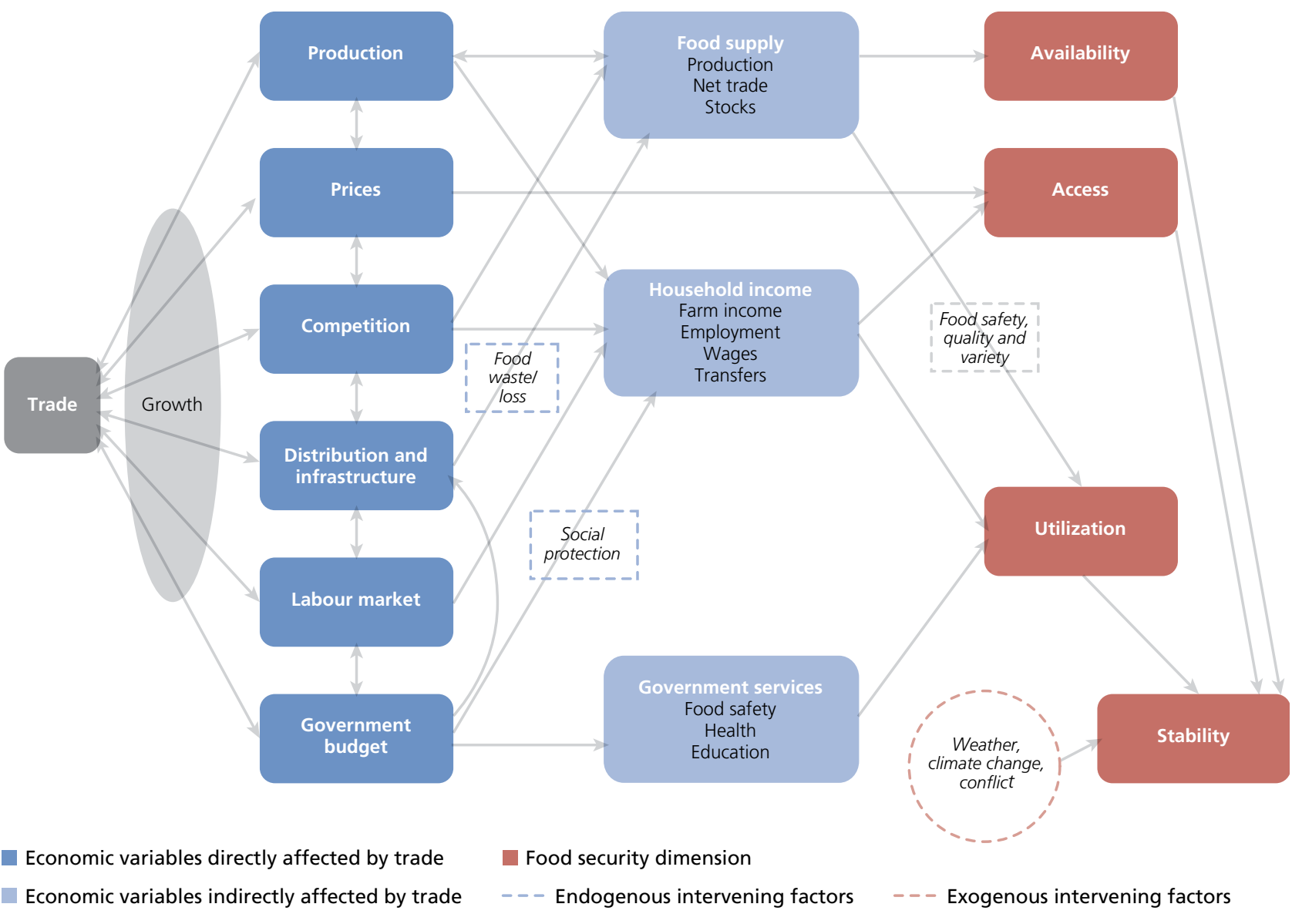

Source: Adapted from E. Díaz-Bonilla, M. Thomas, S. Robinson and A. Cattaneo. 2000. Food security and trade negotiations in the World Trade Organization: a cluster analysis of country groups. TMD Discussion Paper 59, Figure 1. Washington, DC, IFPRI. 
BOX 5

\section{Growth, poverty reduction and food security}

Growth can create the conditions for improving food security and nutrition through poverty reduction. However, those people who are living in extreme poverty and are most affected by hunger may not be able to take advantage of the benefits that growth may bring. Trade policies, and other macroeconomic policies and events, affect the rate and variability of overall growth, but also affect its "quality" - the employment, income distribution and poverty effects of growth.

On average, across the developing world since the early 1990s, economic growth has contributed to strong and persistent hunger reduction. However, not all the countries achieving strong economic growth have performed well in reducing hunger. Some countries have progressed well towards the international hunger targets, while others have experienced setbacks. In general, there has been uneven progress in translating economic growth into improvements in food security.

Source: FAO, IFAD and WFP. 2015. The State of Food Insecurity in the World 2015. Meeting the 2015 international hunger targets: taking stock of uneven progress. Rome, FAO.

security, highlighting that short- and long-term effects can work in different directions and that the effects on different pillars can be heterogeneous. For example, increasing food availability through imports is beneficial to food security, but the long-term implications for dietary composition, and therefore the utilization pillar, need to be considered to understand the overall effects on food intake and nutrition.

Figure 13 depicts three types of relationship: direct relationships between trade and economic parameters; intervening factors that modify these relationships; and relationships with the dimensions of food security. The relationships are influenced by the economic context discussed in the following section, which is followed by discussions of the key relationships and the channels of interaction.

\section{Economic context and growth}

The relationship between trade and poverty is a central element of the trade and food security nexus, because poverty, particularly extreme poverty, is a principal underlying factor of undernourishment. While a clearly attributable link between trade and income growth has been difficult to establish, many agree that trade has played an important role in the overall policy package in most countries where high income growth has been sustained over time. Although there is no simple determinant of growth, more open economies tend to grow faster.

At the same time, there is extensive evidence that opening to trade can have very heterogeneous effects on poor households, depending on the type of policies being changed and on complementary conditions. These conditions include the ease with which factors of production can move between activities, and the sector in which the poor work, with those working in export industries generally benefiting from trade expansion, while those working in import-competing sectors that were previously protected may lose..$^{30}$ Episodes of growth accompanied by strongly worsening income distribution may reduce or wipe out income gains for vulnerable groups, thus affecting their food security (Box 5). ${ }^{31,32}$

Besides growth in general, it is also important to consider the sectoral composition of growth. Growth in agriculture and food production generates broad employment and income opportunities that can be crucial for food access. To the extent that poverty is the main cause of food insecurity, agricultural growth, which has been demonstrated to have positive effects on poverty alleviation, will contribute to reducing food insecurity.

Agricultural growth is not only pro-poor in reducing poverty and/or increasing the income of the lower quintiles of the income distribution more than others, but it also has larger effects on poverty reduction than growth in other sectors has. ${ }^{33}$ Exceptions to these results have occurred in developing countries with large inequalities in landholdings, where agricultural growth appeared uncorrelated to poverty reduction. The correlation weakens as a country's income increases. In richer countries, agricultural growth does not have stronger effects on poverty reduction compared with growth in other sectors.

\section{Direct effects on key domestic variables}

Domestic production of food, food prices (at both the farmgate and retail levels), employment and government revenues are key variables that are directly affected by trade and that play an important role in determining the physical and economic access to food of populations suffering from hunger and malnutrition. 
BOX 6

\section{Reviews of country experiences}

Country case studies can shed light on the different ways in which moving towards more open trade can affect food security. FAO (2006) assessed the impact on food security of economic reforms affecting agricultural trade in developing countries by conducting 15 country case studies.

Comparing the average production per capita of calories in the period 1999-2001 (after reforms) with two previous periods, 1980-82 and 1990-92, this study shows that the indicator increased in eight countries and declined in four against both periods, with three countries showing mixed results depending on the period of comparison. The analysis noted that trade-specific policies were usually part of wider policy reforms including other macroeconomic aspects (such as exchange rate, fiscal and monetary policies) and microeconomic and institutional issues (including privatization or reform of public-sector enterprises related to the agriculture sector). The reforms also happened at different times, their pace varied and they included reversals. It was therefore not always easy to attribute results clearly to the trade policies considered.

Mixed evidence on the outcomes of trade for food security is also reported by McCorriston et al. (2013), who reviewed different studies of trade liberalization and food security. The authors conclude that of the 34 studies, 13 reported improvements in the food security indicators utilized, 10 showed declines, and the other 11 had mixed results, with food security metrics varying across segments of the population, regions and periods, or with alternative food security metrics indicating different outcomes for specific countries. The authors conclude that the results are mixed because trade liberalization was usually part of a broader policy programme of reforms, and the initial situations in the countries when policy reforms were implemented were very different.

Sources:

E. Díaz-Bonilla. 2015. Lost in translation: the fractured conversation about trade and food security. Background paper prepared for The State of Agricultural Commodity Markets 2015-16. Rome, FAO.

FAO. 2006. Trade reforms and food security: country case studies and synthesis. Rome, Italy.

S. McCorriston, D.J. Hemming, J.D. Lamontagne-Godwin, J. Osborn, M.J. Parr and P.D. Roberts. 2013. What is the evidence of the impact of agricultural trade liberalisation on food security in developing countries? A systematic review. London, EPPI-Centre, Social Science Research Unit, Institute of Education, University of London.

Trade is endogenous to the economic system comprising these and other macroeconomic variables - while changes in trade affect prices and production, these variables will have an impact on trade flows.

Another important variable is government operations (expenditure, regulation and services), and the quality and efficacy of governance. Governments' effectiveness in designing and implementing policies and programmes for food security, particularly those that support rural and agricultural development, is of critical importance in achieving food security objectives

Two aspects of the effectiveness of governance may in turn be affected by trade. One is whether international trade agreements and frameworks such as the WTO create legal and institutional constraints to the range of possible policies that can be implemented. The other aspect of effectiveness is the availability of resources and whether trade and trade policies have an impact on government revenues through customs duties and export taxes.

In the longer run, trade also affects competition, infrastructure development and the development of marketing channels and distribution networks, as it affects the incentives for public and private investments and new players' entry into markets. All of these factors play important roles in overall food supply and incomes.

\section{From economic variables to food security indicators}

The direct effects of trade on the key variables translate into changes in food security indicators through three main intervening factors: total food supply, household income, and government services.

Production and net trade form an integral part of domestic food supplies, which in turn define food availability. As well as the immediate effects of trade, food supplies are also affected by changes in productivity, the composition of agricultural output, and market structure, all of which can be triggered by changes in trade patterns. Food prices and household income, which largely consists of proceeds from activities such as farming, wages and transfers, determine the purchasing power of consumers. This in turn defines their access to food. These components are all affected by trade through its effect on the reallocation 
of resources across productive activities and returns to factors of production.

Government revenue and institutional capacities determine the availability of resources and the delivery mechanisms necessary for implementing food security programmes, including those directed to consumers (social protection, education and other services addressing the basic needs of the population) and those directed to producers (government purchases and food stockholding, extension services, rural infrastructure and other types of support). The public sector has a key role in both fostering agricultural development and addressing poverty through income redistribution, affecting availability as well as access. Government services that ensure food safety and consumer rights are also essential for the utilization component of food security. However, the nutritional value of food available to consumers depends not only on government regulation and control systems, but also on market forces that have an impact on the variety and quality of food supplies.

Stability entails sustainable and consistent performance of availability, access and utilization indicators over a longer time horizon. Consistent performance requires coordinated and predictable government policies. A crucial element is risk management in agriculture, addressing both weather variability and market risks. However, stability also depends on external factors that the government may not be able to control, such as global economic turmoil and trade policies of trading partners.

Box 6 outlines some of the effects that trade can have on food security in selected countries. 


\section{Trade expansion and the four dimensions of food security}

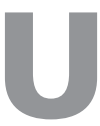

sing the conceptual framework set out in section 2 , the possible effects of trade expansion on the four food security dimensions are summarized in Table 5. Key factors affecting the outcomes for each of the dimensions are then discussed.

\section{Availability}

Through its impact on agricultural and food production, trade determines national food availability. Trade also affects how food supplies are distributed at the subnational level,

TABLE 5

Possible short-, medium- and long-term effects of trade on the four dimensions of food security

Possible positive effects

Short term

- Trade boosts imports and increases both the quantity and the variety of food available.

Medium-to-long term

- The resulting specialization can lead to increased production of food through efficiency gains.

- Greater competition from abroad may trigger improvements in productivity through greater investment, R\&D, technology spillover.

Possible negative effects

Medium-to-long term

- For net food-exporting countries, higher prices in international markets divert part of production previously available for domestic consumption to exports, potentially reducing domestic availability of staple foods.

- For net food-importing countries, domestic producers who are unable to compete with imports are likely to curtail production, reducing domestic supplies and foregoing important multiplier effects of agricultural activities in rural economies.

Access

\section{Short term}

- For net food-importing countries, food prices typically decrease when border protection is reduced.

- Imported food and input prices are likely to decrease.

Medium-to-long term

- In the competitive sectors, incomes are likely to increase as the result of greater market access for exports.

- The macroeconomic benefits of greater trade, such as export growth and inflow of foreign direct investment, support growth and higher employment, which in turn boost incomes.

\section{Short term}

- For net food-exporting countries the domestic prices of exportable products may increase.

Medium-to-long term

- Employment and incomes in sensitive, import-competing sectors may decline, with some producers transitioning out of agriculture.

- Unequal distribution of gains may occur through enclave developments in export crops to the detriment of broadbased smallholder food crop production.

\section{Short term}

- Greater reliance on imported foods is often associated with an increase in consumption of cheaper and more readily available foods that are high in calories and low in nutritional value.

Medium-to-long term

- Prioritization of commodity exports diverts land and resources from traditional and indigenous foods, which are often superior from a nutritional perspective.

\section{Short term}

- Assuming obligations with regard to trade policies may reduce the policy space to deal with short-term market shocks.

- Imports reduce the seasonal effect on food availability and prices to consumers.

- Imports mitigate likelihood of shortages resulting from local production risks.

Medium-to-long term

- Shallow versus deep markets: global markets are less prone to policy-or weather-induced shocks.
- Vulnerability to changes in trade policy by exporters, such as export bans.

Medium-to-long term

- Sectors at earlier stages of development may become more susceptible to price shocks and/or import surges. 
across domestic regions, between urban and rural markets, and at different points in time, affecting availability geographically and temporally. Trade can also affect the stability of availability.

Whether or not food imports displace or complement domestic production is an important consideration when trying to understand the effects of greater levels of imports on domestic food availability. If trade is displacing domestic production there could be less availability overall, especially when imports are suddenly constrained because of restrictions imposed by exporting countries. On the other hand, food imports may simply be supplementing the availability of food without displacing domestic production, responding to growing demand when incomes rise and offering consumers additional supply that is not available domestically.

As shown in Part I, at the global level, agricultural and food trade has increased in all developing country regions. In developing countries as a whole, there is therefore more

BOX 7

\section{Causality between domestic production and imports}

A recent analysis of production and imports in developing countries indicates that causality runs from changes in production to changes in trade for both agricultural and food products in LDCs and LIFDCs, while the reverse causality from imports to production is not supported by the data.

This lends support to the hypothesis that trade has a stabilizing effect on supplies whereby shortfalls in production resulting from exogenous shocks, such as droughts or other natural disasters, are compensated for by increased imports to stabilize domestic consumption, while imports diminish in periods of abundant domestic output.

Rather than production being suppressed by expansion in imports, both production and trade seem to expand over time, driven by growing demand resulting from increases in population and incomes. In the case of NFIDCs the statistical tests do no provide evidence of causality in either direction. In other words, a change in the level of production does not appear to affect the level of imports; nor does a change in the level of imports appear to displace production.

Source: E. Díaz-Bonilla. 2015. Lost in translation: the fractured conversation about trade and food security. Background paper prepared for The State of Agricultural Commodity Markets 2015-16. Rome, FAO. food production (total and per capita) and more trade. This fact seems to be more compatible with the hypothesis that increases in income and population are, in aggregate, leading to both more food production and more trade than it is with the notion that trade is displacing domestic production (Box 7). There is however a large degree of heterogeneity among countries, and such conclusions therefore need to be treated with caution.

The period over which expansion in imports takes place is important. If importing countries have time to adjust to increased imports, domestic producers may be able to cope better with the increased competition. On the other hand, sudden changes in import volumes can be disruptive to the domestic economy, creating unemployment or reducing incomes in some sectors and therefore affecting the welfare and food security of some population groups.

As countries become more open to international trade in agricultural products, they become more exposed and potentially more vulnerable to sudden changes in global agricultural markets. For example, import surges - sudden increases in volumes of imports - can hinder the development of agriculture in developing countries if the sector is frequently exposed to fluctuating levels of imports. Even if temporary in nature, an import surge may disrupt domestic production if producers are not adequately equipped to bear market risks, with potentially disastrous impacts on domestic farmers and farm workers through significantly reducing domestic producer prices, and with subsequent redundancies, reduced incomes and foregone multiplier effects in the rest of the economy, which can have negative consequences for food security. In particular, poor farmers who are at the limit of their survival strategies with no appropriate safety nets could be affected severely in the long run, as negative price shocks may imply bankruptcy, with longer-term implications for the welfare of the household (Box 8).

In many developing countries, those involved in agriculture sector activities - producers, traders or processing industries - generally have limited ability to offset the risks associated with the market instability that can result when significant changes in volumes of imported products increase competition on domestic markets or cause falls in market prices, which might reduce returns to investments in domestic agricultural activities. The potential for these disruptions has been used to support arguments both for a more cautious approach to opening agricultural trade and for the establishment of effective safeguards in new trade agreements. The rationale for effective safeguards is discussed further in Parts III and IV.

Another issue that continues to receive considerable attention is whether the expansion of trade may be shifting production patterns at the local level in a way that favours cash crops (or products primarily destined for exports) and displaces food production for family consumption, with negative impacts on food security (Box 9). 
In developing countries that have a comparative advantage in producing cash crops, such as coffee or tropical fruits, and that have successfully incorporated smallholder farmers into export-oriented supply chains, growing export earnings can also enable producers to purchase larger quantities, and possibly a wider variety, of food products. Moreover, at the national level, earnings from cash crop exports can help to offset the negative impacts of the growing food import bill at times of high food prices. For example, during the price spikes of 2006-08, the aggregate of low-income developing

BOX 8

\section{Negative consequences of import surges}

A case study analysis undertaken by FAO in the mid2000s provides a number of examples of potential injury resulting from surges in imports. Perhaps most dramatic were those associated with the 1998 collapse in the Russian poultry market - which had previously accounted for a quarter of global poultry imports following a significant currency depreciation. This collapse resulted in a significant suppression of world market prices (with cuts reaching 32 percent) and trade diversion causing poultry product import surges into third markets, particularly in Caribbean and several African countries, including Côte d'Ivoire and Ghana. In Côte d'Ivoire, poultry output declined by two-thirds as imports increased sixfold between 1998 and 2004, with 1500 producers going out of business and 15000 jobs lost. In Ghana, capacity utilization in poultry processing fell to 25 percent while poultry imports increased from 4000 tonnes in 1998 to 124000 tonnes in 2004.

More generally, import surges can affect market share. In Sri Lanka, the ratio of milk imports to consumption increased from 20 percent in 1981 to 70 percent in 2006. In the 25 -year period, milk imports increased sevenfold, but domestic production rose by less than 15 percent. Similarly, in Ghana, the market share of local tomatoes fell from 92 to 57 percent between 1998 and 2003. Imports increased from 3300 to 24740 tonnes, a 650 percent increase, while fresh tomato production fell from 215000 to 200000 tonnes. The imports, primarily from Italy, were supported by export restitutions equivalent to about 10 percent of the local wholesale price.

Source: FAO. 2006. Import surges in developing countries: the case of poultry. FAO Briefs on Import Surges: Commodities No. 1. Rome. economies spent substantially more on importing cereals and oils than prior to the price spike. In some countries, the increase in the cost of food imports was offset to a large extent by the higher values of coffee, tea, cocoa, spices, fish and fishery products. Again, the extent to which higher import bills were offset by increased commodity exports differs significantly across countries.

BOX 9

\section{Expansion of cash cropping and food security - positive evidence}

A series of studies suggests that trade allows the expansion of production, which may become more diversified without leading to a decline in traditional food crops, eventually resulting in the emergence of new food products that add to dietary diversification. In general, staple food production per capita is maintained or increased even though cash crops also expand, and overall household incomes increase, resulting in more food purchased at the household level, although clearly not for all households.

Cash crop production can enable farmers and farm workers to increase their living standards, thus contributing to food security. Perhaps even more important are the opportunities that the production of cash crops offers farmers for investment and improving management of their farms, stimulating agricultural innovation and increasing yields. More incomes from cash crops and better technologies may therefore also lead to more production of food by farmers.

For example, when Madagascar started to export fruits and vegetables to Europe under contract farming, rice productivity increased by 70 percent through technology spillovers, and the lean period for food availability was reduced by 2.5 months for contract farmers compared with those not included in the scheme (1.7 months with a contract versus 4.3 months without).

Sources: Based on J. von Braun and E.T. Kennedy, eds. 1994. Agricultural commercialization, economic development, and nutrition. Baltimore, USA, Johns Hopkins University Press for IFPRI; T.J. Achterbosch, S. van Berkum and G.W. Meijerink. 2014. Cash crops and food security: contributions to income, livelihood risk and agricultural innovation. The Hague, LEI Wageningen UR (University and Research Centre); J. Swinnen, 2015. Supply chains, trade and food security: Linking rich consumers to poor producers through value chains. Presentation at FAO, Rome, Italy, March 2015. 


\section{Access}

Access to food, which is primarily determined by the purchasing power of consumers, is affected by trade through the impact of trade on growth, incomes, prices and poverty levels. Broad employment and income opportunities, along with adequate food prices and low food inflation, facilitate economic access. Therefore, much depends on the level, inclusiveness and stability of the growth rate generated by expanded trade. Government budgets for social protection and agricultural development can also play a role.

Stable access can be analysed at the national level and the household and/or individual level. At the national level, access depends on variables such as domestic income or GDP, trade, external financing (including remittances) and foreign reserves. At the household level, access to food depends on the relationship between household income and the cost of minimum household food requirements.

Prices play a particularly important role in determining access to food. They tend to be more volatile than incomes, and sudden changes in prices can trigger severe repercussions for households' ability to feed themselves. Trade is only one determinant of prices; others, such as domestic marketing arrangements, transportation, availability of storage and, particularly, local weather conditions affecting yields, can have more significant impacts on the prices paid by consumers or received by producers.

For net food-importing countries, opening to trade is often associated with a decrease in food prices resulting from increased supplies and greater competition between foreign and domestic producers. However, a common concern is that employment opportunities in sensitive import-competing sectors may decline and appropriate safety nets and opportunities for transitioning to other sectors to cope with the negative consequences may be lacking, threatening the livelihoods and food security of those who derive their incomes from these sectors.

\section{Utilization}

For utilization, which primarily concerns nutritional aspects, the critical issue is how trade and globalization have affected diets. Dietary diversity has been associated with better nutritional outcomes - computed through anthropometric measures such as stunting and wasting ${ }^{34}$ - and therefore deserves particular consideration. The question is whether expanded trade could result in an accelerated major shift in the structure of diets, and how these changes would affect the nutrition and health status of the population (Box 10).

Empirical studies show that trade has contributed to greater availability and, more important, to more diversity in the average supply available for consumption. Food production in many developing country regions is less diversified than food availability, which also includes imports. Therefore, it could be argued that trade leads, on average, to a more varied diet and could therefore improve nutrition. However, trade is also associated with shifts in consumption habits and the so-called "nutrition transition", which is having major repercussions for health in developing countries.

It has been argued that trade has played a role in the nutrition transition by reducing prices and increasing the availability of a variety of unhealthy foods, such as those that are richer in calories, poorer in nutrients and higher in saturated fats and salt than more healthy foods. ${ }^{35}$ However, these effects may also be the result of autonomous demand shifts linked to urbanization and higher incomes and/or the advertisement and cost/benefit calculations of processors, which affect trade, rather than the other way around.

These developments emphasize the need to consider the different outcomes that trade will have for people at risk of undernutrition relative to those at risk of excessive consumption, for urban compared with rural populations, and for the poor relative to the rich, with the risk that poor consumers may be more susceptible to adopting unhealthy diets than are wealthier consumers, who have access to more resources and information. In Brazil, China and India, increased production and consumption of vegetable oils, and changes linked to market reforms had the effect of integrating the three countries into the global soybean oil market, thereby facilitating the dietary convergence of soybean oil consumption worldwide, not only in cooking, but also in processed foods through hydrogenation, a process that creates trans fats, which increase the risk of coronary heart disease. ${ }^{36}$

Trade can also affect the safety of food products for human consumption. Imports increase the risks of contaminated foods entering domestic markets. On the other hand, it can be argued that wider participation in global value chains, which can result from greater FDI in domestic food industries, can provide important spillover benefits through better production and distribution processes and stricter food safety controls. Typically, companies set standards for the quality, health and safety of both the products and the processes that occur in their supply chains, sometimes in cooperation with NGOs and governments, such the Global Food Safety Initiative, which is likely to benefit domestic consumers. ${ }^{37}$

\section{Stability}

The stability of food supplies, food quality and diversity, purchasing power and other key determinants relates to the fourth component of food security and nutrition. Stability is closely linked to volatility in agricultural markets. The critical question is whether trade makes markets more volatile by introducing greater uncertainty with regard to growth, incomes and prices, all of which affect stable access to food. Even if trade accelerates growth, the poor may suffer if the growth is associated with more volatility and if the likelihood of crises increases, with negative impacts on the poor's incomes, employment and livelihood strategies. 


\section{BOX 10}

\section{Trade, nutrition and malnutrition}

Malnutrition represents a global challenge that encompasses three dimensions simultaneously: undernourishment and food insecurity, through insufficient intake of dietary energy and protein; undernutrition or micronutrient deficiencies; and overnutrition, through excess intake of dietary energy, manifest in the number of overweight and obese people. These three dimensions are known as "the triple burden of malnutrition". In developing countries, it has been documented that both under- and overnutrition may coexist even within a single family.

An increase in food imports can have nutritional implications by altering food availability, affordability (prices) and diversity, thus helping to shape preferences. The rise of international food trade, especially imports, has therefore been associated with the "nutrition transition" to energy-dense, poor-quality diets leading to obesity and diet-related chronic diseases, which is a growing phenomenon in middle- and high-income countries (or developed and transitioning countries).

The shift typically begins with major increases in domestic production and imports of oilseeds and vegetable oils. Consumption of animal-source foods (meat, milk) and processed foods such as snacks, soft drinks, breakfast cereals and processed dairy products then increases. As a result of these changes, people who do not consume sufficient energy face nutrition insecurity through an inadequate supply of micronutrients, while those who do consume sufficient energy also face nutrition insecurity through an intake of unhealthy levels of saturated fat and free sugars.

The evidence on whether food imports have changed the nature of the food supply, rather than just substituting for foods previously produced domestically, is rather thin, except for some explicit cases in India and the Pacific Islands. In India, market liberalization in the mid-1990s stimulated a rapid increase in imports of low-priced vegetable oils, which corresponded to a simultaneous increase in consumption and stimulated a switch in the types of oil consumed, away from traditional peanut, rapeseed and cottonseed oils, towards imported palm and soybean oils. In the Pacific Islands, various studies show that imported foods have altered the traditional diet, particularly by increasing fat consumption, especially high-fat meat cuts. However, increasing attention to the health implications of malnutrition, and to the related impacts on economic growth, is encouraging more analysis of the links among nutrition, trade and investment.

Source: Based on C. Hawkes, M. Chopra and S. Friel. 2009. Globalization, trade, and the nutrition transition. In R. Labonté, T. Schrecker, C. Packer and V. Runnels, eds. Globalization and health: pathways, evidence and policy, pp. 235-262. New York, USA, Routledge.

Domestic production in individual countries can be more volatile than in global and regional country aggregates. Trade can allow pooling of the risks associated with production shortfalls, be they weather-, conflict- or policy-induced, across suppliers. With a large share of the food consumed in developing countries produced domestically, having food trade as a complement can provide the margin of supply necessary to stabilize food prices and quantities.

Although some developing countries have successfully managed external volatility, there are many examples in which efforts to shield domestic markets from global volatility have instead led to increased internal volatility. For instance, it has been demonstrated ${ }^{38}$ that: i) food price volatility in several
sub-Saharan African countries is higher in domestic markets than in international markets; ii) such domestic food price volatility has not changed much despite increases in international price volatility in the late 2000s; iii) commodities that are more heavily traded internationally have lower volatility than those that are less traded; and iv) volatility is higher in countries and for commodities where governments intervene in markets through state-owned enterprises. ${ }^{39}$

Volatility in agricultural markets may also be associated with environmental risks. While analysing whether climate change and environmental degradation make markets more volatile is beyond the scope of this report, it is important to consider that environmental sustainability also has implications for the stability of food availability, access and utilization. 


\section{Determinants of the strength of linkages: markets in the trade and food security nexus}

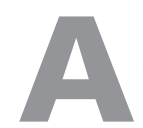
number of variables, particularly those related to the functioning of domestic markets, have strong implications for the way in which trade interacts with food security outcomes, determining whether the impacts turn out to be positive or negative.

Competition issues in agriculture affect all of the major variables that determine the purchasing power of the poor and the level of agricultural production: prices and price transmission; the availability of inputs; volumes of production; and the level of investment in rural infrastructure. ${ }^{40}$ The degree of vertical integration and the shares of total value-added captured by different stakeholders in the value chain also affect the poor's food security. The scale of production, the structure of value chains, government regulation and entry barriers in the marketing channel, and parastatals or state trading enterprises all have roles to play. Moreover, the extent to which smallholder family farmers are able to participate in markets is also a crucial determinant of food security, as more than 90 percent of farms worldwide are managed by an individual or a family. ${ }^{41}$ Trade outcomes for poverty and malnutrition depend on these factors. However, trade itself also affects agrarian structures through the creation, transformation and destruction of markets.

Several concerns have been voiced about what has been perceived as an increasing concentration in many markets, at both the global and domestic levels, and about the implications these developments may have for food security and the poor. ${ }^{42}$ Capturing the dynamics of concentration and assessing the consequences for producers, consumers and other stakeholders is particularly difficult in the new global context of complex value chains and networks of suppliers, the consolidation of firms in many industries, the advance of supermarkets, and the use of private standards. The current global agrifood system is large and complex: more than 450 million farmers worldwide - 85 percent of whom operate on 2 hectares or less - buy inputs, equipment and machinery from a variety of industrial firms, and then supply their products to an intricate network of processors, traders and retailers, which in turn face a market of about 7 billion potential consumers worldwide. ${ }^{43}$ Transactions and trade occur across all these segments, which have become more integrated at the global scale, with large players active in each. ${ }^{44}$

\section{New players in domestic markets}

Changes in food markets at the national level also have substantial implications for food security through the effects on producers and consumers. One important shift is the so-called "supermarket revolution", ${ }^{45}$ with the proliferation of supermarkets in developing countries being driven by multiple factors. In addition to trade, these factors include urbanization, increases in incomes, changes in lifestyles and women's participation in the labour force, liberalization of FDI in developing countries, increasing use of refrigerators and other domestic appliances, and changes in information technology that facilitate better organization of supply chains.

Consumers in developed and developing countries have benefited from lower costs and a larger variety of products ${ }^{46}$ resulting from the highly competitive supermarket supply chain, in which markets have been very competitive, or at least contestable, because of the need to increase market share to achieve economies of scale. However, these competition pressures have increased the pressure on producers to supply higher-quality goods at lower prices. Changes in the retail sector may therefore have mixed or negative effects on farmers, as investments and organizational adjustments to meet volume, cost, quality and consistency standards may be challenging for many farmers and processing firms, particularly small farmers.

Contrary to the view that quality standards and the strategies of dominant companies in value chains have led to the marginalization of small and poor farmers - with negative effects on welfare and poverty - case studies ${ }^{47}$ in different countries and geographical settings show an increasing number of small and poor farmers being included in supply chains, which play a crucial role in technology transfer and productivity growth, with positive direct and indirect implications for food security. Moreover, even if small farmers are not directly included, there can be improvements in poverty and food security through other channels such as employment. In any case, the presence of large players in 
different segments of these value chains highlights the need to pay attention to the relative market power of different actors, in both product and input markets. ${ }^{48,49}$

\section{Farmers' participation in value chains and labour markets}

Supply chains play a crucial role in linking smallholder producers to markets through facilitating technology transfer to enhance productivity growth, providing critical inputs and guaranteeing market outlets. These factors imply that farmers who are engaged in value chains typically increase their incomes and move out of poverty, ${ }^{50}$ which has direct implications for their food security and can have important spillover effects on rural economies.

However, not all farmers can take advantage of market developments. The access of smallholder farmers - many of whom are food-insecure - to evolving agricultural markets, especially higher-value chains, is commonly constrained (Box 11). Remoteness and insufficient productive resources can make it too costly to participate in modern marketing channels, or may limit the amount of surplus production that smallholders are able or willing to sell. ${ }^{51}$ Smallholders are likely to increase their engagement in markets when particular conditions, such as stable prices and availability of credit, efficient infrastructure and extension services, are in place, allowing them to sell products that can be absorbed by the market at a reasonable cost.

Another issue that has received particular attention is the potential impact of trade on the balance of large commercial farms, family farms and landless workers within the agrarian structure of developing countries. Some criticisms of open trade relate to potentially negative impacts of market liberalization on the agrarian structure, such as expansion of larger and more industrialized farms at the expense of smallholders, where the expansion of market opportunities is seen as shifting relative prices against the poor, reducing productive and income-generating opportunities for them, increasing the competitive advantage of large firms and/or reinforcing the power of already dominant actors, such as large landowners and commercial enterprises, allowing them to extract further incomes from the poor or to expropriate the poor's assets, such as land or access to water. Debates include renewed attention to land tenure issues, as manifested in concerns about "land-grabbing", and the loss of smallholders' autonomy in decision-making and livelihoods. ${ }^{52,53}$

These empirical issues need to be considered, particularly in recognizing that agrarian structures are far more complex than the dichotomy between industrial agriculture and family farms. Agrarian structures include a variety of commercial and family farmers, landless workers and vulnerable rural groups, whose fate also has to be taken into account.

A related issue is the effect of trade on agricultural employment. The evidence is somewhat inconclusive,
BOX 11

\section{Constraints to smallholders' participation in markets}

In low-income countries, agricultural markets are often underdeveloped and characterized by multiple failures and imperfections. With smallholder farmers accounting for a large share of agricultural production in many developing countries, the bulk of this production is characterized by small production volumes of variable quality, limited access to inputs and finance, low levels of investment, and limited access to, and knowledge of, improved agricultural technologies and practices.

High levels of price and production risk and uncertainty, and limited access to tools for managing them, deter investment in more productive new technologies that would enable smallholders to produce surpluses for sale in markets. Inadequate infrastructure, high costs of storage and transportation and non-competitive markets also militate against production of a marketable surplus. These constraints mean that the majority of farms in developing countries are not integrated into formal markets and do not take full advantage of the opportunities that trade could otherwise provide.

Source: P. Arias, D. Hallam, E. Krivonos and J. Morrison. 2013. Smallholder integration in changing food markets. Rome, FAO.

with country studies illustrating that the effects of trade reform on employment depend on the nature of the reforms and, particularly, on whether they are multilateral, regional or unilateral. Effects on employment also differ by sector and type of worker - highly skilled or low-skilled. ${ }^{54}$ Where trade has resulted in positive employment outcomes, asset distribution was more equal initially and there were lower barriers to labour mobility. Evidence suggests that enabling policies have to be put in place at the same time as trade reforms to benefit agricultural employment and incomes.

It is difficult to draw conclusions regarding rural populations, as subsistence agriculture is often a more common activity than waged employment in agricultural households, although incomes from agricultural production are generally complemented by off-farm employment. Productive off-farm employment is an important driver of rural incomes, generally through the multiplier effects of increasing agricultural productivity; as such, it plays a key role in strengthening food security. These aspects are considered in more detail in Part III. 
In summary, both global and domestic agrifood value chains are very complex. When discussing market power and concentration it is therefore important to define the level and focus of analysis. Even if quantitative measures of concentration appear to be increasing, the questions are what impacts do these developments have on consumers, producers and workers, and what is the role of trade and trade policies in this process. It is important to determine whether concentration has led to more economies of scale and specialization that reduce costs for all, or has generated abuse of market power by international or domestic companies, leading to increased margins to the detriment of final consumers, primary producers and workers.

The discussion in Part II shows that the links between trade and food security are inherently complex, with several channels of interaction affecting the different dimensions of food security simultaneously, making it difficult to determine, a priori, the directions and magnitude of the end result. Complicating matters further are the different effects on key economic and social variables that trade has in the short, medium and long terms. Market fundamentals - domestic food supply, demand and prices - are affected almost immediately by changes leading to greater or lesser imports and exports. In the very short term, no factor movement across sectors takes place, and the first-order effects of trade on consumers and producers are through prices of goods produced and consumed in the domestic market. In the medium term, factor prices adjust, and labour and capital move in response to the changes, shifting the economy towards a new equilibrium in employment, incomes and other key variables. The dynamic effects of trade on production structure, land use, productivity, dietary patterns and other important determinants may take even longer to materialize, reinforcing or reversing the initial effects in the longer run. On balance, and considering the longer horizon, the positive effects of trade outlined in Table 5 seem to outweigh the negative ones, especially when changes occur gradually and the possible risks arising from opening to trade are mitigated with complementary measures.

In conclusion, the linkages between trade and food security, and the dynamics of these interactions, are largely context-specific. The advantages and disadvantages of greater openness to trade depend to a large extent not only on the resource endowment and comparative advantages of a country, but also on the role of agriculture in the economy and the composition of production (predominance of small versus large farms, whether farmers are net producers or net consumers, etc.) at the current level of the country's development. This issue is explored in more depth in Part III. 


\section{Part III}

\section{Trade and related policy supportive of food security}

$\mathrm{T}$ his third part of the report examines the factors to consider in formulating trade and related policy to ensure that it is supportive of food security.

The first section of Part III considers policy-makers' objectives for both short-term management of trade and markets and longer-term economic and social development, and the contexts within which trade and related policies are formulated. A major distinction is made between policies implemented to address short-term, transitory food security concerns and those designed to promote the sustained agricultural productivity increases needed for reducing levels of food insecurity over the longer term.

In assessments of the appropriateness of trade and related objectives, short-term policy responses often receive the most attention, so these are examined in section 2, along with key determinants of their impacts. However, the longer-term implications of trade and related policy use require more attention. The stage of agricultural transformation and the role of the agriculture sector in broader economic and social development are key, and are therefore explored in detail in section 3. The appropriateness of different policy approaches changes as these processes play out. Insights into the balance between short- and long-term support can be gained from observations of historical patterns of agricultural support in countries at different levels of economic development; these factors also have potential implications for defining future levels and types of policy, as discussed in section 4 . The final section of this part explores the national trade and non-trade strategies that inform agricultural trade and related policy design and implementation.

This part concentrates on the appropriateness of different types of policy intervention from the perspective of national objectives, interests and impacts. In Part IV, the conclusions drawn here will be counterposed against the global perspective, in which the impacts of trade policy on other countries need to be considered.

\section{Main messages}

- The objectives of policy interventions should be paramount in determining the appropriateness and informing the design of trade-related policy. These objectives will address different dimensions of food security, will differ across countries, and will change over time. Policy-makers need to be cognisant of these changes and to establish mechanisms for adjusting trade and related polices accordingly.

- The debate on the appropriateness of alternative trade policies has to consider the longer-term context of economic structural transformation and the role of agricultural commercialization within this transformation. At earlier stages of transformation, increases in levels of agricultural productivity are key, and trade and related policies have a critical role, but at later stages, the use of such policies can become increasingly detrimental.

- In recent decades, the structure and type of support have changed significantly in both developed and developing countries. Whether this is a positive or negative development for food security at the global, national and household levels remains unclear, but the trend continues to pervade the debate on contemporary policy interventions. Perceptions that some policy instruments have been problematic when used in developed countries should not be used as the main argument against their use in other countries.

- Greater openness to trade is an inevitable part of the growth of countries' national trade strategies. However, the process of opening to trade, and the consequences of doing so, will need to be appropriately managed and to reflect the country's specific context if trade is to work in favour of improved food security outcomes. 


\section{Policies and policy objectives}

\section{Defining trade and related policy}

In this report, trade and related policy instruments are defined as those that potentially affect trade flows, be they instruments of border protection or domestic market interventions. FAO's Food and Agriculture Policy Decision Analysis ${ }^{55}$ classifies policy measures according to whether they are: i) consumer-oriented, including market management measures such as food stocks and price controls, social protection measures such as school feeding, food for work, food subsidies and cash transfers, and nutrition assistance measures such as food fortification; ii) producer-oriented, including producer support such as input subsidies and production subsidies, and market management measures such as interventions to fix minimum and maximum prices for food staples; and iii) trade-oriented, including border measures and broader macroeconomic policy measures.

Trade-oriented border measures are applied when goods and services cross a country's frontier. These policies include import tariffs and quotas, export subsidies or taxes, import or export bans, trade facilitation and other non-tariff measures such as health and safety procedures. This report does not address policy responses to the potential nutrition impacts of trade, which at a minimum will require stronger consumer-oriented policy responses such as education and nutrition labelling. However, tackling nutrition problems is likely to require broader cross-sectoral responses, including taxes, regulations and a variety of policy instruments, most of which are unrelated to trade policies. A better understanding of the relationship between trade and nutrition will inform the debate on whether to adjust the way in which food systems operate to make trade more conducive to better nutrition and healthier lives.

Consideration of both producer- and consumer-oriented measures is equally important, both because of their direct effects on national production levels and because of the indirect effects that changes in national production can have on trade flows and global markets.

At the national level, different types of so-called domestic support instruments can have different degrees of productivityenhancing effect and different implications for producer and consumer prices. However, the measures that directly affect prices, often called "price policies", are generally believed to have the most significant effects on production and trade.

Price policy, broadly defined as policy that changes the domestic prices of inputs or outputs from those that would otherwise prevail, takes many forms and can target consumers, producers and/or trade. It can also be designed and implemented in different ways, with quite different impacts.

\section{Categories of price policy}

As debates about the appropriateness of different policy types are often clouded by simplistic classifications, it is helpful to consider the different forms of price policy in more detail, before exploring their appropriateness.

Three types of basic agricultural producer support that work through their influence on price incentives can be identified: ${ }^{56}$

- Output price support, in which intervention prices, import restrictions such as quotas or tariffs, or export promotion have the effect of raising domestic prices, creating welfare losses for consumers, who pay a higher price and may consume less, and welfare gains for producers, who receive a higher price and may produce more. The cost to government is the loss incurred in the disposal of any surplus production, whether through storage nationally or export at less than the national market price.

- Output price subsidies, such as minimum guaranteed prices paid directly to producers, or subsidies on certain consumer food products, raise the prices received by producers and/ or lower the prices paid by consumers. Both consumers and producers gain from increased quantity consumed and produced, while consumers benefit from paying lower prices and producers from receiving higher prices. The cost to government is the difference between the consumer and producer price for the entire quantity traded. Unless the subsidy overcomes a market failure that inhibits supply, total consumer and producer gains will be less than the total cost to government, the difference representing a "deadweight loss".

- Input subsidies, such as credit or fertilizer subsidies, which lower production costs, with impacts that are analogous to those of producer price subsidies. 
Agricultural support to producers may take many other forms, including public investments in infrastructure, research or market development, services, or regulation and standards; and private investment subsidies such as government grants for private provision of infrastructure, research or extension facilities. Such support is considered to provide less incentive to increase the levels of production of specific products.

\section{Context-specific policy objectives}

Thinking in terms of the dimensions of food security can assist in differentiating among the contexts that, in turn, inform policy objectives. The distribution and location of food-insecure populations can affect the balance between objectives focused on increased production and rural incomes and those focused on securing cheaper food for urban populations. For example, if most consumers are smallholder producers, price stabilization policies, perhaps associated with the use of safeguards, may have a role in ensuring remunerable and reliable prices for producers, kick-starting productivity increases and eventual falls in wage-adjusted food prices. By contrast, if most consumers are urban, greater openness to food imports, combined with targeted policies for the relatively smaller number of producers, may make more sense. ${ }^{57}$

Continental Latin America is considered more urbanized than other developing country regions, which may explain, in part, the continent's greater openness to trade. However, there is diversity across Latin America, and different degrees of trade openness can be explained to a certain extent by differences in resource availability and productive capacity, in population growth rates and in rates of urbanization.

When determining policy objectives, the level of economic development also matters. In countries with underdeveloped agriculture sectors, objectives of productivity enhancement are likely to be more important initially because of the significant multiplier effects that are generated through productivity increases in agriculture. As the economy develops and the gap between urban and rural incomes widens, income support tends to become a more important objective. In more mature economies, by contrast, the objectives of trade and related policy reach far beyond agricultural production and food security, which may become residual targets of policy-makers.

\section{Trade and related policy in achieving short- or longer-run objectives}

In discussing the appropriateness of different types of policy, a critical distinction needs to be made between whether trade and related policies are being used to achieve shortrun or longer-run objectives. In the context of food security, attention is often on the use of trade policy in pursuit of short-term objectives. However, balancing short- and longerrun objectives is vitally important as they can have conflicting implications for food security (Box 12).
BOX 12

\section{Balancing short- and longer-term objectives}

National food security objectives have been primary factors in determining trade and related market policy interventions in many African countries since long before the current global context of increased food price volatility. Many governments are concerned about their ability to source food staples regionally and the consequent domestic food price increases if they are unable to do so.

This concern is often compounded by the shortage of information on the physical availability of staples both within countries and regionally at any point in time, meaning that countries often do not know whether sufficient surpluses or stocks will be available when and where they are needed. Further compounding this issue is the intervention of many neighbouring countries in the markets for staples, which can effectively negate the opportunity for potential trading partners to source staples from surplus areas or countries.

As a consequence, some countries have intervened heavily through trade policy to restrict exports as a way of ensuring that domestic prices do not increase substantially during periods of domestic shortage. When exports are restricted, incentives for investments in market development are reduced, limiting the potential for addressing food security concerns through increased regional trade.

Source: J.A. Morrison and A. Sarris. 2015. Food staple market volatility and food security in eastern and southern Africa: what role for intra-regional trade and market policy? In African Development Perspectives Yearbook. Volume 18: Africa's progress in regional and global economic integration. Bremen, Germany, Institute for World Economics and International Management (IWIM).

Although food availability is likely to increase with greater openness to trade, concerns about the ability to manage short-term food availability and food prices during periods of crisis may reduce countries' willingness to reduce their use of restrictive trade policies, particularly in the absence of safeguards. Other short-term, often political, objectives may require that the move to greater openness to trade is timed to ensure that food availability can be guaranteed through increased reliance on regional and/or global markets, and that the stabilization of prices is not compromised. 


\section{Determining the impact of short-term trade policy interventions on food security}

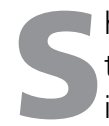
hort-term trade and related policy interventions tend to have the most visible impacts. The significant increases in food import bills following the increases in food prices in 2008, and the waning confidence in global markets as a reliable source of affordable food, provide an example of numerous short-term responses. Many countries adopted policies in an attempt to influence domestic prices directly through border measures and price controls, sometimes with the intention of creating incentives for increasing domestic supply, and sometimes coupled with social protection measures to reach poor consumers.

Export restrictions and the elimination of import tariffs were the most extensively used trade policy instruments. Border measures were particularly attractive for policymakers because they represented an option for rapidly containing the negative effects of global price increases on domestic consumers, and were also a less costly to implement than other options such as subsidies for consumers. Export taxes were also seen as measures for boosting fiscal revenues, especially for countries that faced fiscal difficulties during the financial crisis in 2008. The set of trade instruments depended mainly on whether the country was a net importer or a net exporter of the products that were most widely consumed domestically, and focused on the products that made up the basic consumption basket, typically cereals.

\section{Tariff reduction or elimination}

Many food-importing countries lowered import tariffs on food items, agricultural inputs and equipment. Import duties inflate domestic consumer prices relative to world prices, and reduce imports. The direct effect of the reduction or removal of an import duty on a given product is to lower the price of the imported good, thus contributing to reducing domestic consumer prices. However, in most net food-importing countries, tariffs on food products were already low and their reduction had a minimal impact on domestic prices. Reduced tariffs on inputs (machinery, seeds, fuel) lower the cost of production and provide an incentive for domestic production. Lower taxes, if not compensated for by higher revenue collected from greater amounts of imported goods, will have negative implications for government budgets.

\section{Export restrictions}

During periods of high food prices or shocks to domestic supplies, net food exporters have the incentive to place restrictions on exports to guarantee sufficient supplies to domestic markets in the short term. These restrictions are imposed for various reasons, such as when governments perceive that other means of stabilizing prices have not produced the desired results, when additional taxes could be used as a means of boosting government revenues or when there is uncertainty about the level of grain stocks at the national or local level. Absence of official supply and demand balances for individual crops, and weak market price monitoring systems can exacerbate this uncertainty. These deficiencies in the operations of the agencies responsible for food reserves and in the monitoring of food security indicators at the national level may lead to the application of export restrictions as easier to implement than other options for mitigating price fluctuations.

Export restrictions can be in the form of export taxes or quantitative limitations, including export bans. Reducing or banning exports can constrain increases in domestic prices, at least in the short run, by increasing supplies to the domestic market. However, producer prices are also likely to be pushed downwards, creating disincentives for expanding production and reducing supplies in the medium term. The effectiveness of the measure may be undermined by illicit exports. At the global level, when put in place by several exporters simultaneously, export restrictions reduce global supplies and exacerbate uncertainly and volatility in global food markets. ${ }^{58}$

The experience in developing countries, for example in Latin America, shows that the consistency and transparency of policy played an important role in determining the outcomes of trade policies applied during the recent years of higher global food prices. In some countries, export restrictions were initially put in place temporarily, but were later extended, making it difficult for producers to make informed production and marketing decisions. 
This contributed to an uncertain policy environment, reducing farmers' incentives and ultimately leading to diversification away from the crops affected by frequent policy changes. ${ }^{59}$ At the same time, reductions in tariffs applied in food-importing countries did little to control the sharp increases in domestic food prices. In many cases, trade policy measures had limited effects on the internal market, while at the global level the reduction in import barriers in some countries, coupled with the introduction of export restrictions in others, led to tightening of the balance between demand and supply, putting upwards pressure on world prices.

In most instances, budgetary constraints and the sheer scale of price increases have precluded successful stabilization, and have instead exacerbated the negative impacts of the price rises. As many of these interventions were deemed inappropriate, there have been many calls for improved policy choices to prevent and/or manage sudden food price rises. Similar calls for improved discipline of markets were made during almost all previous episodes of high prices, but were largely abandoned after the spikes abated, because the policy measures were either deemed too difficult to implement or entailed excessive fiscal costs, or because complacency set in when low prices ensued.

\section{Implementing multiple policies in combination}

Analysts generally hold that production impacts can be very different when a combination of policies work together rather than being implemented separately. Although this is not a novel observation, there is little empirical work on producers' reactions to different types of support when the effects of multiple policies are taken into account. Policy interventions need to be considered as part of packages that, as well as trade and related price policy, include other policies, such as consumer-oriented ones for providing food aid and other forms of social protection.
Such policies can increase the effective demand for food and, in addition to directly reducing the incidence of food insecurity, can indirectly result in increased domestic production by creating market opportunities and/or imparting upwards pressure on local market prices, especially when the policies are implemented at scale.

A recent ex-ante analysis of alternative strategies for managing food insecurity risks in Indonesia ${ }^{60}$ investigates the potential impacts of combinations of different policies relating to rice production and consumption. The analysis notes that market price support is used in combination with unconditional cash transfers, a domestic food aid programme that provides subsidies to poor households, and fertilizer subsidies. Several conclusions are drawn. Under "normal" conditions, price support to producers increases levels of undernutrition in the population overall through its effect in raising consumer prices. During episodes of rice price hikes, price support policies reduce the incidence of undernutrition, and this effect is added to by consumer subsidies, cash transfers and, marginally, fertilizer subsidies. By contrast, in scenarios of crop failure, price support can increase undernutrition rates, but the effects are mitigated through consumer subsidies, cash transfers and, particularly, crop insurance. Over a set of hypothetical shocks, the cash transfers appear to be most effective in mitigating negative effects on food insecurity, the effects of fertilizer subsidies are marginal, but - other than in instances of price spikes - price support is demonstrated to increase undernutrition rates in macroeconomic crises and natural disasters.

Typically, analysis of policy impacts on food security tends to reflect the static perspective in which short-term interventions are made. However, the dynamic effects, for example in changing productivity levels or the behaviour or structure of markets, ${ }^{61}$ are of much greater interest in developing countries because of their impacts on wider growth and the potential for reducing levels of food insecurity. 
3.

\section{Longer-term structural transformation and policy interventions}

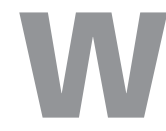
hen assessing the impact, and therefore the appropriateness, of trade and related policy in achieving food security objectives, it is important to look beyond short-term policy interventions and their possible short-term consequences.

Moving beyond static, short-term considerations, such as the impact of a border restriction on consumer prices, helps to set the discussion in the context of the longer-term dynamics that characterize the development pathways of most countries, and to identify the policy interventions that countries should ultimately aim to support.

\section{The role of agriculture in structural transformation}

In a standard view of structural transformation, countries at low levels of development start from a position of having a

FIGURE 14

\section{Standard understanding of structural transformation}

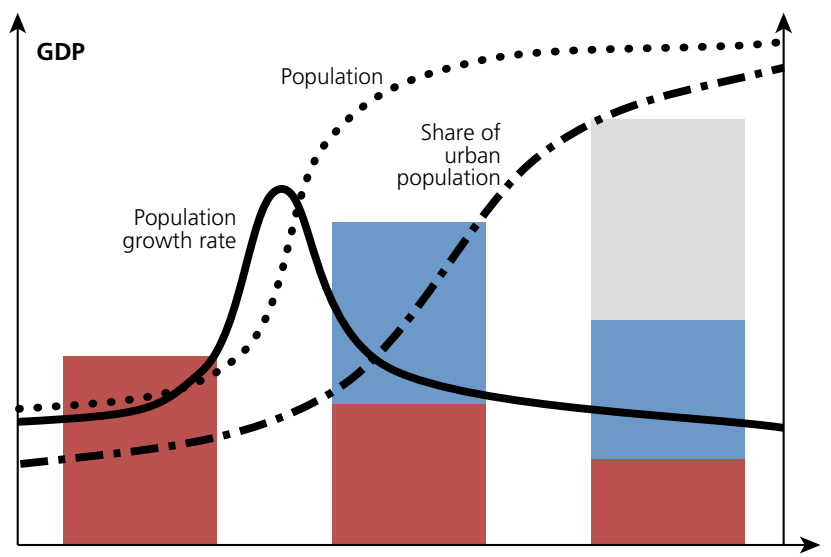

Time/level of development

Agriculture Manufacturing Services

Source: Adapted from T. Giordano. 2015. Lessons from experience of structural transformation: is Africa different? Presentation to FAO informal consultation on Trade policy supportive of food security, 20-21 April 2015, FAO, Rome. large, non-commercial agriculture sector that accounts for a large proportion of their GDP and an even larger proportion of employment. In this view, balanced growth is achieved if the agriculture sector becomes increasingly commercialized and competitive while the manufacturing sector grows (Figure 14).

The characteristics of agricultural development that lead to a greater positive impact on broader economic development generally involve its substantial linkages to the local economy, with backward linkages including greater use of locally provided inputs or services, forward

FIGURE 15

Stylized trends in output per agricultural worker and agriculture as a share of the labour force and GDP during structural transformation

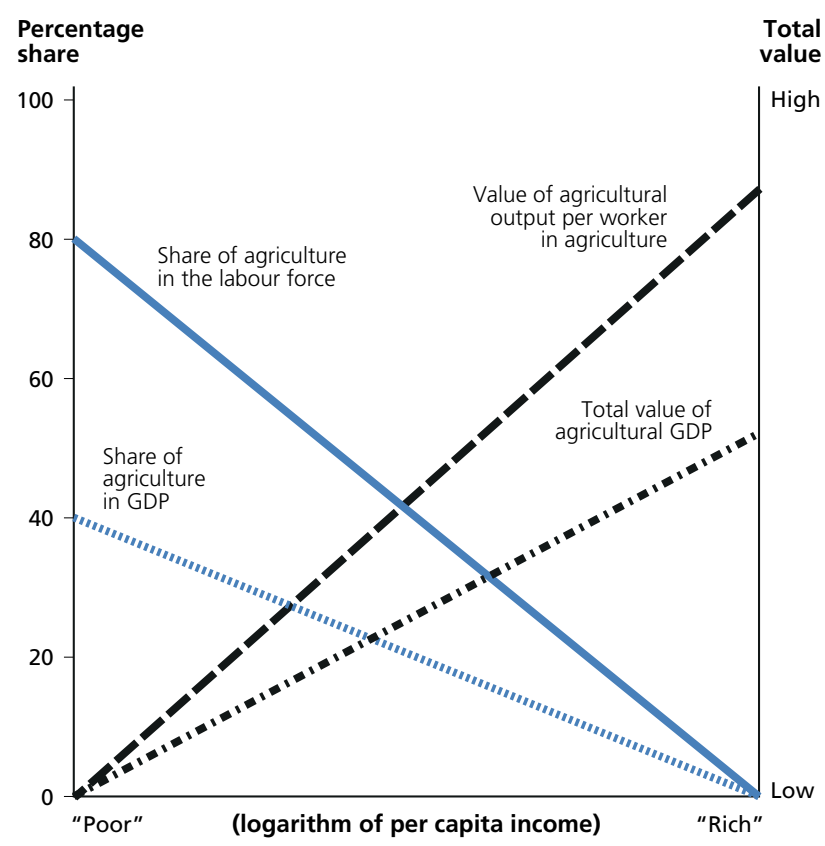

Source: C.P. Timmer. 2014. Managing the structural transformation: a political economy approach. UNU-WIDER Annual Lecture 18, 18 November 2014, United Nations, New York, USA. Unpublished. 


\section{BOX 13}

\section{Critical dimensions of structural transformation}

1. Agricultural transformation must occur simultaneously with structural transformation. Raising productivity in agriculture is key to sustaining transformation. Rapid growth in agricultural productivity, with sustained participation by smallholder farmers where they are a significant part of the production structure, is increasingly recognized as an essential element in countries' overall development strategies, and critical in reducing levels of food insecurity.

2. A dynamic agriculture sector can make significant contributions to broader development, but the relative importance and nature of these contributions vary in different country situations and as the importance of the agriculture sector declines within the overall economy. Where the agriculture sector accounts for a large proportion of GDP and an even larger proportion of employment, increasing agricultural productivity is essential, first in fostering investment in agriculture itself and then in releasing surplus capital and labour to other sectors of the economy.

3. Markets are central to the successful management of structural transformation, but the process of structural transformation has never been driven entirely by market forces. The challenge for governments is to determine when and how much to intervene. These decisions will differ in each country. For example, some countries have used agricultural price policy as a way of managing structural transformation by influencing domestic terms of trade. This strategy often requires large subsidies, and trade barriers to make them effective.

4. While historical patterns of structural transformation display significant commonalities, global economic growth processes have become progressively less successful at integrating low-productivity agricultural labour into the rest of the economy. Timmer notes that the stagnation of growth in labour productivity in sub-Saharan Africa stands out, with virtually no gain between 1961 and 2010. A core reason appears to be that the transformation process has become blocked as a result of the low share of the manufacturing sector, with rapid urbanization effectively taking place without industrialization.

5. While transformation is occurring, the lag in real earnings from agriculture is the fundamental cause of significant political tensions. This lag is growing more extreme, for example in some Asian countries, as the urban-rural income gap tends to get larger during early stages of transformation.

Source: C.P. Timmer. 2014. Managing the structural transformation: a political economy approach. UNU-WIDER Annual Lecture 18, 18 November 2014, United Nations, New York, USA. Unpublished.

linkages that produce products for local processing, and consumption linkages that generate the income spent on goods and services with a large local content. Such "linkage-rich" agricultural development is encouraged by labour-intensive, rather than capital-intensive, methods of production, more equitable distribution of income, local consumption patterns favouring local rather than imported goods and services, and links to wider produce markets that can absorb continuing production increases without large falls in producer prices.

Initially, manufacturing may be based on agriculture through processing and agribusiness, but manufacturing and the economy will ultimately become diversified, and agriculture will account for a diminishing share of the economy as growth continues.

During this process of transformation, the proportion of the labour force engaged in agriculture remains above the share of agriculture in GDP, with important implications for labour productivity and for continued growth in agricultural production as resources shift to other sectors of the economy (Figure 15).

Peter Timmer has written extensively on the importance of better understanding and management of both the short- and the longer-run determinants of structural transformation:

The food system is at the core of this process in both the long run and short run. In the long run, the food system is a key element of the structural transformation, which historically has been the only sustainable pathway out of poverty. In the short run, the food system is the arena in which many of the poor make their living, and also face the risks of volatile food prices. ${ }^{62}$

Understanding how greater openness to trade affects the food system in both the short and longer runs is critical to 
GOVERNMENT ACTION

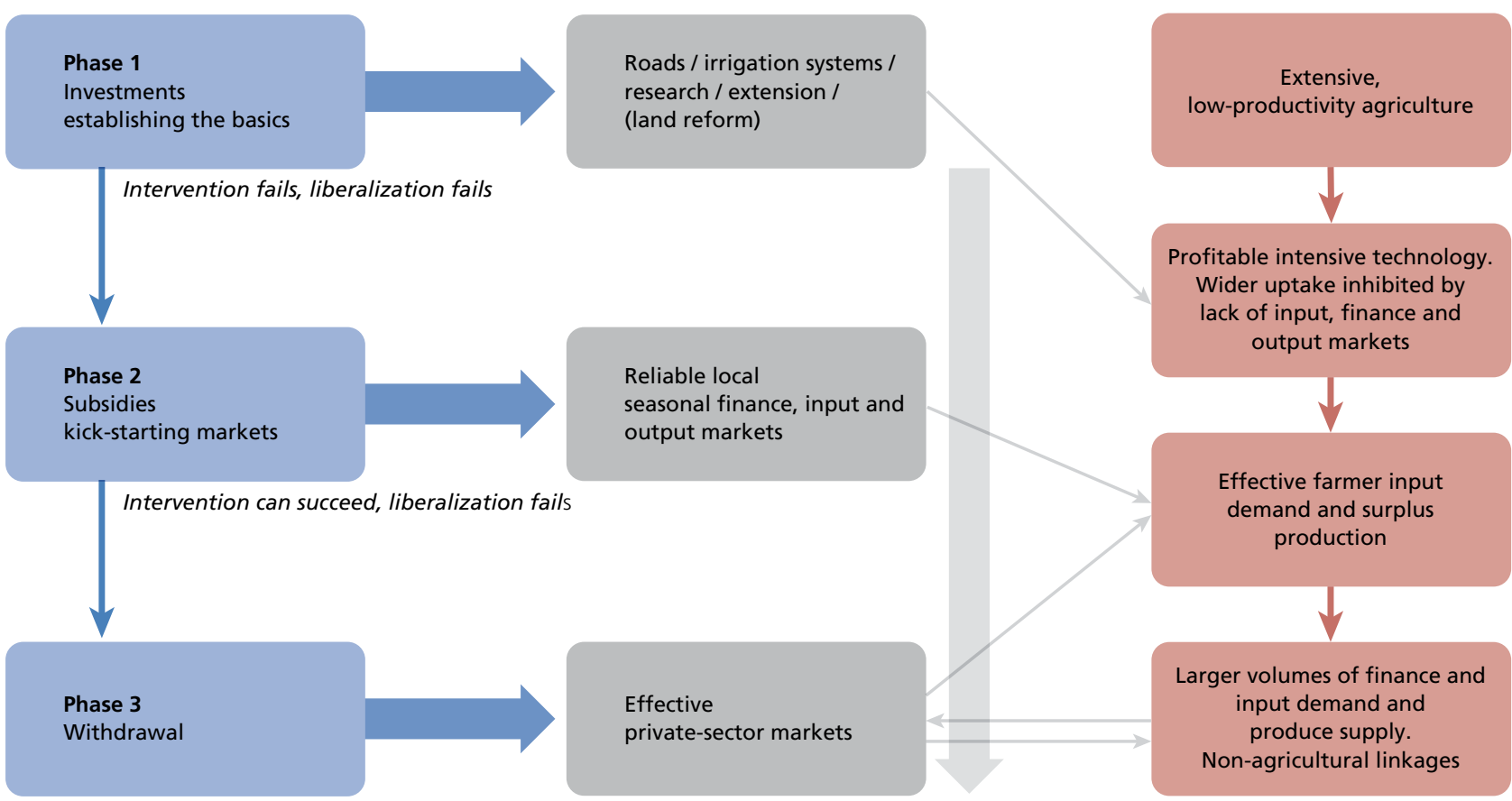

STATUS OF AGRICULTURE

Intervention fails, liberalization can succeed

Source: Adapted from A. Dorward, J. Kydd, J.A. Morrison and I. Urey. 2004. A policy agenda for pro-poor agricultural growth World Development, 32(1): 73-89, Figure 1.

determining the appropriate role of trade and related policies. In illuminating this understanding, Timmer draws attention to several critical points, which are summarized in Box 13.

\section{Government intervention in agricultural productivity during structural transformation}

In conceptualizing the time-sensitive nature of returns to different interventions, exemplified in the Indian Green Revolution, but also observed in, albeit short, phases of production increases in sub-Saharan Africa, Figure 16 shows the contributions of financial, input and output market interventions by governments in different phases of agriculture sector development.

Figure 16 shows that at different stages of commercialization from low-productivity to more commercially oriented agriculture, the relative effectiveness of interventionist versus more liberal approaches to policy changes. In phase 1, in which agriculture is characterized by widespread, semi-subsistence production and low levels of market participation, support should involve basic investments to establish conditions for the adoption of new technologies and practices. Uptake is likely to be limited to a small number of farmers with access to seasonal finance and viable markets.

Rapid agricultural transformation needs to be kick-started by government interventions in trade and markets (phase 2), providing larger numbers of farmers with access to seasonal finance and seasonal input and output markets at low cost and low risk, to allow them to generate surplus for markets as a business decision.

Once farmers have become used to the new technologies, and when volumes of credit and input demand and of produce supply have built up and the transaction costs per unit are falling, governments can withdraw from market activities and allow the private sector to take over the provision of critical market services (phase 3).

This conceptual framework is supported by empirical evidence from India on the returns to agricultural GDP from different types of government expenditure across time. ${ }^{63}$ Expenditures are categorized into investments (in roads, education, irrigation infrastructure and agricultural research and development) and subsidies (on fertilizer, credit, 
10

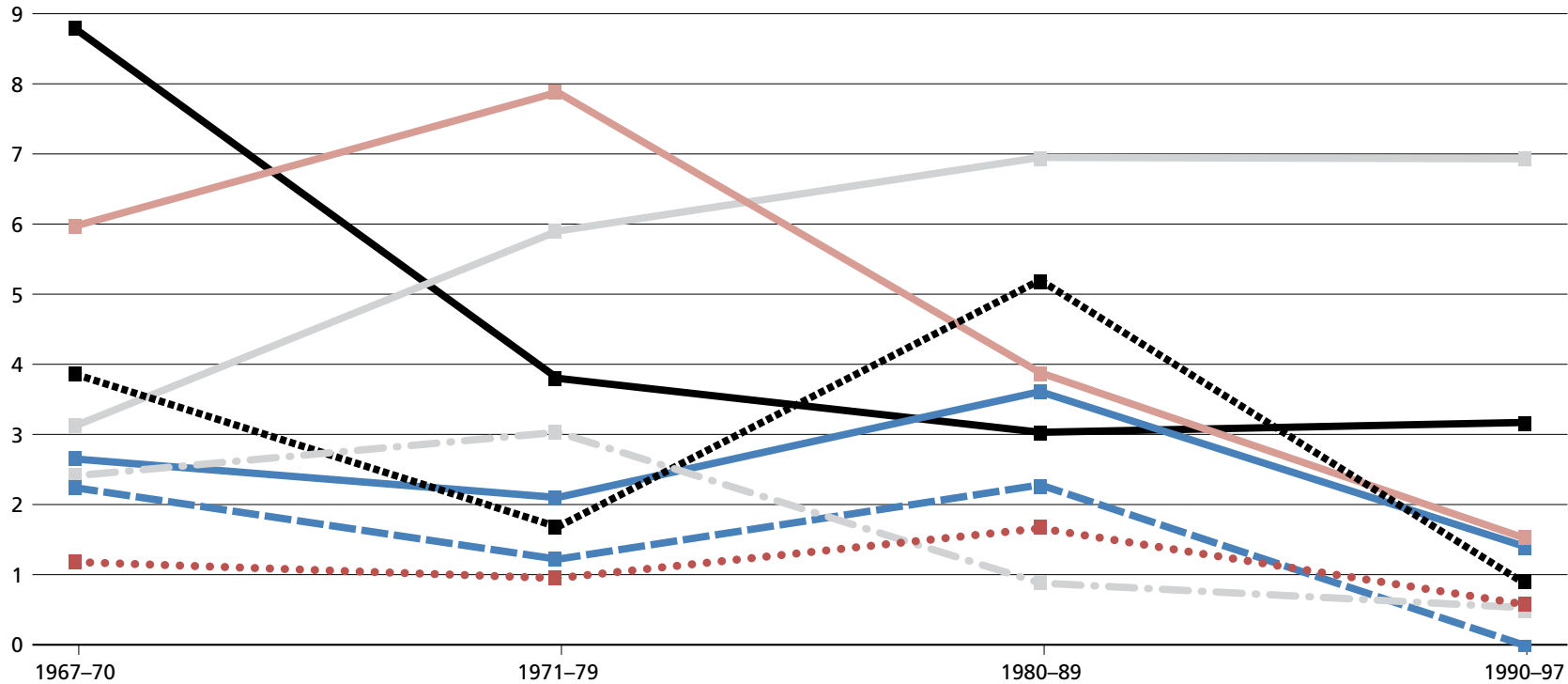

Investments

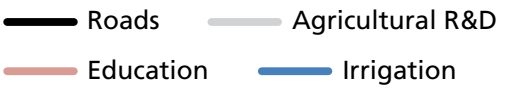

Subsidies

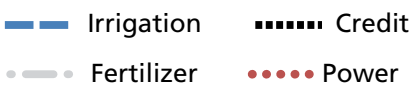

Source: Data from S. Fan, A. Gulati and S. Thorat. 2007. Investments, subsidies and pro-poor growth in rural India. IFPRI Discussion Paper No. 716 , Table 6. Washington, DC, IFPRI.

irrigation and power). The results (Figure 17) show strong evidence of very favourable returns to investments in roads and education in the 1960 s and in education in the 1970s, but reduced returns in later years. By contrast, the returns to investments in agricultural research and development are high in the later decades of the 1980s and 1990s, but much lower in the earlier years.

Returns to spending on subsidies are generally lower than to spending on investments in roads, education and agricultural research and development. Returns to subsidies on fertilizer were positive in the earlier years of the Green Revolution, but then declined, whereas returns to subsidies on irrigation and credit showed a mixed trend. Returns to spending on all subsidies are very low in the last decade, the 1990s.

The conclusions of such analyses are important given the predominant view of many commentators that governments would do best to avoid subsidies altogether and to focus on investments in research and development. The analysis shows that although returns to subsidies may be lower than those to investments, they were nevertheless positive. It also suggests that the rates of return to different types of expenditure differ according to the stage of transformation, and that the returns to some forms of spending increase much later than others.

\section{Challenges to the use of price policy}

Major difficulties have to be overcome in managing interventions to facilitate the process of transformation effectively and efficiently, and in resisting political pressure to expand and continue market interventions and subsidies when they are no longer necessary and can start to have negative impacts, both fiscally and in crowding out private-sector actors. Moreover, in some cases agricultural subsidies have been demonstrated to have regressive effects, as they have tended to benefit larger and better-off farms. This is not just the case in developed economies, as amply documented by the OECD Secretariat, but also in more advanced developing countries (Box 14). ${ }^{64}$

Difficulties with timing, and the high net costs of such interventions when they are introduced too early or 
THE STATE OF AGRICULTURAL COMMODITY MARKETS 2015-16

BOX 14

Input subsidies in developed countries - a mixed record

The use of input subsidies has a mixed record, giving rise to diverse debates about their appropriateness. Some programmes have led to clear increases in food production, but the evidence is generally insufficient or too mixed to enable robust judgements about clear food security and poverty reduction benefits.

Foster notes that while evidence supports the conclusion that fertilizer subsidies promote household incomes, farm productivity and production in aggregate, there are possible costs of foregone investments elsewhere, displacement of the private sector and disproportionate capture of subsidy benefits by larger farmers. He further states that "history is replete with examples of agricultural subsidies on farm inputs tending to expand as farmers, input producers and suppliers, and other self-interested parties discover how to take advantage both of bureaucratic rules and of often indifferent bureaucracies with enfeebled incentives to take care of other peoples' money".

Such conclusions have played against the wider use of input subsidies.

However, as Chirwa and Dorward note, there is considerable scope for improving impacts through better implementation and integration with complementary policies. Well designed and implemented, input subsidies can incentivize productivity enhancement through "thickening" rural input and output markets, thus lowering real staple food prices and increasing wages. This can result in increasing real incomes and food security for both recipients and non-recipients. In addition, in longer-term economic structural changes, the increased demand for higher-value farm and non-farm goods and services, together with the expanded supply capacity of land and labour released by higher staple crop productivity, can facilitate economic development.

Sources: Based on E. Chirwa and A. Dorward. 2013. Agricultural input subsidies. The recent Malawi experience. Oxford, UK, Oxford University Press; W. Foster. 2014. A review of the international experience with fertilizer subsidies. Unpublished.

continued for too long are among the many reasons for arguing strongly against the use of price policy. However, this does not mean that the potential benefits of such policies during a critical, but possibly short, period should be overlooked.

It should be noted that the outcomes discussed in Box 14 apply particularly to input subsidies. Other types of price policy, such as producer price support, while incentivizing production for market, can harm poor consumers and depress potential increases in real wages. Similarly, consumer price subsidies on staple foods may provide benefits to poor food buyers, but not necessarily to semi-subsistence producer households, even though these households could also be net food buyers.
One difficulty in assessing the impacts of different types of policy instrument is that the actual impacts will depend not only on the type of policy that is put in place, but also on the way in which the policy is designed, enforced or implemented in practice. An example of the potential effects of one type of instrument - public procurement of food staples - illustrates the complex interactions among objectives, design and implementation (Box 15).

In addition, some policies have simply been badly implemented, often because they are inherently difficult to implement well. This has contributed to a loss in credibility for a number of policy instruments, including the use of floor prices, and policies to smooth interseasonal price volatility. 
BOX 15

\section{Implications of objectives and design in public procurement}

Public procurement and stockholding systems vary in their objectives and design, pursuing different goals and targeting different types of producer. Some programmes aim to support producer prices by setting administered purchase prices. In India, the government intervenes in wheat and rice markets through a system of purchase, storage and distribution that both supports producer prices and provides staples to poor consumers at subsidized prices. In Ecuador, the government operates a procurement and distribution scheme that provides support prices for rice and maize farmers. Nicaragua has reactivated its state trading enterprise, ENABAS, which is involved in purchase, storage and distribution of basic grains.

However, there are alternatives to buying at administered prices while guaranteeing more stable markets for targeted producers. In Brazil, food purchased through the Food Acquisition Programme is used partly to build up strategic reserves and partly in food security programmes. Unlike many others, the Brazilian government purchases food at market prices, constantly revising the prices at which it buys from farmers to reflect the prices in local markets.

The extent and effects of the impacts of such programmes on food markets also differ, depending on whether the programme intervenes at the procurement, holding or stock-releasing phase.

Whether or not markets are affected during procurement phases depends on the magnitude of the price distortion that is created by the public procurement programme. In turn, this depends on the scale of the intervention - the proportion of the product procured from a specific market channel.

The need to release stocks onto domestic or international markets can result in sales, through commercial channels or government-to-government contracts, at below market prices. The timing of release, especially if unpredictable and not factored into traders' decision-making, can significantly influence price levels and volatility, domestically and, if the country is a significant trader, internationally.

The implications of stock use can be significant if the stock is exported after being purchased at above market prices, rather than being consumed domestically. While procurement strategies can provide a subsidy effect, this effect can be cancelled out by the implicit taxation resulting from release, whether strategic or as a result of poor timing.

The implications of public procurement and stockholding therefore need to be considered in light of multiple determinants, which include the different phases of operation, the timing, predictability and transparency of operational decisions, the structure and functionality of markets from which stock is procured and into which it is sold, and - not least - the supply-responsiveness of producers.

The complexity of public procurement programmes implies the need for a high degree of organization and skills in responsible public institutions. The fiscal cost can be substantial, especially if the prices paid to farmers exceed market prices. The sustainability of these programmes is a critical issue, as they depend on the availability of fiscal funds and political will, and caution is needed to avoid making farm incomes dependent on specific government programmes.

Sources: International Centre for Trade and Sustainable Development (ICTSD) and FAO. 2013. G-33 proposal: early agreement on elements of the draft Doha accord to address food security. Information note. September 2013. Rome, FAO; P. Arias, D. Hallam, E. Krivonos and J. Morrison. 2013. Smallholder integration in changing food markets. FAO, Rome. 


\section{Changing patterns of support to agriculture: lessons for the future}

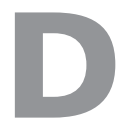
ebates over the appropriateness of different types of trade and related policies are, to a certain extent, clouded by historical experience of their differentiated use in developed and developing countries, with significant positive support to producers having characterized developed country agriculture, and implicit taxation of producers being the norm for many developing countries.

The structure of support to agriculture, in terms of both the aggregate positive or negative level of distortion created by the support and the type of support provided, has changed significantly over the past 30 to 40 years.

Analyses led by Kym Anderson and collaborators present a dramatic picture of these changes. ${ }^{65}$ Using the nominal rate of assistance (NRA) as a proxy for the level of support to, or taxation of, producer prices, the authors show that in aggregate, developed country producer support has fallen sharply from its peak in the mid-1980s, while developing country support has increased from a position of net taxation to one of marginally positive support (Figure 18).
However, the reduction in the NRA indicator does not imply that producers in developed countries now receive less support than in the past. ${ }^{66}$ Rather, the type of support has shifted from that directly affecting producer prices (and therefore reflected in the NRA indicator) to policies that do not directly affect prices and are therefore not picked up to the same extent in the traditional NRA measure. While some of these new types of support have been deemed to be both less distortive and more efficient instruments, at least for achieving contemporary objectives in developed countries, their potential to be production-distorting has also been highlighted.

While the reduction in the use of distortionary support in developed countries has been a welcome development in reducing distortions to global food markets, there have also been strong concerns that:

- the shift to less distortionary support in developed countries has not resulted in reduced excess production;

- while the negative taxation of agriculture has been significantly reduced in developing countries (at least in

FIGURE 18

HIGH-INCOME COUNTRIES

Nominal rate of assistance (percent)

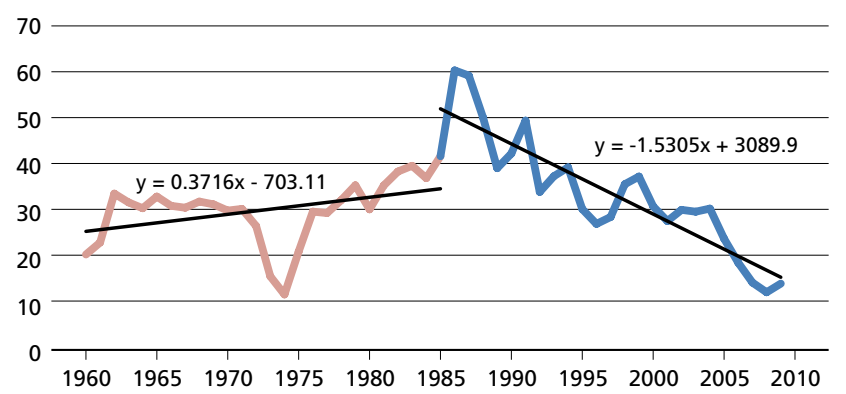

DEVELOPING COUNTRIES

\section{Nominal rate of assistance (percent)}

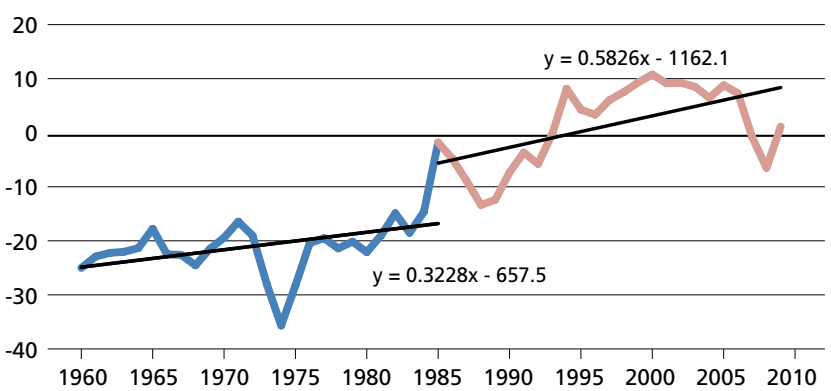

Note: The nominal rate of assistance is defined as the percentage by which national government policies raise gross returns to farmers above the level without intervention.

Source: S. Nelgen. 2015. "Positive" or "negative" trends in support to agriculture? Presentation to FAO informal consultation on Trade policy supportive of food security, 20-21 April 2015, FAO, Rome. 


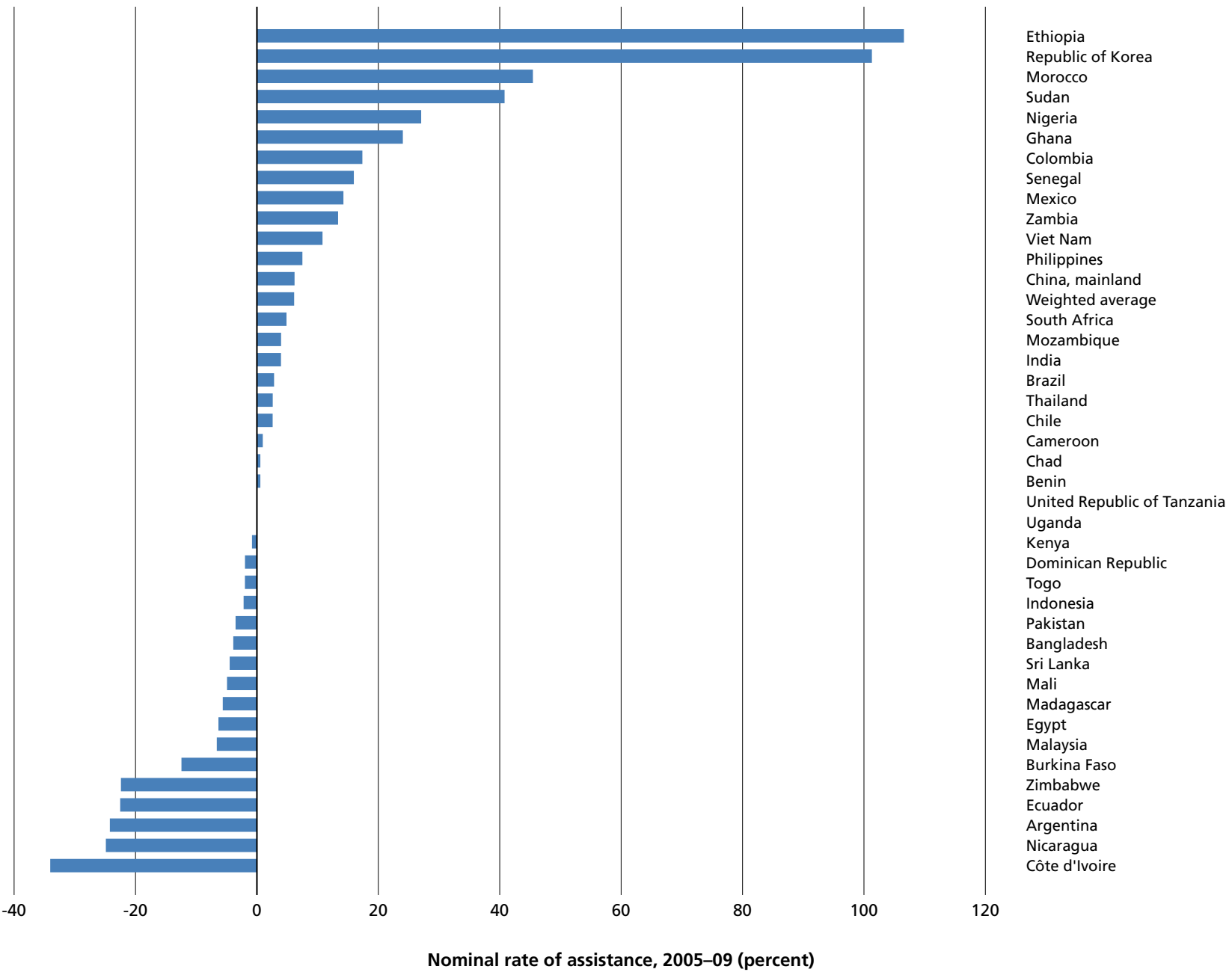

Source: S. Nelgen. 2015. "Positive" or "negative" trends in support to agriculture? Presentation to FAO informal consultation on Trade policy supportive of food security, 20-21 April 2015, FAO, Rome.

the larger emerging economies), the positive trend has not reached zero, and the support policies creating these more recent positive price gaps are of a type that may distort production. Growing government support in the larger emerging countries has been of particular concern to some commentators, as the sheer size of the economies concerned means that their agriculture sector programmes are more likely to affect other countries. However, when relating these trends to their potential impact on food security, a number of factors require consideration:

- The trends are aggregates, while patterns of change in net support differ significantly by country, as depicted for developing countries in Figure 19, and commodity. The so-called white commodities - cotton, sugar and milk - and some livestock products receive significant support, while others, typically tropical products such as palm oil, groundnuts and coffee, are still taxed, in aggregate.

- The composition of the NRA differs among countries. The NRA comprises the effects of both border policies and domestic support policies. The domestic support policies primarily affect the availability of food through their effects on increased domestic production. By contrast, price support provided through border policies such as tariffs will have a direct effect on prices, including those faced by consumers, which will potentially restrict consumers' economic access.

- In some developing countries, a third factor in determining the implications of the trend to more 
positive support is the existence of a market development gap. ${ }^{67}$ This gap refers to inefficiencies in domestic food systems that act as additional disincentives at the producer level. It stems from a range of factors including exchange rate misalignments, high marketing costs because of limited investment in infrastructure, and illicit taxes. Measured as the average cost that these inefficiencies in domestic value chains represent to producers, the market development gaps ranged from about 10 to 17 percent between 2006 and 2010 in a sample of sub-Saharan African countries. The gap highlights the potential gains, or cost savings, that could be achieved if the necessary investments were made and adequate measures taken to reduce costs. A market development gap can have significant impact on the efficacy of a policy intervention, effectively cancelling out positive incentives created by support policies. As a result, protection or support does not necessarily translate into producer incentive.

The negative connotations of the high levels of support in developed countries have made it difficult for commentators to argue for the use of more positive support in developing countries. Indeed, the tendency towards increasing levels of support to agricultural producers in some developing countries has caused disquiet. Wide-ranging concerns about this tendency include wasteful use of scarce budgetary resources, scope for corruption, regressive benefits favouring larger producers, unsustainable use of natural resources, and the potentially trade-distorting nature of the support, and have been cited by those arguing against the increased use of support policies.

It is hard to dispute that these policies are now inconsistent with the contemporary objectives of many developed countries, but arguments against their use tend to overlook their progress towards achieving the original objectives from when they were introduced some decades ago, particularly those aiming to increase agricultural productivity. While unconstrained use of such policies can clearly be detrimental to the implementing country, the assumption that policies inappropriate for countries that now have efficient, commercialized agriculture sectors are also inappropriate for countries with sectors at quite different levels of development and with quite different policy objectives is misleading, and could result in poor policy guidance.

A more nuanced debate, reflecting the needs of different developing countries, is therefore required if opportunities for implementing policies that support the adoption of productivity-enhancing technology are to be grasped. Not all developing countries are increasing their levels of support as incomes rise, often because their agriculture sectors are more commercialized and competitive or account for lower proportions of the workforce. However, for countries with agriculture sectors at an earlier stage of commercialization, where domestic market outlets function inefficiently and risk management instruments are unavailable or ineffective, productivity-enhancing domestic support policies should not be rejected out of hand. 


\section{Determinants of national trade strategies}

$\mathrm{T}$ he discussion in Part II illustrated how more open trade in agricultural products can help improve countries' food security status. The discussion of the determinants of appropriate trade and related policy in Part III have raised questions as to how, and at what speed, to open to trade. Taking a longer-term perspective, these questions are intractably linked to decisions regarding when to support agricultural productivity increases and the types of intervention to use.

\section{The role of trade policy}

Trade policy should not be used as the main instrument for correcting the market failures that are preventing productivity increases in agricultural production and/or investment in higher-value activities. For example, trade protection has been used to compensate the agriculture sector for overvalued exchange rates, without solving the underlying problem, which may be related to fiscal and monetary imbalance. However, for a defined period of interventions to promote productivity-enhancing investments, some level of border protection may be required to provide the stability for producers to react positively to the incentives created by the interventions. The question is therefore when, rather than whether, countries should open their agriculture sectors to greater competition. Many arguments for or against further openness arise from the issue of sequencing.

A longer-term objective for a more liberal agricultural trading system is justified, with trade barriers playing a minimal, if any, role in offsetting or reducing the risks associated with appropriate levels of private-sector investment in agriculture. However, this is because markets (input, credit and output, including adequate risk management instruments) are expected to function adequately in the long run, so government interventions other than regulatory controls are not required.

In the absence of well-functioning markets, and perhaps in conjunction with other targeted state interventions, a less than liberal trade policy regime may have a role in countries with underdeveloped agriculture sectors, much as it did in the now more advanced economies when they were at earlier stages of development. Recent research shows that positive levels of support for the primary sector lead to better outcomes in most dimensions of food security (availability, access and utilization), while taxation is detrimental. ${ }^{68}$ When markets begin to function more competitively, it may be appropriate to liberalize agricultural trade policy to release further agricultural growth potential.

Such arguments are not made to support blanket protectionist trade policy, but reflect recognition that the stage of agricultural transformation is critical in determining appropriate agricultural trade and related policy and that some form of intervention may be required to ensure the desired resource reallocation at early stages. It is also recognized that the role of trade policy will need to change as the agriculture sector matures.

\section{Risk management and safeguards}

Another consideration in developing trade strategies relates to the permanence of protection or support. In this report, the focus has been on the use of policy for the longer-term management of trade, as opposed to policy reactions to short-term shocks. In this longer-term perspective it is important to take into account the risks facing producers and the mechanisms that producers have for mitigating these risks. In underdeveloped agriculture sectors, producers may be significantly and continuously exposed to lower-cost imports and unable to progress to the next level of commercialization. Investments in production for market will not be made. In such contexts, a relatively moderate level of longer-term protection may be appropriate, perhaps as part of a common external tariff with partner countries at similar levels of development.

In more developed sectors, which are in a position to compete but where a lack of risk management instruments leaves producers vulnerable to shocks (such as import surges), low levels of protection associated with safeguards may provide adequate risk mitigation to allow the necessary investments to be made. However, in this context it is important to note that risks do not stem from exposure to international markets alone. In fact domestic markets tend to be more volatile than world markets because of their relatively smaller size. 
Box 16

\section{Ad hoc policy interventions reducing incentives for intraregional trade}

A key determinant of increased intraregional trade is sustained private-sector engagement and investment in market development. However, in many East and Southern African countries, engagement and investment have been discouraged by uncertain business environments, which are often attributable to government concerns over the food security-related risks of increased openness to trade and the knock-on effects that policies implemented to mitigate these risks can have on private-sector activity. For example, concerns about the food balance situation may result in a government restricting exports of a food staple at short notice. If private-sector exporters have already entered into contracts to supply a commodity to buyers in an importing country, these restrictions can result in significant losses, both financial and reputational. Such losses will reduce the willingness of exporters to enter into contracts in the future and the likelihood that they will invest in the market-related infrastructure, including for storage, required to expand volumes of trade. Sudden export restrictions could also have serious consequences for the food security of importing countries whose food security strategies rely on imports to satisfy the domestic food demand.

Governments have tended to intervene through national trade and market policy interventions that have increased price-related risks for producers and post-production value chain actors, consequently reducing private investments in both on-farm production and off-farm market infrastructure. In doing so, they have restricted the sustained growth in regional trade that would be required to allay the concerns that they are seeking to address.

It is often not the policy instruments themselves that contribute to the uncertainty, but the inconsistent and less than transparent way in which they are implemented. Addressing this situation requires that governments are confident about being able to ensure that food security-related objectives are met through more transparent use of both public-sector interventions and market-based approaches.

Increasing confidence requires strengthened evidence on the merits of alternative market-based instruments in different contexts and at different stages of the transition to a less discretionary policy environment, and on the merits of an appropriate blend of policy and market instruments during this transition, in addition to improved dialogue and capacity development to generate stakeholders' willingness to adopt these instruments.

Source: J.A. Morrison and A. Sarris. 2015. Food staple market volatility and food security in Eastern and Southern Africa: what role for intra-regional trade and market policy? In African Development Perspectives Yearbook. Volume 18: Africa's progress in regional and global economic integration. Bremen, Germany, Institute for World Economics and International Management (IWIM).

In still more mature economies, arguments for protection or support based on the risks posed by international markets are likely to be even weaker. In these economies, the provision of subsidized risk mitigation instruments may result in inappropriately high levels of investment, retention of resources in the sector and consequent excess production.

\section{Transition paths and backsliding}

In the design of trade strategies for greater openness, it is important to ensure stability in the types of intervention made. This requirement cautions against the introduction of radical changes in trade and related policy. Examples of successful rapid shifts to the optimal trade strategy are few and far between. Countries that embark on radical reforms often quickly backslide to the previous status quo or - worse - to higher levels of intervention.

Improving trade policy support is a long-term process that requires guiding the evolution of trade policy and strengthening supportive institutions. These institutions are important in facilitating the necessary changes in intervention, as the need for and objectives of support change during structural transformation processes. However, it is important to distinguish between the evolving objectives and associated interventions and the consistency of these objectives - their predictability.

The stability of policy interventions matters. Producers react to price levels and price expectations rather than to the size of the gap between the border and the domestic price. Government's propensity to intervene in an ad hoc way will be factored into producers' expectations, reducing their incentive to invest in increased levels of productivity (Box 16). Consistency in policy interventions can be as important as the scale of intervention. Priority should be given to building trust between government and the private sector. Building trust is a long-term process involving predictable and consistent policies from the government, and commitment to long-term trade development from the private sector. $^{69}$ 


\section{National, regional and global frameworks for government actions}

While trade is not intrinsically detrimental to food security, for some countries, particularly those at earlier levels of development, greater openness to trade can pose a significant challenge and involve risks for food security in the short-tomedium term if trade openness is introduced without a policy package designed to offset the negative effects of liberalization. On the other hand, the use of greater protection can pose its own challenges and risks for food security.

A policy package that involves trade reforms must suit the overall economic and social development needs and priorities of the country. It is therefore important to take into account the possible implications of changes in trade policies for the different productive sectors, including agriculture, and the fiscal space for providing vital public-sector services and safety nets to address food security concerns. This implies that to address their development needs consistently and systematically, countries need to have a better overview of all the policy instruments available to them and to weigh the pros and cons of each, including the costs and ease of implementation and monitoring.

For agriculture, the policy mix needs to take into account the specifics of the sector in each country.
For example, in countries where rural inhabitants account for a large share of the population, and agricultural production is dominated by smallholder farmers, the set of policies will need to be quite different from that in countries where the agriculture sector is more concentrated in large farms and more capital- and technology-intensive. Similarly, if smallholder households account for the predominant share of food-insecure households, measures that provide opportunities and incentives for increasing production may have a crucial role, while if the majority of those suffering from hunger are the urban poor, trade openness, combined with targeted income support measures for producers, could be preferable.

Understanding the ultimate objectives that policies (trade, agricultural or other) are intended to achieve is paramount, and the expected gains and distributional effects should be clarified ex ante, with winners and losers clearly identified and adjustment measures, such as skill development and job placement, defined for those who are negatively affected.

The formulation of trade strategies and the design of associated trade and related policies do not take place in a vacuum. The set of policies that is appropriate from a national perspective may not be the most appropriate from the collective regional or global point of view. The implications of wider policy processes are considered in Part IV. 



\section{Part IV}

\section{Towards improved governance for trade and food security}

$\mathrm{T}$ he governance systems affecting trade and food security are currently being redefined through the post-2015 development agenda, regional processes such as the Comprehensive Africa Agriculture Development Programme (CAADP) and the related Malabo Declaration, and the strengthening of dialogue and coordination at the national level. The changes brought about by this redefinition offer new challenges and opportunities to the development of the multilateral trading system.

However, while the attention of analysts is often squarely on the policy space provided by trade agreements, negotiators have so far failed to find common ground for reconciling the concept of national sovereignty with that of providing a global trading system that ensures that each country, while pursuing its national interests, does not harm third countries unnecessarily.

In this final part of the report, the linkages between trade and food security are considered through the lens of the processes that guide policy discussion and decisionmaking in trade and agriculture and that ultimately determine the effectiveness of trade and related policies in contributing to the elimination of hunger and food insecurity. Trade and food security governance has suffered from weak connections among these processes at all levels - global, regional and national. These weaknesses have compounded the lack of coherence among trade-related priorities and approaches and made it difficult to provide a global framework for guiding national-level action.

Ultimately, they have affected the capacity of countries to formulate coherent trade policies and strategies that support food security.

Part IV first considers the multilateral framework within which national trade policies must be crafted. In recognizing the difficulties of identifying relevant and useful flexibilities in a multilateral context, it then focuses on the weaknesses in governance systems at the global and national levels and the opportunities for strengthening these systems. This discussion may facilitate more informed identification and use of trade and related policy that is appropriate to the achievement of national objectives while cognizant of the potential spillover effects on the global community.

\section{Main messages}

- The WTO Agreement on Agriculture (AoA) provides the basis for improved articulation of trade and food security concerns in the multilateral trading system.

- By most traditional measures, developing countries have access to significant policy space, but the identification of this space needs to be informed by each country's specific needs.

- Shifting attention from the pros and cons of specific policies to addressing weaknesses in the governance processes of agriculture and trade-related policy-making will contribute to improved identification of the policy space required and its appropriate use.

- Building synergies between agriculture and trade-related policy-making processes at all levels will increase policy coherence for food security, enable national governments to improve the balance among priorities in developing trade policies, facilitate the mobilization of finance to implement these priorities, and improve compliance with regional and global trade frameworks. 


\section{Food security in the multilateral trading system}

\section{Addressing food security in the changing agrifood trade and policy landscape}

Trade agreements are at the heart of the trade and food security debate as they set out the rules for national trade and agricultural policies, which - as described in the previous section - play a key role in determining food security outcomes. The WTO AoA, which resulted from the Uruguay Round of multilateral trade negotiations, was the first attempt to agree a comprehensive set of disciplines on members' agricultural trade policies. ${ }^{71}$ As mandated in its Article 20, negotiations for continuing the agricultural trade reform process began before the end of the process's implementation period. These negotiations subsequently became part of the Doha Round of multilateral trade negotiations launched in 2001. The relationship between trade rules and food security has become an increasingly central element in this round of negotiations.

The fact that trade rules impinge on food security is formally recognized in the preamble to the AoA, which notes "that commitments under the reform programme should be made in an equitable way among all Members, having regard to non-trade concerns, including food security [...]", and is explicitly mentioned in several provisions of the agreement, including the Marrakesh Decision. ${ }^{72}$ It is also recognized in Article 10.4, which establishes the criteria for differentiating between legitimate international food aid and disguised government export subsidies; Article 12, which sets out the consultation process for implementation of export restrictions or prohibitions; and Annex II, which lays out the conditions for public stockholding of food and domestic food aid programmes. ${ }^{73}$ Food security is specifically addressed as part of the Doha mandate, in which "operationally effective special and differential treatment for developing countries is mandated to enable them to effectively take account of their development needs, including food security and rural development" ${ }^{74}$

The contribution that trade can make to a country's food security is partly determined by the disciplines that apply to other countries' policies, but also by the "policy space" that the country itself is permitted under WTO rules. In the AoA, specific flexibilities are provided to developing countries to help them pursue their food security goals (Table 6).

Although significant flexibilities exist through these provisions, there has been continuing debate over whether the AoA disciplines more generally are appropriate for developing countries seeking to promote their agricultural development and food security..$^{75} \mathrm{~A}$ common argument is that existing WTO rules constrain food-insecure countries' policy space for building their food security independence, which for some countries may require providing support to agriculture and/or protecting their domestic markets.

Another concern is that WTO rules are no longer appropriate in a context of higher and more volatile prices for agricultural products. As illustrated in Part I, today's global food system is different from what it was in 2001 when the Doha Round was launched. The argument is that the change in the world market price context has had very important consequences for the way in which food security concerns are framed in WTO negotiations and that this changed market environment has to be reflected in current trade negotiations.

Finally, the AoA was negotiated under quite different geopolitics from those of today. The North-South view of multilateral rule making for agricultural trade diverges increasingly from current realities. South-South agricultural trade is growing in importance. In addition, while agricultural support has been falling in OECD countries, it has been growing rapidly in a number of the larger middleincome developing countries. ${ }^{76}$ As the trade rules that have been perceived as advantageous to developed countries will be used increasingly by developing countries, affecting their trade relations, the question as to whose policy space is being considered will become ever more urgent.

\section{Limitations of the multilateral trading system in addressing food security}

WTO rules seek to solve a collective action problem. ${ }^{77}$ Such problems arise when countries, rationally pursuing their own self-interest, create an outcome that is less desirable than the outcomes that could be achieved through cooperative action. When individual countries use trade policy as a 
TABLE 6

Flexibility provisions for developing country WTO Members in the Agreement on Agriculture

\begin{tabular}{|c|c|}
\hline Article 6.2 & $\begin{array}{l}\text { Investment subsidies that are generally available to agriculture, agricultural input subsidies generally available to low-income } \\
\text { or resource-poor producers, and support to encourage diversification from growing illicit narcotic crops, are exempt from } \\
\text { domestic support reduction commitments. }\end{array}$ \\
\hline Article $6.4(B)$ & $\begin{array}{l}\text { Higher de minimis percentage for AMS commitments under this paragraph of } 10 \text { percent (as against } 5 \text { percent for other } \\
\text { Members). }\end{array}$ \\
\hline Article 9.2(B) & $\begin{array}{l}\text { Lower rate of reduction for export subsidy commitments on budgetary expenditure and quantities benefiting from such } \\
\text { subsidies. }\end{array}$ \\
\hline Article 9.4 & $\begin{array}{l}\text { During the implementation period, developing countries did not have to undertake commitments on certain export subsidies: } \\
\text { subsidies to reduce the costs of marketing exports of agricultural products, and providing internal transport charges on } \\
\text { export shipments more favourable than those for domestic shipment. }\end{array}$ \\
\hline Article 12.2 & $\begin{array}{l}\text { Exemption for developing country net food importers from the requirement to give due consideration to the effects of export } \\
\text { prohibitions and restrictions on other importing Members' food security and to give notice and to consult with other } \\
\text { importing Members on such measures. }\end{array}$ \\
\hline Article 15.1 & $\begin{array}{l}\text { General requirement that special and differential treatment should be reflected in the commitments undertaken under the } \\
\text { Agreement on Agriculture. This was implemented with respect to the market access, export subsidy and domestic } \\
\text { support commitments by mandating reduction commitments two-thirds of those required of developed country Members, } \\
\text { as embodied in the Schedules of concessions and commitments of each Member. }\end{array}$ \\
\hline Article 15.2 & $\begin{array}{l}\text { Developing countries to have the flexibility to implement reduction commitments over a period of up to ten years. } \\
\text { Least-developed countries are not required to undertake reduction commitments. }\end{array}$ \\
\hline Article 16 & $\begin{array}{l}\text { Refers to the "Decision on Measures Concerning the Possible Negative Effects of the Reform Program on Least-Developed and } \\
\text { Net Food-Importing Developing Countries". This Decision foresees several mechanisms to guarantee a special treatment for } \\
\text { least-developed countries and net food-importing developing countries, such as improved access to investment facilities and } \\
\text { the establishment of sufficient food aid levels. }\end{array}$ \\
\hline Annex 2 & $\begin{array}{l}\text { Governmental stockholding programmes for food security purposes whose operation is transparent and in accordance with } \\
\text { officially published criteria, as well as domestic food aid and subsidy programmes, are deemed to be Green Box measures. }\end{array}$ \\
\hline
\end{tabular}

Note: $\mathrm{AMS}$ = aggregate measurement of support.

Source: A. Matthews.2015. Articulating trade concerns related to food security in multilateral trade rules. Background paper prepared for The State of Agricultural Commodity Markets 2015-16. Rome, FAO.

domestic policy instrument to support their own production and stabilize their own domestic markets, they can be better off in the short run. In the long run, however, such actions particularly when carried out by larger trading countries - can have a cascading effect as other countries react with offsetting measures. The final outcome can make all countries worse off.

A country's attempts to shield itself against imported price volatility and stabilize its domestic prices can have the effect of further destabilizing world market prices for all other trading countries. Discussion of the importance of policy space often ignores the negative spillover effects that policy actions by one country have on other countries, which can adversely affect the other countries' food security.

The WTO occupies a distinct space in the global architecture, but it is both unrealistic and inappropriate to expect the organization to expand its responsibilities to cover all relevant issues. This makes it important to examine the potential for using other non-trade processes to agree on common and shared objectives, and to identify the mix of policies for enhancing the role of trade in contributing to food security.

Looking at non-trade processes is also preferable to looking at alternatives to the multilateral trading system, such as bilateral or regional trade agreements, which are increasingly regarded as a possibility for creating alternative policy space for food security, although they can offer only partial solutions. Most recent RTAs cover agricultural products, but issues such as subsidies can only be negotiated multilaterally, as no country would agree to discipline the use of agricultural subsidies in an RTA context without the assurance that other large countries were accepting similar disciplines. Moreover, the political challenges of obtaining legislative approval of such agreements may not be much less than those of passing a multilateral trade deal. RTAs also raise systemic issues for the multilateral trading system because, by definition, they discriminate against countries outside the RTA. With the negotiation of "mega-regionals" this problem will become even more pressing. 


\section{2.}

\section{The policy space available to developing countries}

critical question that pervades the debate on the requirements of AoA disciplines is that of policy space - the flexibilities that countries have for implementing policies within the general constraints imposed by disciplines that seek to ensure a wellfunctioning and reliable world trading system from which all countries benefit.
Whether the existing policy space is sufficient and adequate is a controversial issue. Some argue that the AoA provides developing countries with more than sufficient policy space and that even in the absence of flexibilities such as the proposed special products provisions and special safeguard mechanism (SSM), these countries are unlikely to be constrained by a new agreement. Others have suggested

FIGURE 20

Unused agricultural tariff policy space by country groups, 2013

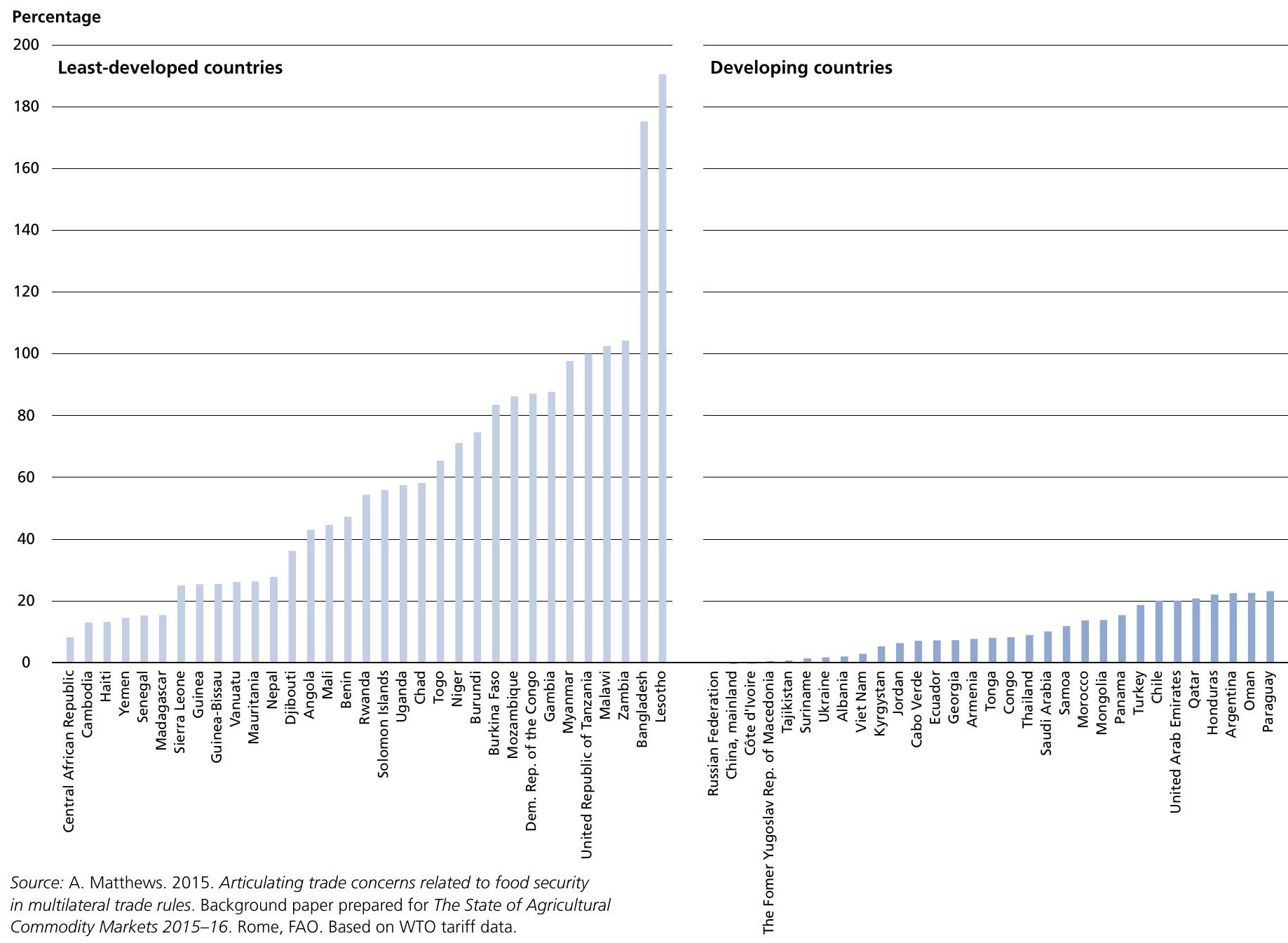


that measurements of policy space fail to distinguish between space that is available and space that is actually useful or relevant to the specific country. This difference in perspective is contributing significantly to the difficulties in achieving agreement.

The AoA imposes limitations on the policy space of all WTO members, including developing countries, under each of its pillars: market access, domestic support and export competition.

\section{Market access}

The policy space available with respect to market access is defined by the bound tariffs that WTO members commit to not exceeding. When looking at the aggregate pattern of the average structure of bound tariffs, a clear hierarchy emerges. On average, LDCs have the highest tariffs, followed by developing countries; the lowest tariffs are in developed countries. However, when the tariffs actually applied are examined, there is almost no difference among the three groups. Consequently, on average, it appears that both LDCs and developing countries have considerably more unused policy space (the difference between their average bound and applied tariffs) than developed countries (Table 7 and Figure 20).

However, looking at averages may be misleading as there is great heterogeneity within these categories. The heterogeneity of country situations in these broad groupings is not linked to any evident criteria, such as level of development, but is the result of historical differences in the way in which bound tariffs were established. Some countries bound their tariffs at the outset of the AoA, at their applied rates at the time or on the basis of tariffication. These countries, which made use of the option for applying ceiling bindings (in the case of previously unbound tariffs), made very different choices in their schedules of commitments. Members that acceded to the WTO after 1995 had to offer lower bound tariffs as part of their accession agreements.

In aggregate, the evidence appears to show that WTO tariff bindings have not been a major factor in constraining 
TABLE 7

Average agricultural tariff structures, by main country groups, 2013

\begin{tabular}{lccc} 
& Average bound tariffs & Average applied tariffs & Average unused policy space \\
\cline { 2 - 5 } & & Percentage & \\
\hline Least-developed countries & 73.5 & 15.3 & 58.1 \\
\hline Developing countries & 54.3 & 15.0 & 39.3 \\
\hline Developed countries & 31.4 & 16.1 & 15.2 \\
\hline
\end{tabular}

Source: A. Matthews. 2015. Articulating trade concerns related to food security in multilateral trade rules. Background paper prepared for The State of Agricultural Commodity Markets 2015-16. Rome, FAO. Based on WTO tariff data.

\section{BOX 17 \\ Examples of exempt policies under the AoA}

Policies exempted from AMS commitments under the green box include general services such as research, training, pest and disease control, marketing and promotion, infrastructure, farmer settlement, land reform, rural development and rural livelihood security; public stockholding for food security purposes; domestic food aid; decoupled income support, income insurance and income safety nets; environmental payments; and relief from natural disasters.

Developing countries (with the exception of China) enjoy additional flexibilities, for example under development provisions (Article 6.2). Under these provisions, developing countries can exclude from their current total AMS calculation investment subsidies that are generally available to agriculture, agricultural input subsidies generally available to low-income or resource-poor producers, and support to encourage diversification from growing illicit narcotic crops.

the ability of developing and least-developed countries to set their applied tariffs since the AoA came into force. ${ }^{78}$ It appears that bound tariffs for many countries were set at sufficiently high levels for most developing countries to retain the flexibility to apply tariffs at the level they wanted.

However, the use of averages hides the fact that policy space at the level of the individual tariff line may be limited, and this could be an issue for products that are considered sensitive or strategic for food security. Policy space at the individual tariff line is highly specific to the commodity and the country. ${ }^{79}$

Therefore, measurements of policy space for market access can be misleading. For developing countries, the major challenge is not so much the availability of policy space measured as the gaps between applied and bound tariffs, but rather the relevance of that policy space and the possibility for the country concerned to use it in a way that promotes its food security.

The difficulty in using the gap between bound and applied rates as a space within which to adjust the level of tariffs - either because tariffs are already at or close to the bound tariff level, or because longer-term use of the gap would be detrimental to consumers or is legislatively problematic - has been a factor in the request of many developing countries for a tool such as the SSM to provide additional flexibility for them to use the policy space in market access to promote their food security when needed. Such a mechanism would provide a safety net, allowing developing countries to raise tariffs temporarily to deal with surges in import volumes or associated price depressions. However, the SSM remains controversial because of the conditions to be met for invoking it and the remedies that can be used once it is invoked.

Previous FAO work ${ }^{80}$ has shown that many factors could be linked to import surges. These include external factors such as subsidies given by other countries or volatility of world prices, and internal factors such as the structure of the internal market or extreme weather events. In this regard, as experience with the existing special safeguard shows, it should not be expected that developing countries will automatically use the SSM whenever an import surge is identified. A well-designed mechanism could be a very useful tool in efforts to serve food security objectives, while also providing more predictability on the use of the policy space of importing developing members.

\section{Domestic support}

The general approach of the AoA with regard to domestic support is to discipline measures that are deemed to be production- and trade-distorting, but to impose no restrictions on policies considered to have no or minimal trade-distorting effects. Exempt policies (Box 17) under the green box include measures that meet the requirement for having no, or at most minimal, trade-distorting effects or 
TABLE 8

Domestic support policy space in the Agreement on Agriculture

\begin{tabular}{|c|c|c|c|}
\hline Members & Exempt measures & Non-exempt measures & Numbers (early 2015) \\
\hline $\begin{array}{l}\text { Members with scheduled Bound } \\
\text { Total AMS commitment levels }\end{array}$ & $\begin{array}{l}\text { Required to comply with the } \\
\text { relevant exemption criteria }\end{array}$ & $\begin{array}{l}\text { Required not to exceed the Bound } \\
\text { Total AMS commitment levels } \\
\text { (Article 3.2) }\end{array}$ & $\begin{array}{l}15 \text { developed countries } \\
17 \text { developing countries }\end{array}$ \\
\hline $\begin{array}{l}\text { Members with no scheduled Bound } \\
\text { Total AMS commitment levels }\end{array}$ & & $\begin{array}{l}\text { Required not to exceed the } \\
\text { elevant de minimis levels }\end{array}$ & $\begin{array}{l}4 \text { developed countries } \\
96 \text { developing countries }\end{array}$ \\
\hline
\end{tabular}

Notes: For countries with a Bound Total AMS, the amount of support that would otherwise count towards that limit can be reduced by the de minimis exemptions for product-specific and non-product-specific support.

AMS = aggregate measurement of support.

Source: A. Matthews. 2015. Articulating trade concerns related to food security in multilateral trade rules. Background paper prepared for The State of Agricultural Commodity Markets 2015-16. Rome, FAO.

effects on production and that satisfy the specific criteria outlined in Annex 2 of the AoA. In addition to measures covered by the green box, two other categories of domestic support measures are exempt from reduction commitments under Article 6 of the AoA: certain developmental measures in developing countries (Article 6.2); and certain direct payments under production-limiting programmes under the blue box (Article 6.5). So-called de minimis levels of support are also exempted from reduction (Article 7.2(b)). ${ }^{81}$ Nonexempt policies are disciplined through commitments based on the aggregate measurement of support (AMS).

Policy space in relation to domestic support is defined by a country's right to exempt payments under some policies when calculating its current AMS, and by the size of its AMS limits.
Some countries have an upper limit on their current total AMS as part of their WTO schedule of commitments. This limit is called the Bound Total AMS. For most developing countries, trade-distorting support is limited to de minimis amounts under their AoA commitments (Table 8).

The de minimis ceiling can be highly constraining on the use of market price support in developing countries because of the way in which market price support is calculated when determining a product's AMS (Box 18). The impact of the market price support formula used in the WTO rules was not an issue during the early years of the AoA, or when the Doha Round was launched in 2001, because of the limited change in nominal average global agricultural prices between 1986 and 2003. Since then, however, the formula

BOX 18

The de minimis constraints under the AoA

All policies that are not excluded from reduction commitments fall under the amber box and are subject to reduction commitments based on the AMS.

In developing countries, product-specific policies whose value is less than 10 percent of the farmgate value of the country's production of that product are exempt from the AMS calculation (8.5 percent for China, 5 percent for developed countries). Similarly exempt are non-product-specific policies whose value is less that 10 percent of the total value of agricultural production in the country (8.5 percent for China, 5 percent for developed countries). WTO members without a Bound Total AMS are entitled to provide production- and trade-distorting support only up to their de minimis levels. As long as their product-specific and their non-product-specific support do not together exceed their de minimis level, these countries are in compliance with their commitments.

The formula currently used to calculate market price support is to take the difference between the administered price and a fixed external reference price based on the years 1986 to 1988 and to multiply this difference by the amount of eligible production that will receive support.

Interaction between the AoA formula for calculating market price support resulting from the use of administered prices, and the much increased level of world market prices compared with the AoA base period in the mid-1980s means that developing countries may breach their domestic support commitments even when their administered prices are set at levels lower than current world market prices.

Source: Derived from A. Matthews. 2015. Articulating trade concerns related to food security in multilateral trade rules. Rome, FAO. 
BOX 19

\section{Options for disciplining export restrictions}

The policy reactions of some of the main exporters when facing high and volatile food prices had important repercussions for food supplies and, in consequence, for the food security of several NFIDCs. Export restrictions have proved to exacerbate significantly the negative effects on food security when an unexpected, rapid increase of food staple prices occurs, and have weakened the reputation of international markets as a reliable source of food.

WTO discipline of export restrictions is an area of evident "underregulation" or "regulatory deficiency", as it neither properly defines the circumstances under which quantitative restrictions can be used, nor regulates export taxes. Article XI of GATT 1994 states that imports and exports can be restricted or inhibited, but only by means of duties and taxes, while the use of other export-reducing policy instruments, such as quotas or export licences, is not allowed (Article XI par. 1). The prohibition on using quantitative restrictions is relaxed in the case of "export prohibitions or restrictions temporarily applied to prevent or relieve critical shortages of foodstuffs or other products essential to the exporting contracting party" ( Article XI par. 2a). As "critical shortages" are not clearly defined, countries are left with ample space for policy decision-making on export restrictions, while lacking space for restricting imports.

To avoid the negative effects on several NFIDCs, it would be useful to have in place an improved, multilaterally agreed regulatory framework governing the use of export restrictions. However, despite the widely shared concern that has emerged in recent years regarding the need to introduce more stringent WTO disciplines on export restrictions, so far no agreement has been reached.

Six alternative options for modifying the current disciplines on export restrictions for agricultural goods in the event of suddenly and rapidly soaring international prices have been outlined by Anania, and are presented in increasing order of their implications for the policy space of exporting countries:

- exempting from export restrictions the food purchases made by international organizations for distribution as food aid;

- improving the enforceability of existing disciplines by clarifying the conditions in current GATT provisions for allowing the use of export restrictions;

- limiting the impact of export taxes and restrictions on world markets by making the use of export restrictions conditional on the percentage of domestic production of the specific commodity that is exported;

- prohibiting the use of export restrictions, other than export taxes, on exports to poor net food-importing countries;

- introducing stricter disciplines for export restrictions and export taxes;

- achieving full symmetry in regulating import and export restrictions.

Source: G. Anania. 2013. Agricultural export restrictions and the WTO: what options do policy-makers have for promoting food security? ICTSD Programme on Agricultural Trade and Sustainable Development, Issue Paper No. 50. Geneva, Switzerland, International Centre for Trade and Sustainable Development.

has become more constraining because of the steep rise in nominal world food prices. While most developing countries report no or minimal use of trade-distorting policies, some emerging economies have been increasing their support. However, in some cases, these increases are amplified by the interpretation of the parameters of the formula used to calculate the country's market price support.

Since the AoA was introduced, it has been argued that domestic support disciplines are effective in reducing the amount of trade-distorting domestic support provided by developed countries. Policy reforms have made a major contribution to reducing the most trade-distorting instruments of support in OECD countries, but some of the apparent reduction in domestic support has been cosmetic, such as where the abolition of administered prices has not resulted in any real reduction in economic support to farmers because tariff protection has remained almost unchanged. In other cases, amber or blue box measures have been replaced by budget support policies under measures categorized as green box, a phenomenon known as "box shifting". This is confirmed by the fact that in many developed countries the reduction in non-green box support has been accompanied by an increase in green box support. ${ }^{82}$

\section{Export competition and restrictions}

In the past, the use of export subsidies by some developed countries was an important factor exacerbating depressed global prices and contributing to instability in both prices and import volumes in many developing countries. During the Doha Round negotiations, developing countries have therefore made the ending of export subsidies a key demand. The Doha Ministerial Declaration mandates 
negotiations aimed at reducing all forms of export subsidies, with a view to phasing them out.

However, the situation changed with the 2008-09 food price spike, and some developing countries resorted to export restrictions to stabilize their domestic prices. Attention shifted to the continued availability of supplies from major exporters, and the response of countries using export restrictions to try to limit the extent of price increases for their populations (Box 19).

The lack of discipline on export restrictions in the AoA provides a considerable amount of policy space for countries to respond to domestic price volatility, and therefore address short-term food security concerns. However, it is an important weakness in the multilateral trading system and could have major repercussions for food security, especially of importing developing countries.

The more countries that resort to export restrictions during a price spike, the less effective such measures are at stabilizing domestic prices and the greater the destabilization of world market prices. The use of trade measures to insulate economies from shocks to world prices can, at best, transfer the risks associated with commodity production and trade. If many countries seek to transfer price risk to others, the outcome could leave everyone worse off than before ${ }^{83}$

Analysis of the three pillars of the AoA shows that policy space for food security is generally available within the current WTO disciplines, although it may not be available for particular countries, commodities or tariff lines. However, whether such policy space is relevant and useful for developing countries enhancing their food security remains a controversial issue. The difficulty in identifying the appropriateness and relevance of the policy space often arises from the fact that they may depend on specific country characteristics and the stage of development of the country, as argued in Part III. Moreover, national trade policies that are disciplined by the AoA are not determined in a vacuum. Instead, they are pursued by governments as part of broader policy agendas with various objectives, some of which may not be related to trade, and political realities also have to be considered. Shifting attention to the national-level policy processes that define policy use may help in this identification, as explored further in the next section. 


\section{From policies to processes for improving coherence and policy space}

\section{National-level processes and the formulation of agricultural trade policies and strategies}

Trade and related policies are expected to play an increasingly important role in supporting the implementation and financing of agriculture and food security strategies and investment plans. For example, in Africa, the Malabo Declaration ${ }^{84}$ made a clear commitment to boosting intraAfrican trade in agricultural commodities and services, resulting in greater emphasis on trade and related issues in the new implementation strategy of CAADP (Box 20). ${ }^{85}$

Trade policies are especially relevant through their capacity to create the enabling conditions for mobilizing different sources of finance, including foreign aid in the form of Aid for Trade (AfT), trade finance and private investments.
How they achieve these conditions depends on the specific country context, especially the role of the agriculture sector in the country's growth process; on reaching agreement across sectors on objectives and priorities for agricultural trade development; and on identifying a mix of policies that can help achieve these objectives and priorities - recognizing that trade alone is not enough.

In most developing countries, agriculture and traderelated objectives and strategies are identified through separate prioritization, negotiation and coordination processes, associated with agriculture and trade ministries respectively. These processes are often poorly coordinated: agriculture-related plans are normally identified and negotiated with donors without engaging trade ministries; while trade ministries often do not fully identify and reflect

\section{BOX 20 \\ Strengthening trade priorities in the context of the Comprehensive Africa Agriculture Development Programme}

CAADP is an Africa-wide agricultural programme aiming to improve food security and nutrition and increase incomes in Africa by raising agricultural productivity by at least 6 percent per year and increasing public investment in agriculture to 10 percent of annual national budgets.

CAADP priorities at the national level are defined through national compacts and investment plans, whose development is coordinated by national structures attached to the ministry of agriculture and that are meant to guide donor support to CAADP implementation.

CAADP has contributed to strengthening and/or creating agriculture-related financing mechanisms for Africa. In addition to the CAADP Multi-Donor Trust Fund administered by the World Bank and to the Global Agriculture and Food Security Program, other mechanisms include equity and semi-equity funds such as Agvance Africa and the Africa Agriculture Fund, and pull mechanisms such as AgResults.

CAADP was originally meant to improve coordination among players in agriculture strategy development and to mobilize expertise and resources to support them. While trade and market development is a founding pillar of the CAADP framework, engagement and coordination of trade institutions in the development and implementation of CAADP compacts and investment plans has always been weak. However, the Malabo Declaration and the related Strategy and Roadmap to Achieve the 2025 Vision on CAADP provide considerable potential for strengthening the mainstreaming of trade within the CAADP implementation process at both the regional and national levels.

Source: FAO. 
BOX 21

\section{Coordination efforts under the Aid for Trade initiative}

The AfT initiative was launched in 2005 to: i) strengthen developing countries' productive capacity; ii) tackle their supply-side constraints; and iii) address their needs in trade-related infrastructure.

The initiative was originally meant to bridge the gaps between sectors by establishing regional and country-level processes to support the development and implementation of comprehensive trade strategies that package regional and national trade priorities under one umbrella. By doing so, the initiative contributed to bringing trade ministries into the development arena as another channel for overseas development assistance (ODA).

The centrality of trade ministries is especially evident in the LDCs, where efforts to package national trade priorities under the AfT umbrella are supported by a structured process coordinated through the Enhanced Integrated Framework for Trade-related Technical Assistance (EIF). The EIF is a multi-donor programme that supports LDCs in becoming more active players in the global trading system. The EIF is supported by national implementation units embedded in the trade ministries of LDCs and is the main process for coordinating the development of diagnostic trade integration studies (DTIS), which analyse the internal and external constraints to countries' integration in the global trading system and recommend areas where technical assistance and policy action are needed. The DTIS Action Matrix is the main reference framework for donors' coordination of trade-related support to a country and the leverage of additional AfT.

The AfT initiative contributed to strengthening and multiplying the number of trade-related financing instruments for channelling ODA. Examples of trade-related financing mechanisms attached to AfT and the EIF include mechanisms with a geographic focus (AfT trust funds of regional banks, the EIF Trust Fund for LDCs) or a thematic focus (the World Bank's Trade Facilitation Facility, the Standards and Trade Development Facility, the World Bank's Multi-Donor Trust Fund for Trade and Development). Some countries have established national-level trade financing mechanisms, which differ from country to country (e.g. the Cambodia Trade Sector-wide Approach).

However, the coordination efforts promoted through the AfT initiative have been poorly implemented in the agriculture sector because of the weak engagement of agricultural institutions in the AfT process at all levels. At the global level, policy dialogue has been limited mainly to trade institutions, while at the national level implementation has centred too closely on the trade ministries.

Source: FAO.

agricultural development priorities when developing trade policies and negotiating trade agreements, and rarely involve agriculture ministries.

This situation can result in different perceptions of the national priorities for agricultural trade, which can lead to gaps in the country's capacity to design and implement appropriate trade strategies and policies supportive of agriculture sector development and associated food security improvements, and therefore gaps in identification of the required policy space.

Moreover, by articulating incoherent or even conflicting priorities, the "sectoral divide" also contributes to inefficient allocation of resources. Donors and development partners have exacerbated the divide by providing support to sectoral processes through different departments or agencies, which are also poorly coordinated. The AfT initiative has identified and tried to change the approach to elaborating trade strategies, but with limited results in the agriculture sector (Box 21).

The example of African LDCs is emblematic. In these countries agriculture and trade-related strategies and investment plans are generally framed in two separate processes, CAADP and the EIF, which involve different ministries (agriculture and trade respectively), stakeholders, development partners and sources of financial support.

Poorly articulated linkages between these processes often result in partial strategies. For example, the DTIS elaborated under the EIF often focus on export crops at the expense of support to import-competing food crops. By contrast, CAADP compacts tend to prioritize food crop productivity without sufficient consideration of opportunities and constraints in obtaining access to, or competing on, regional and international markets. The inefficient use of resources is evidenced by the presence of specific financing mechanisms to support each process, with each donor generally contributing to these different mechanisms through different departments and programmes (Figure 21).

Figure 21 could be adapted to climate change and include environment ministries and National Adaptation Programmes for Action, as the funding mechanisms attached to the climate change process face strikingly similar issues. The nutrition dimension could also be elaborated by 


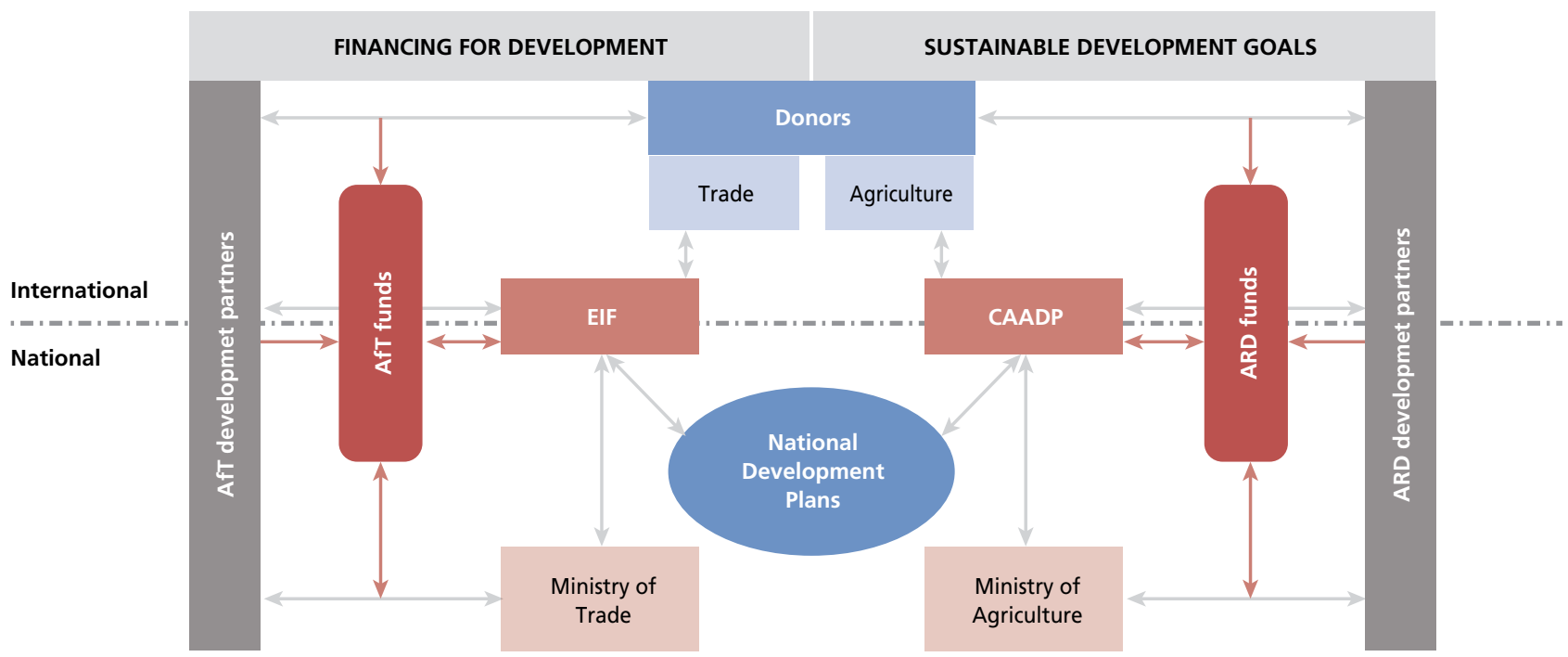

Notes: AfT = Aid for Trade; ARD = Agriculture and Rural Development; CAADP = Comprehensive Africa Agriculture Development Programme; $\mathrm{EIF}=$ Enhanced Integrated Framework for Trade-related Technical Assistance.

Source: Adapted from E. Canigiani and S. Bingi. 2013. Connecting food value chains in Africa. GREAT Insights, 2(5). July-August 2013. Maastricht, Netherlands, European Centre for Development Policy Management.

making a bridge with health ministries and the processes for designing national nutrition policies. This situation points to the need for more coherence, not only in policy, but also in aid and other financing instruments. It is interesting to note that the governance weaknesses observed at the national level reflect the broader challenge of connecting policy processes addressing social, economic and environmental issues at the global level. While agriculture and food security (and climate change and nutrition) issues are discussed as part of the Sustainable Development Goal (SDG) framework, trade issues are part of the financing for development (FfD) process. Global governance is analysed in the following, final section of the report.

In this context, making trade policies work better for food security is a political as much as a technical economic challenge. Country policies have to balance competing objectives, and policy-makers have to balance the interests of diverse groups within and outside their countries' borders. Once the objectives are set, the value of policy coherence becomes more obvious, as does the need for countries to transform their policies and make them consistent with development goals.

\section{Mainstreaming food security into decision-making for national trade policy}

While developed countries examine how best to reform their institutional governance to strengthen their capacity to include development policies in a broader package of policies for expanding economic growth through trade and investment, it is important that developing countries are supported in reforming their own governance systems to facilitate the mainstreaming of food security into decisionmaking processes for national trade policy. A common challenge for both developed and developing countries is strengthening capacities to work across sectors.

Bridging the gaps between sectoral processes is possible through:

- greater engagement of trade stakeholders, including trade ministries, export promotion boards, industrial associations and chambers of commerce, in the development of agriculture strategies and investment plans;

- aligning agriculture strategies and investment plans with trade-related policy and planning frameworks such as import and export strategies and DTIS - in many cases, this will require renegotiation of national agricultural trade priorities by the agriculture and trade ministries to improve the balance between expanding trade and providing support to strategic importcompeting food commodities; these more coherent priorities should also be reflected in countries' development strategies and long-term programme documents agreed with donors and international organizations, for example in countries' United Nations Development Action Frameworks; 
- including trade and agriculture experts in the formulation of each other's strategies and investment plans;

- connecting the national structures attached to sectoral processes (e.g. CAADP, the EIF), where they exist.

However, the bridging of agriculture and trade-related processes will not occur spontaneously. Improving policy coherence requires leadership and political commitment, continuous facilitation through policy dialogue among different stakeholder groups, and institutional strengthening and capacity building to fill knowledge gaps. Facilitation is often overlooked, resulting in underestimation of the resources needed to build bridges between sectors.

In supporting national-level processes, it is essential that the global governance systems affecting these processes are also coherent and can ensure that trade-related processes are supportive of countries' pursuit of food security objectives. 


\section{Linking trade and food security in the post-2015 development framework}

\section{Challenges}

The post-2015 development framework places significant emphasis on both food security and international trade. Food security is clearly identified as part of the SDGs under Goal 2, End hunger, achieve food security and improved nutrition and promote sustainable agriculture.

On the other hand, trade is also seen as an enabler in achieving the SDGs, and is included among the means of implementation (Mols), ${ }^{86}$ which specify the tasks, responsibilities and resource commitments for implementing the SDGs. All Mols are clustered under Goal 17, Strengthen the means of implementation and revitalize the global partnership for sustainable development. With the exception of two trade-related targets under Goal 2, which only tangentially captures trade issues that are relevant to food security, the specific linkages between trade and food security remain poorly articulated in the SDG framework.

TABLE 9

Sustainable Development Goals and trade targets relevant for food security

Proposed goal Trade targets

Goal 2

End hunger, achieve food security and improved nutrition and promote sustainable agriculture

Goal 8

Promote sustained, inclusive and sustainable economic growth, full and productive employment and decent work for all

Goal 10

Reduce inequality within and among countries

\section{Goal 14}

Conserve and sustainably use the oceans, seas and marine resources for sustainable development

\section{Goal 17}

Strengthen the means of implementation and revitalize the global partnership for sustainable development

2.b Correct and prevent trade restrictions and distortions in world agricultural markets, including through the parallel elimination of all forms of agricultural export subsidies and all export measures with equivalent effect, in accordance with the mandate of the Doha Development Round.

2.c Adopt measures to ensure the proper functioning of food commodity markets and their derivatives and facilitate timely access to market information, including on food reserves, in order to help limit extreme food price volatility.

8.a Increase Aid for Trade support for developing countries, in particular least-developed countries, including through the Enhanced Integrated Framework for Trade-Related Technical Assistance to Least Developed Countries

10.a Implement the principle of special and differential treatment for developing countries, in particular least developed countries, in accordance with World Trade Organization agreements

14.6 By 2020, prohibit certain forms of fisheries subsidies which contribute to overcapacity and overfishing, eliminate subsidies that contribute to illegal, unreported and unregulated fishing and refrain from introducing new such subsidies, recognizing that appropriate and effective special and differential treatment for developing and least developed countries should be an integral part of the World Trade Organization fisheries subsidies negotiation. [Footnote: Taking into account ongoing World Trade Organization negotiations, the Doha Development Agenda and the Hong Kong ministerial mandate.]

17.10 Promote a universal, rules-based, open, non-discriminatory and equitable multilateral trading system under the World Trade Organization, including through the conclusion of negotiations under its Doha Development Agenda

17.11 Significantly increase the exports of developing countries, in particular with a view to doubling the least developed countries' share of global exports by 2020

17.12 Realize timely implementation of duty-free and quota-free market access on a lasting basis for all least developed couantries, consistent with World Trade Organization decisions, including by ensuring that preferential rules of origin applicable to imports from least developed countries are transparent and simple, and contribute to facilitating market access

Source: Based on United Nations General Assembly. 2014. Report of the Open Working Group of the General Assembly on Sustainable Development Goals. New York, USA, United Nations. 
However, as Table 9 demonstrates, a number of goals could provide scope for strengthening the linkages.

The challenges to linking trade and food security under the SDGs result in part from including the Mols as part of a separate goal. If, rather than specifying how they are expected to contribute to each goal through measurable indicators, the instruments and resources for achieving the goals become goals in themselves, there is potential for creating an incoherent governance framework.

This potential incoherence could be amplified by the negotiation of the Mols in the FfD process, separately from the SDGs, while yet another process, the G-20, is dealing with the same issues in seeking to provide the enabling macroeconomic environment and structural transformation for achieving the post-2015 vision.

Box 22 outlines how the SDG process is building on experience with the Millennium Development Goals (MDGs).

The potential disconnect between trade and food security in these major global processes is therefore the consequence of a broader disconnect in the global governance between sustainable development and structural macroeconomic issues, trade and finance. This division is also reflected in the institutional architecture that governs these issues at the international and national levels.

In the absence of common and shared goals across sectors, which the SDGs aim to provide, this disconnect has created silos that are no longer appropriate in today's more interconnected world. Overcoming the silos and finding a new institutional structure able to deliver on more integrated SDGs is a major challenge for future global governance.
The situation becomes more complicated when other processes that may have direct or indirect impacts on the relationship between trade and food security are considered. Directly relevant processes include those that address the rules of international trade, international reserves and stocking policies, the use and expansion of biofuels, the management of fisheries, investments in agricultural land, commodity markets, and international assistance during crises and emergencies. Processes with an indirect influence on the relationship between trade and food security include competition policies, international environmental regimes, climate policies, energy market regulation, and the international human rights regime.

For example, countries may have to strengthen domestic policy and legislation, such as antitrust laws to govern monopolistic structures. There will be a parallel international challenge if the horizontal and vertical integration of the agrifood system makes the global food system less competitive. At a minimum, it would be useful to improve information about competition issues related to the international agrifood system. Efficient functioning of the global agrifood system may need an internationally agreed framework for competition policies, to facilitate this process. ${ }^{87}$

Global governance is undergoing a transition phase in which roles and responsibilities are being redefined in a much more complex and interconnected global landscape in which the contours are still not clear. However, it is generally agreed that sustainable development is no longer a question of North-South relationships, but rather a universal concern, and all countries are therefore expected to contribute towards

\section{BOX 22}

\section{Comparing the SDGs and the MDGs}

There is broad agreement that the eight MDGs have helped to galvanize development efforts and guide global and national development priorities. The goals were easy to communicate and accompanied by a clear measurement and monitoring mechanism. However, they have been criticized for a number of reasons, including for being too narrow, for being developed from the perspective of rich donors aiding poor recipients rather than through an inclusive process of consultation with all stakeholders, and for not considering the initial conditions of the various regions and countries implementing them.

Building on the lessons learned from the MDGs, ${ }^{1}$ at the Rio+20 Conference on Sustainable Development, the United Nations initiated an inclusive intergovernmental process for preparing the set of SDGs. Discussions on the SDGs were ongoing during the drafting of this report, and questions remain regarding the number of goals and the resources for implementing them, but it is generally recognized that many of the weaknesses of the MDGs have been addressed. In particular, the process of consultation has been more extensive and inclusive, the need to build synergies among economic, environmental and social aspects of development is more explicit, and the different situations and capacities of countries in contributing to the goals are acknowledged.

1 See also UN System Task Team on the Post-2015 UN Development Agenda. 2012. Review of the contributions of the MDG agenda to foster development: lessons for the post-2015 UN development agenda. Discussion Note. New York, USA, United Nations. 
achievement of the SDGs in ways that are commensurate with their circumstances, capacities and capabilities.

Building a more coherent global framework for trade and food security is therefore closely linked to broader reform of global governance and the institutional and financial architecture that supports it. The building of closer synergies among the institutions, financing mechanisms and processes established to address social, economic and environmental issues at all levels is fundamental to achieving an ambitious agenda of global and shared goals. The first step towards achieving such synergies for agricultural trade development would be to reach agreement across sectors on the longterm objectives and priorities for guiding the development of trade policies.

For trade and food security, a major challenge is in balancing the differentiation among countries that is advocated by the SDGs with the concept of doing no harm to third countries that is at the core of the multilateral trading system. The competing pressures in ensuring that countries are not restricted in their use of policies in the pursuit of national food security concerns while also ensuring that they do no harm to third countries is posing difficulties to the design of a coherent global governance framework.

\section{Opportunities}

The capacity to realize the transformative potential of the SDGs depends on the FfD process clarifying the role of the Mols, and the resources associated with them, which in turn is linked to the ongoing reform of ODA.

Until recently, ODA has been seen as the main source of funding for development. However, ODA represents only part of the flows targeting development. According to OECD statistics, ${ }^{88}$ ODA accounts for 28 percent of all official and private flows from the 29 member countries of the OECD's Development Assistance Committee. ${ }^{89}$ Other sources include finance provided by public bodies at close to market terms and/or with a commercial motive; private finance at market terms, such as FDI; and private grants from philanthropic foundations and NGOs. ${ }^{90}$

All countries now have a wider range of options for financing their development. In addition to domestic public resources (tax and non-tax revenues) and domestic private finance, which are the largest source of finance for all country income groupings, other financing options include developing countries' support to each other through South-South cooperation, foundations, direct giving, social business, and remittances, ${ }^{91}$ with the pattern of finance (the mix of national, international, public and private sources) evolving at different levels of income and development. Therefore, the constraining factor in achieving a transformative post-2015 development agenda will not necessarily be an overall shortage of funds, but rather the way in which the funds are mobilized and used.
The future of development financing builds increasingly on the recognition that developing countries must own their development strategies and seek to finance their own structural transformation. This has led to a fundamental questioning of the importance of foreign aid in the future development agenda. The challenge has become how to make aid "smarter" in countries where it is less important, and more effective in leveraging other sources of finance where it remains influential. ${ }^{92}$ The role of ODA as a means of delivering on the SDGs is therefore being reconsidered in the light of other enablers or Mols, including trade, whose function is to help move beyond aid by mobilizing different sources of finance that are more appropriate to the level of development and income of the country. In this context, ODA becomes a catalyst for international funds that supports enabling regulatory environments and increases the benefits of broader public and private investment.

The economic concept underpinning these developments and the post-2015 vision is economic diplomacy, defined as "the process through which countries tackle the outside world, to maximize their national gain in all the fields of activity including trade, investment and other forms of economically beneficial exchanges where they enjoy comparative advantage; it has bilateral, regional and multilateral dimensions, each of which is important". ${ }^{93}$ This process provides the basis for a more holistic approach to international relations that is more concerned with economic policy issues, connects national with international policy interests more effectively, views development policies as part of a package of policies, and prioritizes long-term transformation over short-term political or commercial interests.

In this evolving context, the declining relative importance of aid also focuses attention on other areas of policy that are essential for supporting continued development. ${ }^{94}$ This "beyond aid" agenda focuses on other policies that bring larger benefits to the poor than are provided by aid. In particular, policies are deemed to play an increasingly important role for the effective mobilization and use of finance, and are therefore also seen as enablers of finance. The policies concerned include domestic policies that can promote the mobilization of domestic resources, and international agreements and policy frameworks that create the enabling conditions for the design and implementation of national-level policies.

Trade and related policies can play a major role in promoting and supporting this shift beyond aid, as they can create the enabling conditions for facilitating structural transformation and mobilizing other sources of finance that are more appropriate to the income level of an increasingly diverse group of developing countries. Consequently, while the role of ODA is being reconsidered, a new vision taking shape among donor countries places trade at the core of international cooperation. Increasingly, donors are considering transforming aid relations into trade relations 


\section{BOX 23}

\section{Mapping Africa's untapped financing potential}

The African Union's Agenda 2063 has encouraged debate on how Africa can fund its own development. The continent's unexploited potential for financing development is confirmed by a number of studies, which have revealed a broad range of resources available in Africa and possible mechanisms and instruments for channelling such funding. The European Centre for Development Policy Management (ECDPM) has mapped an approximate overview of these resources and accompanying mechanisms and instruments. The mapping is based on estimates of the potential financial resources/needs derived from various sources:

- The continent generates more than US\$520 billion annually from domestic taxes.

- Africa earns more than US\$168 billion annually from minerals and mineral fuels.

- African countries hold more than US\$400 billion in international reserves in their central/reserve banks.

- Stock market capitalization rose from US\$300 billion in 1996 to US\$1.2 trillion in 2007.

- Ten African countries have established sovereign wealth funds with a total estimated value of about US\$160 billion. By setting up adequate frameworks and mechanisms in partnership with international actors, African countries can potentially raise additional funds, including through the following examples:

- African diaspora remittances climbed to US\$64 billion in $2013^{1}$ and have the potential to generate an additional US $\$ 10$ billion annually through securitization, and up to US\$20 billion when diaspora bonds are included.

- Further potential funds could be generated by debt relief measures that could amount to US\$114 billion.

- The curtailing of illicit financial flows would make US\$50-60 billion available for development, which has so far been lost to the continent.

1 AFDB, OECD and UNDP. 2014. African Economic Outlook 2014, Chapter 2 - External financial flows and tax revenues for Africa. Africa Development Bank (AfDB), OECD, United Nations Development Programme (UNDP).

Source: ECDPM. 2014. Implementing African development initiatives: opportunities and challenges to securing alternative financing for the Agenda 2063. Briefing Note No. 65. Maastricht, Netherlands.

and using ODA as a catalyst for private investment. In addition to improving the integration of international and national policies, the international community is also seeking to coordinate better with the private sector to enable the leveraging of private investments for sustainable development objectives.

In preparation for implementing this new vision, some donor countries are reorienting their strategies and some are also reforming their organizational structures. Australia, Canada and the Netherlands have significantly changed their institutional architecture for bilateral development cooperation policy and implementation by merging the government departments responsible for foreign affairs, trade and development.

It is interesting to note that while developed countries are reinterpreting their ODA mandates and related strategies, developing countries also seem to have a new vision for responding to the changing aid context and its closer ties to markets and private investments. This new vision, which is especially supported by African countries, considers that structural transformation needs to be based on "homegrown" domestic resources (Box 23). Measures that aim to mobilize domestic resources for development must be based on a better understanding of the political, economic and other drivers of, and obstacles to, the mobilization and use of these resources. This mobilization should be carried out at the national and regional levels in developing countries with enhanced financial sectors and markets that work towards this end. ${ }^{95}$

Therefore, although ODA is still recognized as having an important role, this role is increasingly seen as that of a catalyst for the mobilization of domestic finance. For example, African ministers backed the use of ODA and technical assistance for tax reform and public financial management in the lowest-income countries in the hope that it would help domestic resource mobilization efforts in the long run. ${ }^{96}$ At the Fifth Global Review of Aid for Trade, the United Nations Economic Commission for Africa also pointed to the need to use AfT to boost industrialization, a crucial step in fostering the structural transformation process.

Considering trade as an enabler of sustainable development, and the changes that are taking place in the transition to the post-2015 framework, requires serious reflection on the scope of trade-related debates and negotiations, which tend to focus on technical issues at the expense of the increasingly complex political dynamics. In this perspective, the lack of coordination and coherence 
among sectoral processes is not only contributing to deadlocks in international negotiations, but also preventing the use of trade policy to create the enabling environment that will allow both developed and developing countries to make the most effective use of the resources available to them.

Working in silos reinforces the polarization of views and approaches, making it difficult for countries to take advantage of trade agreements and to use trade policies in support of structural transformation:

- Bridging policy processes across sectors and levels by building horizontal and vertical linkages may help to optimize the availability and use of policy space for food security in trade agreements. Stronger synergies among processes can also increase the coherence and predictability of policies, thereby ensuring greater stability of policy objectives over the long term. This coordination will help national governments to define common objectives across sectors and to decide how to balance different factors in the context of agreed global frameworks.
- Strengthening synergies among the processes will also assist countries in their efforts to mobilize the finance required to facilitate processes of structural transformation and economic development, by optimizing the allocation and use of resources across different budgets and channelling them towards the achievement of shared objectives. This will strengthen the capacity of countries to mobilize funds from domestic sources.

With a stronger emphasis on trade and related policies, the challenges and opportunities that the post-2015 scenario offers also call for reflection on the multilateral trading system and the key framework governing it, the WTO AoA. This agreement sets the conditions for designing and implementing national trade policies and, in doing so, the policy space available for countries pursuing the elimination of hunger and food insecurity. Debates on trade, trade policy and trade agreements will need improved consideration and reconciliation of the links among policy space, structural transformation and resource mobilization if the opportunities that trade can deliver for improved food security are to be realized. 


\section{Notes}

1 In this report, the term "food security" is used for ease of reference, but covers both food and nutritional security.

2 In the first half of 2015 food prices were, on average, 28 percent higher in real terms than in the period 1995-2005, but are expected to decrease over the next decade, as production growth, driven by productivity increases and lower input prices, outpaces the slowing growth in demand.

3 FAO and OECD. 2015. OECD-FAO Agricultural Outlook 2015-2024. Paris, OECD Publishing.

4 N. Alexandratos and J. Bruinsma. 2012. World agriculture towards 2030/2050: the 2012 revision. ESA Working Paper No. 12-03. Rome, FAO.

5 FAO. 2009. How to feed the world in 2050. Rome

6 WTO. 2014. World Trade Report 2014. Trade and development: recent trends and the role of WTO. Geneva, Switzerland

7 OECD. 2014. Development Cooperation Report 2014. Mobilizing resources for sustainable development. Paris, OECD Publishing.

8 WTO, 2014 (see note 6).

9 FAO and OECD, 2015 (see note 3).

10 Ibid.

11 Ibid.

12 Ibid.

13 K. Ash and I. Lejarraga. 2014. Can we have regionalism and multilateralism? In R. Meléndez-Ortiz, C. Bellmann and J. Hepburn, eds. Tackling agriculture in the post-Bali context. Geneva, Switzerland International Centre for Trade and Sustainable Development.
14 K.J. Ruhl. 2013. An overview of US intrafirm-trade data sources. New York, USA, New York University Stern School of Business.

15 G. Gereffi and K. Fernandez-Stark. 2011. Global value chain analysis: a primer. Durham, USA, Centre on Globalization, Governance and Competitiveness, Duke University; S. Miroudot and A. Ragoussis. 2009. Vertical trade, trade costs and FDI. OECD Trade Policy Working Paper No. 89. Paris, OECD Publishing; R. Koopman, W. Powers, Z. Wang and S.-J. Wei. 2011. Give credit to where credit is due: tracing value added in global production chains. National Bureau of Economic Research (NBER) Working Paper 16426, September 2010, revised September 2011. Cambridge, USA, NBER; R. Koopman, Z. Wang and S.-J. Wei. 2014. Tracing value-added and double counting in gross exports. American Economic Review, 104(2): 459-494; R. Stehrer. 2013. Accounting relations in bilateral value added trade. The Vienna Institute for International Economic Studies (WIIW) Working Paper No. 101. Vienna, WIIW; M. Timmer, A.A. Erumban, B. Los, R. Stehrer and G.J. de Vries. 2014 Slicing up global value chains. Journal of Economic Perspectives, 28(2): 99-118; R. Baldwin. 2012. Global supply chains: why they emerged, why they matter, and where they are going?, Centre for Economic Policy Research (CEPR) Discussion Paper No. 9103. London, CEPR;

R. Baldwin and S. Evenett. 2012. Value creation and trade in 21st century manufacturing: what policies for UK manufacturing? In E. Greenaway, ed. The UK in a global world: how can the UK focus on steps in global value chains that really add value?, pp. 71-128. London, CEPR;

O. Cattaneo and S. Miroudot. 2013. From global value chains to global development chains: an analysis of recent changes in trade patterns and development paradigms. In E. Zedillo. and B. Hoekman, eds. 21st century trade policy: back to the past? New Haven, USA, Yale University Press.

16 P. Montalbano, S. Nenci and L. Salvatici. 2015. Trade, value chains and food security. Background paper prepared for The State of Agricultural Commodity Markets 2015-16. Rome, FAO. 
17 See for instance, S. Murphy, D. Burch and J. Clapp. 2012. Cereal secrets: the world's largest grain traders and global agriculture. Oxfam Research Reports. Oxford, UK, Oxfam GB.

18 WTO, 2014 (see note 6).

19 M. Maertens, B. Minten, and J. Swinnen. 2012. Modern food supply chains and development: evidence from horticulture export sectors in sub-Saharan Africa. Development Policy Review, 30(4): 473-497.

20 FAO and OECD, 2015 (see note 3).

21 Least-developed countries (LDCS) is a category defined by the United Nations Assembly. Net food-importing developing countries (NFIDCs) is a category that was defined during the Uruguay Round negotiations and incorporated into the current legal system of the WTO.

22 Low-income food-deficit countries (LIFDCS) is a statistical category that FAO uses to present certain data. The classification is based on income and food trade criteria, while an option of self-exclusion is provided.

23 E. Díaz-Bonilla. 2015. Lost in translation: the fractured conversation about trade and food security. Background paper prepared for The State of Agricultural Commodity Markets 2015-16. Rome, FAO; FAO. 2006. Trade reforms and food security: country case studies and synthesis. Rome.

24 J. Clapp. 2015. Food security and international trade: unpacking disputed narratives. Background paper prepared for The State of Agricultural Commodity Markets 2015-16. Rome, FAO.

25 E.H. Pangaribowo, N. Gerber and M. Torero. 2013 Food and nutrition security indicators: a review. Centre for Development Research (ZEF) Working Paper No. 108. Bonn, Germany, ZEF, University of Bonn.

26 IFPRI, Concern Worldwide and Welthungerhilfe developed a Global Hunger Index that attempts to reflect the multidimensional nature of hunger, combining three equally weighted indicators into one index.

27 Clapp, 2015 (see note 24).

28 This and the next two sections draw on Díaz-Bonilla, 2015 (see note 23).

29 E. Díaz-Bonilla, M. Thomas, S. Robinson and A. Cattaneo. 2000. Food security and trade negotiations in the World Trade Organization: a cluster analysis of country groups. IFPRI Discussion Paper No. 59. Washington, DC, IFPRI.
30 L.A. Winters, N. McCulloch and A. McKay. 2004. Trade liberalization and poverty: the evidence so far. Journal of Economic Literature, 42(1): 72-115.

31 Díaz-Bonilla, 2015 (see note 23).

32 M. Lipton and M. Ravallion. 1995. Poverty and policy. In J. Behrman and T.N. Srinivasan, eds. Handbook of Development Economics, Vol. 3, pp. 2551-2657. Amsterdam, North-Holland.

33 See, for instance, Lipton and Ravallion, 1995 (see note 32); R. Eastwood and M. Lipton. 2000. Pro-poor growth and pro-growth poverty reduction: meaning, evidence, and policy implications. Asian Development Review, 18(2): (22-58); L. Christiaensen, L. Demery and J. Kuhl. 2010. The (evolving) role of agriculture in poverty reduction. United Nations University World Institute for Development Economics Research (UNU- WIDER) Working Paper No. 2010/36. Helsinki, UNU-WIDER.

34 See M. Arimond and M. Ruel. 2004. Dietary diversity is associated with child nutritional status: evidence from 11 demographic and health surveys. Journal of Nutrition, 134(10): 2579-2585; R. Remans, S.A. Wood, N. Saha, T. Lee Anderman and R.S. DeFries. 2014. Measuring nutritional diversity of national food supplies. Global Food Security, 3(3/4): 174-182.

35 C. Hawkes. 2008. Globalization of agrifood systems and the nutrition transition. In J. von Braun and E. Díaz-Bonilla, eds. 2008. Globalization of food and agriculture and the poor, pp. 215-49. Oxford, UK, Oxford University Press; J. Kearney. 2010. Food consumption trends and drivers. Philosophical Transactions of the Royal Society B, 365: 2793-2807.

36 Díaz-Bonilla, 2015 (see note 23).

37 B. Hoekman and P.C. Mavroidis. 2015. Regulatory spillovers and the trading system: from coherence to cooperation. E15Initiative. Geneva, Switzerland, International Centre for Trade and Sustainable Development (ICTSD) and World Economic Forum.

38 N. Minot, 2011. Transmission of world food price changes to markets in sub-Saharan Africa. IFPRI Discussion Paper No. 1059. Washington, DC, IFPRI; N. Minot. 2012. Food price volatility in Africa: has it really increased? IFPRI Discussion Paper No. 1239. Washington, DC, IFPRI; A. Chapoto and T. Jayne. 2009. The impact of trade barriers and market interventions on maize price unpredictability: evidence from Eastern and Southern Africa. Michigan State University (MSU) International Development Draft Working Paper No. 102. East Lansing, USA, MSU. 
40 FAO. 2003. Trade reforms and food security: conceptualizing the linkages. Rome; FAO, 2006 (see note 23).

41 FAO, IFAD and WFP. 2015. The State of Food Insecurity in the World 2015. Meeting the 2015 international hunger targets: taking stock of uneven progress. Rome, FAO.

42 For instance, S. Murphy, 2008. Agriculture and market power. In von Braun and Díaz-Bonilla, 2008 (see note 35), pp. 181-88; J. Morrison and S. Murphy. 2009. Economic growth and the distributional effects of freer agricultural trade in the context of market concentration. In A. Sarris and J. Morrison, eds. The evolving structure of world agricultural trade: implications for trade policy and trade agreements, pp. 137-77. Rome, FAO.

43 von Braun and Díaz-Bonilla, 2008 (see note 35).

44 Díaz-Bonilla, 2015 (see note 23).

45 T. Reardon and C. Timmer. 2008. The rise of supermarkets in the global food system. In von Braun and Díaz-Bonilla, 2008 (see note 35), pp. 189-214

46 A different issue is the nutritional impact, as discussed earlier.

47 J. Swinnen. 2015. Supply chains, trade and food security: linking rich consumers to poor producers through value chains. Presentation at FAO, Rome, Italy, March 2015.

48 Díaz-Bonilla, 2015 (see note 23).

49 See for instance the discussion of imperfect competition in the global fertilizer industry in M. Hernandez and M. Torero. 2011. Fertilizer market situation: market structure, consumption and trade patterns, and pricing behavior. IFPRI Discussion Paper No. 01058. Washington, DC, IFPRI. The need to pay attention to the relative power of price formation between supermarkets and processors and exploring price formation in oligopsonistic or oligopolistic settings is also highlighted in Reardon and Timmer, 2008 (see note 45)

50 See, for example, M. Maertens and J. Swinnen. 2009. Trade, standards and poverty: evidence from Senegal. World Development, 37(1): 161-178.

51 P. Arias, D. Hallam, E. Krivonos and J. Morrison. 2013. Smallholder integration in changing food markets. Rome, FAO

52 Díaz-Bonilla, 2015 (see note 23).
53 The Voluntary Guidelines on the Responsible Governance of Tenure of Land, Fisheries and Forests, endorsed by the 38th (Special) Session of the Committee on World Food Security on 11 May 2012, seek to address land-grabbing concerns by providing countries with principles and internationally accepted standards for the responsible governance of tenure. They provide a framework that countries can use when developing their own strategies, policies, legislation, programmes and activities. They allow governments, civil society, the private sector and citizens to judge whether their proposed actions and the actions of others constitute acceptable practices.

54 D. Cheong, M. Jansen and R. Peters, eds. 2013. Shared harvests: agriculture, trade, and employment. Geneva, Switzerland, International Labour Organization (ILO) and United Nations Conference on Trade and Development (UNCTAD).

55 FAO. 2015. Food and Agriculture Policy Decision Analysis (FAPDA). Website (available at http://www.fao.org/in-action/ fapda/background/policy-classification/en/).

56 A. Dorward and J.A. Morrison. 2015. Heroes, villains and victims: agricultural subsidies and their impacts on food security and poverty reduction In G.M. Robinson and D.A. Carson, eds. Handbook on the globalisation of agriculture. Handbooks on Globalisation series. Cheltenham, UK, Edward Elgar.

57 There is also a distinction between the type of policy and the policy setting. For example, a government can have a minimum support price policy, but it makes a big difference if this is set at a safety net level (i.e. below border prices) or above border prices.

58 FAO. 2009. Guide for policy and programmatic actions at country level to address high food prices. Rome.

59 FAO. 2014. Policy responses to high food prices in Latin America and the Caribbean: country case studies. Rome.

60 OECD. 2015 Managing food insecurity risk: analytical framework and application to Indonesia. Paris.

61 P. Arias et al., 2013 (see note 51).

62 C.P. Timmer. 2014. Managing the structural transformation: a political economy approach. UNU-WIDER Annual Lecture 18, 18 November 2014, United Nations, New York, USA. Unpublished.

63 S. Fan, A. Gulati and S. Thorat. 2007. Investments, subsidies and pro-poor growth in rural India. IFPRI Discussion Paper No. 716. Washington, DC, IFPRI. 
64 For the case of Mexico, see for example S. Levy and E. Rodríguez. 2005. Sin herencia de pobreza: El Programa Progresa Oportunidades en México. Washington, DC, InterAmerican Development Bank; H. Rodríguez Vázquez. 2011. Lecciones aprendidas para el Acuerdo de Asociación entre la Unión Europea y Centroamérica en el Acuerdo Global Unión Europea - México. Santiago de Chile, FAO.

65 K. Anderson and S. Nelgen. 2013. Updated national and global estimates of distortions to agricultural incentives, 1955 to 2011. Washington DC, World Bank.

66 Indeed, it has been estimated that, in 2015, producers in the United States of America will receive one of the highest levels of support ever as commodity prices fall. See Reuters. 2015. Think tank says U.S. farm bill payments to peak with 2015 crop. News release (available at http://www.reuters. com/article/2015/03/10/us-usa-agriculture-fapriidUSKBNOM61UD20150310).

67 FAO. 2015. Monitoring and Analysing Food and Agricultura Policies (MAFAP). Website (available at http://www.fao.org/ in-action/mafap/home/en/).

68 E. Magrini, P. Montalbano, S. Nenci and L. Salvatici. 2014. Agricultural trade policies and food security: is there a causal relationship? FOODSECURE Working Paper No. 25. The Hague, LEI Wageningen UR (University and Research Centre).

69 Both the intensity of the policy change and the length of the transition path matter in this regard. In order to stabilize agents' expectations, policy-makers need to announce from the beginning the final goal, even if it represents a radical change from the present situation. Then, it is likely to be optimal to allow for a long and gradual transition path in order to minimize the adjustment costs.

70 This and the next section draw on A. Matthews. 2015 Articulating trade concerns related to food security in multilateral trade rules. Background paper prepared for The State of Agricultural Commodity Markets 2015-16. Rome, FAO.

71 Other WTO Agreements such as the Sanitary and Phytosanitary Measures (SPS) Agreement, the Technical Barriers to Trade (TBT) Agreement and the Agreement on Trade-related Aspects of Intellectual Property Rights (TRIPS) are also relevant to the emerging governance of global food security but are not considered further in this report.

72 Marrakesh Ministerial Decision on Measures Concerning the Possible Negative Effects of the Reform Programme on Least-Developed and Net Food-Importing Developing Countries.
73 O. De Schutter. 2011. The World Trade Organization and the post-global food crisis agenda: putting food security first in the international trade system. Activity report November 2011. Geneva, Switzerland, United Nations Special Rapporteur on the Right to Food.

74 WTO. 2011. Paragraph 13 of the Doha Ministerial Declaration.

75 See for example B. Chatterjee and S. Murphy. 2014. Trade and food security. E15Initiative. Geneva, Switzerland, International Centre for Trade and Sustainable Development (ICTSD) and World Economic Forum; J. Clapp. 2011. Food security and the WTO: will the Doha Round make a difference? Manchester, UK, PovertyDialog.org and The University of Manchester Brooks World Poverty Institute; O. De Schutter. 2009. International trade in agriculture and the Right to Food. Dialogue on Globalization Occasional Paper No. 46. Geneva, Switzerland, Friedrich-Ebert-Stiftung; E. Díaz-Bonilla, 2014. Agricultural trade and food security: some thoughts about a continuous debate. E15Initiative. Geneva, Switzerland, International Centre for Trade and Sustainable Development (ICTSD) and World Economic Forum; C.G. Gonzalez, 2002. Institutionalizing inequality: The WTO Agreement on Agriculture, Food Security, and Developing Countries. Columbia Journal of Environmental Law, 27(2): 433-489; K. Elliott. 2015. Food security in developing countries: is there a role for the WTO? Washington, DC, Center for Global Development; C. Häberli. 2012. Do WTO rules improve or impair the right to food? In J. McMahon and M. Desta, eds. Research handbook on the WTO Agriculture Agreement: new and emerging issues in international agricultural trade law, pp. 50-72. Cheltenham, UK, Edward Elgar Publishing; C. Häberli. 2010. Food security and WTO rules. In B. Karapinar and C. Häberli, eds. Food crises and the WTO. Cambridge, UK, Cambridge University Press; T. Josling. 2015. Rethinking the rules for agricultural subsidies. E15Initiative. Geneva, Switzerland, International Centre for Trade and Sustainable Development (ICTSD) and World Economic Forum; R. Sharma. 2011. Food sovereignty, hunger and global trade rules. ATDF Journal, 8(1/2): 10-17; F. Smith. 2012. Food security and international agricultural trade regulation: old problems, new perspectives. In J. McMahon and M. Desta, eds. Research handbook on the WTO Agriculture Agreement: new and emerging issues in international agricultural trade law. Cheltenham, UK, Edward Elgar Publishing; S. Tangermann. 2013. Agriculture and food security group: a post-Bali food security agenda. Geneva, Switzerland, International Centre for Trade and Sustainable Development (ICTSD).

76 OECD, 2014. Agricultural Policy Monitoring and Evaluation 2014. Paris. 
77 T. Josling, 2014. The WTO, food security and the problem of collective action. Paper prepared for a Conference on Food Price Volatility, Food Security and Trade Policy, 18-19 September, 2014, World Bank, Washington, DC.

78 See also R. Sharma, 2007. Developing country experience with the key policy issues of the Uruguay Round Agreement on Agriculture. In A. McCalla and J. Nash, eds. Reforming agricultural trade for developing countries. Washington, DC, World Bank; C. Laroche Dupraz and A. Postolle, 2013. Food sovereignty and agricultural trade policy commitments: how much leeway do West African nations have? Food Policy, 38(1): 115-125.

79 R. Bernabe, 2008. Treatment of special products: implications of the Chair's May 2008 draft modalities text. Geneva, Switzerland, International Centre for Trade and Sustainable Development (ICTSD).

80 FAO. 2006. Import surges: what are their external causes. FAO Briefs on Import Surges. Rome.

81 See WTO. 2015. Domestic support. Webpage on Agreement on Agriculture (available at https://www.wto. org/english/tratop_e/agric_e/ag_intro03_domestic_e.htm).

82 R. Banga. 2015. Greening of subsidies and food security. Presentation delivered at the United Nations Conference on Trade and Development (UNCTAD) Global Forum on Commodities 2015, 13-14 April, Geneva, Switzerland.

83 W. Martin and K. Anderson. 2012. Export restrictions and price insulation during commodity price booms. American Journal of Agricultural Economics, 94(2): 422-427.

84 Malabo Declaration on Accelerated Agricultural Growth and Transformation for Shared Prosperity and Improved Livelihoods, adopted in June 2014, in Malabo, Equatorial Guinea (available at http://pages.au.int/sites/default/files/ Malabo\%20Declaration\%202014_11\%2026-.pdf).

85 African Union. 2015. Implementation strategy and road map to achieve the 2025 vision on CAADP: operationalizing the 2014 Malabo Declaration on Accelerated African Agricultural Growth and Transformation for Shared Prosperity and Improved Livelihood. Addis Ababa.

86 The means of implementation identified under the SDGs include, in addition to trade, also finance, technology, capacity building, and systemic issues (including, for example, macroeconomic stability, policy coherence and respecting countries' policy space for poverty eradication and sustainable development).
87 For different views on these issues see von Braun and DíazBonilla, 2008 (see note 35).

88 OECD. Development Cooperation Report 2014. Mobilizing resources for sustainable development. Paris.

89 The OECD Development Assistance Committee (DAC) is an international forum of 29 countries, including the largest providers of foreign aid, whose mission is to promote development cooperation and other policies so as to contribute to sustainable development, including pro-poor economic growth, poverty reduction, improvement of living standards in developing countries, and a future in which no country will depend on aid.

90 European Report on Development 2015. Combining finance and policies to implement a transformative post2015 development agenda. European Union. Brussels, Overseas Development Institute (ODI), in partnership with the European Centre for Development Policy Management (ECDPM), the German Development Institute (Deutsches Institut für Entwicklungspolitik) (GDI/DIE), the University of Athens (Department of Economics, Division of International Economics and Development) and the Southern Voice Network.

$91 \mathrm{Ibid}$.

92 ODI. 2015. Designing the development agency of the future: framing paper. London.

93 K. Rana. 2007. Economic diplomacy: the experience of developing countries In N. Bayne and S. Woolcock, eds. The new economic diplomacy: decision making and negotiations in international relations, pp. 201-20. London, Ashgate Publishing Limited.

94 ODI, 2015 (see note 92)

95 European Centre for Development Policy Management (ECDPM). Dossier: Financing for development. Web page (available at http://ecdpm.org/dossiers/financing-fordevelopment/).

$96 \mathrm{Ibid}$. 


\section{\& $\odot \oplus$ OUR PRIORITIES The FAO Strategic Objectives}

Achieving FAO's goals to end hunger and poverty is a challenging and complex task. Today, thanks to major changes in how we do business, FAO is a fitter, flatter and more flexible organization, whose activities are driven by five strategic objectives. The new and improved FAO has a real chance to win the battle against hunger, malnutrition and rural poverty.

\section{HELP ELIMINATE HUNGER, FOOD INSECURITY AND MALNUTRITION}

We contribute to the eradication of hunger by facilitating policies and political commitments to support food security and by making sure that up-to-date information about hunger and nutrition challenges and solutions is available and accessible.

\section{MAKE AGRICULTURE, FORESTRY AND FISHERIES MORE PRODUCTIVE AND SUSTAINABLE}

We promote evidence-based policies and practices to support highly productive agricultural sectors (crops, livestock, forestry and fisheries), while ensuring that the natural resource base does not suffer in the process.

\section{REDUCE RURAL POVERTY}

We help the rural poor gain access to the resources and services they need - including rural employment and social protection - to forge a path out of poverty.

\section{ENABLE INCLUSIVE AND EFFICIENT AGRICULTURAL AND FOOD SYSTEMS}

We help to build safe and efficient food systems that support smallholder agriculture and reduce poverty and hunger in rural areas.

\section{INCREASE THE RESILIENCE OF LIVELIHOODS TO THREATS AND CRISES}

We help countries to prepare for natural and human-caused disasters by reducing their risk and enhancing the resilience of their food and agricultural systems. 


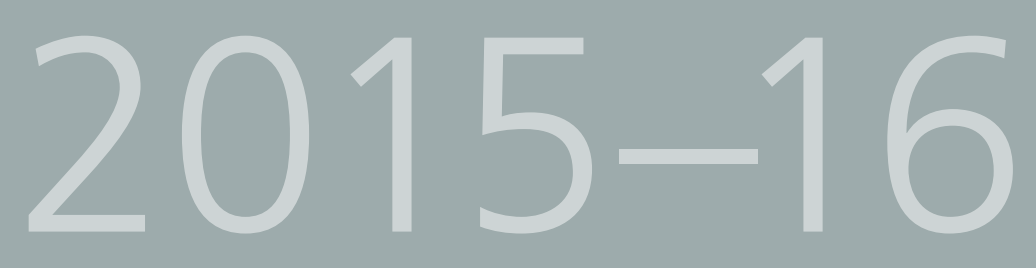

\section{The State of Agricultural Commodity Markets}

Trade and food security: achieving a better balance between national priorities and the collective good

Global trade in agricultural and food products has grown rapidly in recent decades, with countries becoming more engaged in this trade, whether as exporters or importers. This trend is expected to continue over the coming decades. As a consequence, trade will play an increasingly important role in influencing the extent and nature of food security across all regions of the globe.

The challenge has therefore become one of ensuring that the expansion of agricultural trade works for, and not against, the elimination of hunger, food insecurity and malnutrition.

This edition of The State of Agricultural Commodity Markets aims to reduce the current polarization of views on the impacts of agricultural trade on food security and on the manner in which agricultural trade should be governed to ensure that increased trade openness is beneficial to all countries. By providing evidence and clarity on a range of topics, the report seeks to contribute to a more informed debate on policy choices and to identify required improvements in the policy processes within which these choices are made. 